



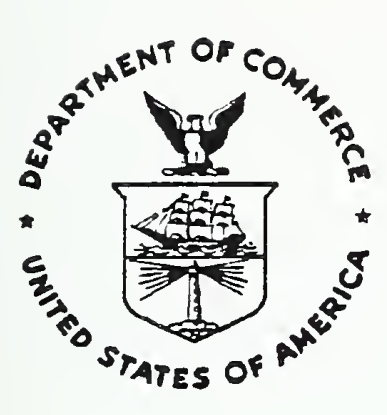

\section{Experimental Study of Gusseted Connections for Laterally Braced Steel Buildings}

John L. Gross and Geraldine Cheok

U.S. DEPARTMENT OF COMMERCE

National Institute of Standards and Technology

(Formerly National Bureau of Standards)

Center for Building Technology

Structures Division

Gaithersburg, MD 20899

November 1988

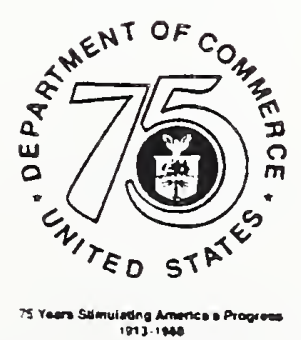




\section{Experimental Study of Gusseted Connections for Laterally Braced Steel Buildings}

John L. Gross and Geraldine Cheok

U.S. DEPARTMENT OF COMMERCE

National Institute of Standards and Technology

(Formerly National Bureau of Standards)

Center for Building Technology

Structures Division

Gaithersburg, MD 20899

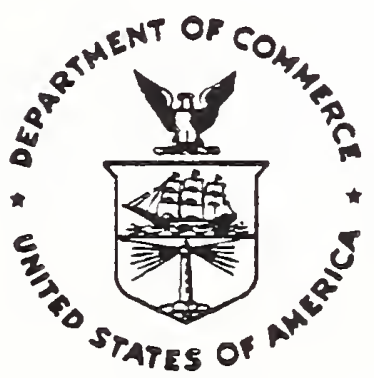

National Bureau of Standards became the National Institute of Standards and Technology on August 23, 1988, when the Omnibus Trade and Competitiveness Act was signed. NIST retains all NBS functions. Its new programs will encourage improved use of technology by U.S. industry.

U.S. DEPARTMENT OF COMMERCE

C. William Verity, Secretary

NATIONAL INSTITUTE OF STANDARDS

AND TECHNOLOGY

Ernest Ambler, Director 


\section{ABSTRACT}

The behavior of three diagonally braced steel subassemblages was studied experimentally. The parameters which were varied included the gusset geometry and column orientation. The specimens were loaded to failure in their plane and load-deformation as well as strain data were recorded. The failure mode for the two strong-axis column connections was gusset buckling. The weak-axis column connection failed by tearing of the gusset plate. The moment introduced by the eccentricity in the bracing was distributed to the beam and column in the strong-axis column connection. This moment was carried almost entirely by the beam in the weak-axis connection due to the flexibility in the web connection. The failure loads for all three specimens were found to be well above those predicted using various analysis methods. Generally, comparisons of design capacities with the experimental values resulted in a factor of safety in excess of two. The current method of computing gusset buckling appears to be slightly conservative predicting a buckling capacity of approximately $65 \%$ of the capacity obtained experimentally. The capacity of the clip angles, in accordance with AISC, was computed to be very low yet no distress in the clip angles was observed. This was because frame action introduced loads in the gusset-to-column bolts which counteracted the load produced by the bracing.

Key words: Braced frames; connections; design; experimental study; gusset plates; lateral bracing; steel buildings 


\section{ACKNOWLEDGEMENTS}

The authors would like to express their appreciation to the many individuals and organizations that contributed to this project. First, the assistance of the AISC Task Group on Bracing for Heavy Construction is gratefully acknowledged. The members of that group include: Roger Brockenbrough, Robert Disque, John Griffiths, James Holesapple, Nestor Iwankiw, Lawrence Kloiber, Prof. Ralph Richard, Dr. William Thornton, James Wooten, Jorge Zorilla. The authors would especially like to express their thanks to Dr. William Thornton for providing the specimen design capacity calculations and procedure for distributing diagonal bracing loads and to Prof. Ralph Richard for providing the computer simulations of the NBS specimens. Finally, the authors would like to thank Cives steel Company for providing and fabricating the test specimens and fixtures. 

LIST OF TABLES . . . . . . . . . . . . . . . . . . . ix

LIST OF FIGURES . . . . . . . . . . . . . . . . . . . . $\mathrm{xi}$

1.0 INTRODUCTION . . . . . . . . . . . . . . . . . . . 1

1.1 General . . . . . . . . . . . . . . . . . 1

1.2 Background . . . . . . . . . . . . . . . . . . 1

1.3 Current Design Practice . . . . . . . . . . . . . . . 3

1.4 Objective of the NBS Research . . . . . . . . . . . . . . 4

1.5 AISC Task Group . . . . . . . . . . . . . . . . 4

2.0 EXPERIMENTAL PROGRAM . . . . . . . . . . . . . . . . 5

2.1 Experiment Design . . . . . . . . . . . . . . 5

2.2 Selection of Subassemblage . . . . . . . . . . . . . 5

2.3 Selection of Gusset Configurations . . . . . . . . . . . . 7

2.4 Test Specimens . . . . . . . . . . . . . . . . . . . . . 8

2.5 Test Facility . . . . . . . . . . . . . . . . 10

2.6 Instrumentation . . . . . . . . . . . . . . . . . 11

2.7 Test Procedure . . . . . . . . . . . . . . 12

3.0 EXPERIMENTAL RESULTS . . . . . . . . . . . . . . . . . 31

3.1 Test Specimen No. 1 . . . . . . . . . . . . . 31

3.1 .1 Test 1A...................... . . 31

3.1 .2 Test 1B......................... 32

3.2 Test Specimen No. 2 . . . . . . . . . . . . . 33

3.2 .1 Test 2A . . . . . . . . . . . . 33

3.2 .2 Test $2 \mathrm{~B}$. . . . . . . . . . . . . . 34

3.3 Test Specimen No. 3 . . . . . . . . . . . . . . . . 34

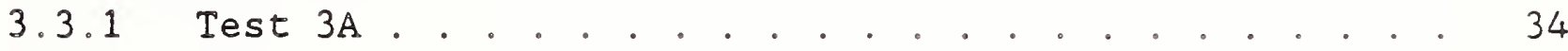

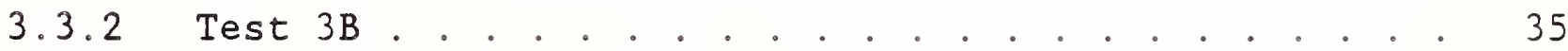

3.4 Material Properties . . . . . . . . . . . . . . . 36

3.5 Comparisons Between Tests . . . . . . . . . . . . 36

3.5.1 Concentric vs. Eccentric Bracing Connection (Test 1A vs. Test 2A). . . . . . . . . . 36 
3.5.2 Strong-Axis vs. Weak-Axis Column Connection

(Test $2 \mathrm{~A}$ vs. Test $3 \mathrm{~A}$ )

4.0 INTERPRETATION AND DISCUSSION OF RESULTS . . . . . . . . . . . . 69

4.1 Whitmore Failure Criterion . . . . . . . . . . . . 69

4.2 Comparison of Analytical and Experimental Results . . . . . . 69

4.3 Design Capacities . . . . . . . . . . . . . . . . . 71

4.3.1 Capacity of Gusset Plate . . . . . . . . . . . 72

4.3.2 Methods to Distribure Brace Loads . . . . . . . . . . 72

4.3.3 Capacity of Gusset-to-Beam Attachment . . . . . . . . 75

4.3.4 Capacity of Gusset-to-Column Attachment . . . . . . . 75

4.3.5 Capacity of Beam-to-Column Attachment . . . . . . . 75

4.4 Comparison Between Experimental and Design Capacities . . . . 76

4.4.1 Bolt Capacity in Clip Angles-to-Column Connection. . '76

4.4.2 Buckling of the Gusset Plate . . . . . . . . . . . 77

4.4.3 Yielding of the Whitmore Section . . . . . . . . 78

4.4 .4 Tearout of the Gusset Plate . . . . . . . . . . . 78

4.5 Comparison Between Experimental and Calculated Capacities. . 80

4.5.1 Buckling of the Gusset Plate . . . . . . . . . . 81

4.5.2 Tearout of the Gusset Plate.......... . . 81

5.0 Summary and Conclusions . . . . . . . . . . . . . . . . . 99

5.1 Summary . . . . . . . . . . . . . . . . . . 99

5.2 Conclusions... . . . . . . . . . . . . . . 100

REFERENCES . . . . . . . . . . . . . . . . . . 103

APPENDIX A . . . . . . . . . . . . . . . . . . 105

APPENDIX B . . . . . . . . . . . . . . . . . 123 


\section{LIST OF TABLES}

Table

3.1a Force Components, Elastic Range . . . . . . . . . 38

3. Ib Force Components, Inelastic Range . . . . . . . . 39

3.1c Force Components at Ultimate Frame Capacity . . . 40

3.2 Material Properties . . . . . . . . . . 41

4.1 Experimental Results vs. Richard's Analytical

Results . . . . . . . . . . . . . 82

4.2 Design Brace Load for Specimen No. 1 . . . . . . 83

4.3 Design Brace Load for Specimen No. 2 . . . . . . 84

4.4 Design Brace Load for Specimen No. 3 . . . . . . 85

4.5 Comparison Between Computed Design Capacities and Measured Capacities for Buckling of Gusset Plate.

4.6 Comparison Between Computed Design Capacities and Measured Capacities for Yielding of Whitmore Section ............... . . . . 86

4.7a Comparison Between Computed Design Capacities and Measured Capacities for Tearout of Gusset Plate, AISC-ASD Design Method . . . . . . . . . .

4.7b Comparison Between Computed Design Capacities and Measured Capacities for Tearout of Gusset Plate, Williams and Richard Method .....

4.7c Comparison Between Computed Design Capacities and Measured Capacities for Tearout of Gusset Plate, Hardash and Bjorhovde Method . . . . . . . .

4.7d Comparison Between Computed Design Capacities and Measured Capacities for Tearout of Gusset Plate, AISC-LRFD Method . . . . . . . . . . . 8

4.8 Comparison between Computed Buckling Capacity and Measured Buckling Capacity for Specimens No. 1 and 2

4.9 Comparison between Computed Buckling Capacity and Measured Tearout Capacity (Specimen No. 1) for Various Methods 



\section{LIST OF FIGURES}

Figure

Schematic of a Typical Braced Connection

2.2

Prototype Beam Axial Loads

2.3

Prototype Diagonal Bracing Loads and Percent

of Total Story Shear Carried by the Bracing

2.4

Prototype Beam Moments

2.5

Prototype Column Moments

Boundary Conditions for Test Subassemblages

Lateral Load vs. Axial Loads in Diagonal Bracing,

Test $1 \mathrm{~A}$

Lateral Load vs. Axial Loads in Diagonal Bracing, Test 1B 
View of Closed Gap Between the Lower Gusset and

the Diagonal, Test $2 \mathrm{~A}$

Lateral Load vs. Axial Loads in Diagonal

Bracing, Test $2 \mathrm{~B}$

Load vs. Deflection, Test 3A . . . . . . . 55

Upper Gusset Plate, Test 3A

Lateral Load vs. Axial Loads in Diagonal

Bracing, Test $3 \mathrm{~A}$

Tear in Upper Gusset which Occurred in Test $3 \mathrm{~A}$

Load vs. Deflection, Test 3B

Lateral Load vs. Axial Loads in Diagonal

Bracing, Test $3 \mathrm{~B}$

Diagonal Brace in Contact with Upper Gusset,

Test $3 B$

Location of Tensile Test Coupons in Gusset

Plates

Stress - Strain Curve for Upper Gusset,

Specimen No. 1

Moment Diagram for Test IA

Moment Diagram for Test 2A

Predicted and Experimental Moments for Test $3 \mathrm{~A}$ 
Schematic Showing Welds from Gusset to Column and to Beam

A. 4

Gusset-to-Column Connection Detail

A. 5

Beam-to-Column Connection Detail

A. 6

Schematic Showing AISC Case II

A. 7

Schematic Showing AISC Case I

A. 8

Force Distribution Using AISC Method for Heavy

Bracing

B. 1

Thornton's Model for Brace Load Distribution . 


\subsection{INTRODUCTION}

\section{$1.1 \quad$ General}

Diagonal bracing systems are frequently employed in steel framed structures to provide stiffness and to resist both wind and seismic loads. It is common in such bracing systems to use gusset plates to attach the diagonal braces to the main framing members. The force distribution in a gusseted connection is extremely complex and designers frequently employ approximate methods to design the gusset plates and the attachment of the gusset to the beams and columns. Analytical studies [1] have shown that the force distribution in a gusseted connection depends upon all of the structural components making up the connection including the gusset plate, diagonal brace, column, beam, and fasteners (bolts or welds).

Experimental work to date has not included the influence of the members framing into a gusseted connection on the stresses in the gusset and on the distribution of loads to the framing members. At the suggestion of the AISC Task Group on Bracing for Heavy Construction, an experimental program was undertaken at the National Institute of Standards and Technology (NIST-formerly the National Bureau of Standards) to determine the behavior of gusseted connections including the influence of the members framing into the connection. Three nearly full-scale braced frame subassemblages were tested. Each represented a different connection configuration to investigate the influence of connection geometry. This report summarizes the findings of the NIST tests and compares the results obtained with current design practice and proposed analytical procedures.

\subsection{Background}

Historically, gusset plates were designed on the basis of ordinary beam formulas, despite the fact that the validity of such formulas is questionable for a gusset plate of normal proportions. One of the most significant studies of gusset plate behavior was that by Whitmore [2] in which he concluded that beam formulas do not accurately predict the elastic stress distribution in a 
gusset plate for a typical bottom chord connection in a Warren truss. Whitmore proposed an effective width design approach which is widely used in practice today. On the basis of full-scale tests, Bjorhovde [3] found acceptable agreement with the Whitmore procedure for the design of gusset plates in braced frames. These tests included tension loading of full-size specimens connected to stub beam and column sections. More recently, the block shear concept has been developed for the prediction of the ultimate strength of a bolted gusset plate in tension. Richard [4] has shown that the block shear criteria is identical to the Whitmore criteria when the gross section is used. On the basis of 28 tests conducted at the University of Arizona, Hardash [5] proposed a design criteria for gusset plates in tension using the block shear concept.

The main focus of previous experimental work has been on tension action with little attention being paid to compression and the study of gusset plate buckling. Thornton [6] describes a rational procedure for checking gusset plate stability based on the Whitmore stress acting on a unit strip of the gusset plate treated as a column. Recently, Hu and Cheng [7] tested gusset plates loaded in compression using various thicknesses and sizes of gusset plate and several different boundary conditions. The gusset plates were designed to fail by elastic buckling and, as in the tension tests by Bjorhovde, the full-size specimens were connected to stub beam and column sections.

Recent analytical studies conducted by Williams and Richard [4] and Fung and Richard [8] have demonstrated the importance of "frame action" effects. That is, a gusset plate becomes part of the beam-to-column moment connection and as such carries load by frame action. Finite element studies of a braced frame subassemblage demonstrated that this action loads the gusset significantly. The influence of framing members on gusset plate behavior has not yet been studied experimentally and the effects of the stresses produced by frame action on the joint capacity is not known.

Also, the additional loads due to the eccentricity introduced into a gusseted connection by the fact that the centroidal axes of the framing members do not intersect at a point, has not been experimentally verified. The elastic tests 
of gusseted connections in trusses by Whitmore [2] and by Vasarhelyi [9], and the tests to failure of braced frame gusseted connections by Bjorhovde [3], all used configurations in which the centroidal axes intersected at a single point.

\subsection{Current Design Practice}

The size and shape of a gusseted connection is generally dictated by fastener requirements. The thickness of the plate is selected on the basis of either the stress on the Whitmore section or by the maximum stress calculated using beam formulas. Beam formulas continue to be used, despite their apparent failings, largely because their use has produced designs that perform satisfactorily. Design of the gusset plate attachments, either bolts or welds, is dictated by the loads which must be transferred to the beam and column. However, the distribution of diagonal bracing loads to the framing members is not well understood. If the line of force in the diagonal passes through the corner of the gusset plate, a common and simple method for distributing the brace load [10] is to assume that the vertical component of the load in the brace goes to the gusset-to-column connection and that the horizontal component goes to the gusset-to-beam connection. If the line of force in the diagonal passes through the intersection of the beam and column centerlines, distribution of the load in the brace could be as suggested in Reference [10] for heavy bracing connections. This method is illustrated in Appendix A. Thornton [6] presents an approach to the design of both the gusset plate and its attachments based on simple statics combined with the notion of adequate strength path. A conservative procedure for checking gusset plate buckling, based on the Whitmore effective width, is also presented. Richard [1] recently proposed a method for determining the distribution of diagonal bracing loads to the framing members on the basis of nonlinear finite element analyses of various connection configurations. The equations for the gusset-to-frame fastener force distributions were found to depend primarily on gusset plate aspect ratio and the brace angle. These various design approaches are presented in more detail in Chapter 4 and comparisons are made between design capacity and experimentally determined capacity for all three specimens. 
The objectives of the NIST research are:

- to obtain experimental results for gusseted connections which include the members framing into the connection and which are loaded in both tension and compression, and

- to compare experimental results with predicted values using various design methods.

\section{$1.5 \quad$ AISC Task Group}

The experimental research program was developed by NIST in cooperation with the AISC Task Group on Bracing for Heavy Construction. The Task Group assisted NIST in developing and carrying out the experimental program by working with NIST to establish the research objectives, and to define the specimen configuration, test set-up, loading sequence and instrumentation. Members of the Task Group representatives from design offices, steel fabricators, universities and standards writing bodies. 


\section{Experiment Design}

To meet the stated objectives, an experimental program was developed to test three braced frame subassemblages. The following general considerations guided NIST in designing the experiments:

- The behavior of the subassemblage model should duplicate as closely as possible prototype braced frame behavior.

- The subassemblage should be as close to full scale as practical.

- The subassemblage must be accommodated by the existing NIST tridirectional test facility.

- The specimens should represent a realistic gusseted diagonal brace connection in a frame structure.

- The specimens should be carried well beyond initial distress (i.e., buckling, yielding, tearing or fracture) with the loading capacity provided by the NIST facility.

\subsection{Selection of Subassemblage}

Many different arrangements of lateral bracing are possible. The configuration selected for study in this project is one having diagonals alternating in direction from story to story. A schematic of the braced core of a multistory steel building having such an arrangement of diagonals is shown in Figure 2.1a. Note that this configuration simulates $\mathrm{X}$-bracing as well as an alternating pattern of vertical bracing. The subassemblage selected for this experimental program is shown schematically in Figure 2.1b.

A linear elastic analysis was performed on a prototype braced frame core to determine the boundary conditions for the subassemblage selected for study. 
The structure was loaded at each floor elevation with an equal magnitude lateral load, $P_{L}$, as shown in Figure 2.2. It was found that the lateral load was resisted almost entirely by the diagonal braces. Very little was carried by frame action as illustrated in Figure 2.3. The beams were found to be in reverse curvature with the point of zero moment almost exactly at mid-span as seen in Figure 2.4. Note that the beams were assumed to be rigidly fixed to the columns, rather than pinned, because a gusseted connection provides a substantial rotational restraint. In addition, the beams in the prototype corresponding to the beam in the subassemblage were found to carry very little axial load. This suggests that the subassemblage shown in Figure 2.1b can be modeled with a pin and roller support at the prototype beam mid-span. The columns (except in the first story) were also in reverse curvature as shown in Figure 2.5 but the point of zero moment was not precisely at the column mid-height. Nevertheless, the assumption of a pin support at the prototype column mid-height appears to be reasonable for the subassemblage. Since the diagonals carry principally an axial load, a pin connection at the mid-point of the diagonal is appropriate as well. Finally, the vertical displacements of the joints at a floor elevation were found to be essentially equal indicating that, for the subassemblage to simulate the behavior of the corresponding portion of the prototype under lateral loading, the top of the column and the top of the upper diagonal must be restrained to translate only in the plane of the frame. The boundary conditions and loading for the braced frame subassemblage are shown schematically in Figure 2.6.

Next, a comparison of analysis results between the prototype and the subassemblage model, restrained and loaded as indicated, was made to verify that the subassemblage replicated prototype behavior. Results showed that the forces in the diagonals differed by less that 6\%. The moment in the beam at the beam-to-column joint differed by less than $1 \frac{8}{8}$ between prototype and model. The axial forces in the columns were found to be different between the prototype and model. This is because column loads resulting from cantilever action in the prototype accumulate from the top of the structure to the bottom; an effect which does not occur in the single story subassemblage. It was concluded that the braced frame subassemblage selected for study provided a good representation of prototype behavior when supported and loaded as shown in Figure 2.6. 
The height of the subassemblage was 9'-0" between column pin supports. This was the largest specimen which could be accommodated in the test facility. The width from column centerline to beam pin support was 7'-6". This represents approximately a 3/4-scale structure. The geometry of the subassemblage and the pin fixtures used to represent the boundary conditions are shown in Figure 2.7 .

\subsection{Selection of Gusset Configurations}

Just as there are many possible arrangements of lateral bracing, so too there are there are many possible configurations for a gusseted connection. Two important aspects were investigated in this study:

- The relationship between the line of force in the diagonal brace and the intersection of the centroidal axes of the beam and column.

- The orientation of the strong axis of the column with respect to the plane of the frame.

If the line of force in the diagonal passes through the intersection of the axes of the beam and column, no moment is produced in the connection by the axial force in the diagonal. This configuration is termed "concentric". While no moment is induced in either the beam or column by the force in the diagonal, this alternative requires a long gusset plate due to the difference in depth. of the column and beam, and the small angle that the diagonal brace makes with the horizontal. This is of particular importance when the gusset is in compression because a long gusset plate has a lower buckling capacity. Also, the gusset plate in a concentric connection is subjected to complex loadings at its boundaries which are difficult to calculate.

If the line of force in the diagonal does not pass through the intersection of the beam and column axes, the force in the diagonal produces a moment which must be resisted by the beam and column. Thus an eccentricity exists with respect to the force in the diagonal and, therefore, this configuration is termed "eccentric". The additional moment is simple to compute but the beam 
and/or column may have to be increased in size to accommodate the additional stresses. If the line of force in the diagonal is made to pass through the corner of the gusset plate, loadings at the gusset boundaries are simple to compute as well.

A rolled steel column section ( $W$ or HP shape) has a strong bending axis and a weak bending axis. Diagonal bracing may frame into either the strong axis of a column, "strong-axis connection" or into the weak axis of a column, "weakaxis connection". In a weak-axis connection, the gusset is connected to the column web which is often more flexible than the flange. No experimental work to date has resolved the difference in performance between a strong-axis and weak-axis connection.

\section{$2.4 \quad$ Test Specimens}

Three specimens, each with a different connection detail were tested. They were as follows:

- Specimen No. 1 - Concentric, strong-axis column connection where the line of force in the diagonal passes through the intersection of the beam and column centroidal axes (Figure 2.8).

- Specimen No. 2 - Eccentric, strong-axis column connection where the line of force in the diagonal passes through the corner of the gusset plate (Figure 2.9).

- Specimen No. 3 - Eccentric, weak-axis column connection where the line of force in the diagonal passes through the corner of the gusset plate (Figure 2.10).

For Specimen No. 1, the gravity axes of the members framing into the joint intersected at a common point and thus no eccentricity was introduced into the connection. As noted earlier, this arrangement produces a long gusset plate which is more susceptible to buckling than a compact gusset plate would be. 
Specimen No. 2 had a much more compact gusset than Specimen No. 1, however, an eccentricity resulted because the centroidal axes of the members framing into the connection did not meet at a single point. The gusset plates for Specimen No. 1 and No. 2 were identical except in length since it was intended to determine if acceptable performance and ultimate strength are obtained when no special provisions are made to account for the eccentricity.

For specimen No. 3, the column was turned so that it acted in its weak direction and the gusset plate was attached to the column web. No web stiffening was provided. The gusset plate and clip angles were the same for Specimen No. 2 and Specimen No. 3 so that a comparison could be made between the results for a strong-axis and a weak-axis connection.

The framing members for each test specimen were the same. The column was a $W 10 \times 49$, the beam $a W 16 \times 40$, and the diagonal braces were $W 8 \times 21$ 's. The gussets were attached to the beam flanges with fillet welds and were connected to the column by clip angles welded to the gusset and bolted to either the column flange or web. The gusset plates were $1 / 4^{\prime \prime}$ thick and the clip angles were $\operatorname{L} 3 \times 3-1 / 2 \times 1 / 4$. The beam flanges were coped to allow the clip angles to run the entire depth of the connection as a single piece thereby simplifying fabrication and fit-up. The diagonal braces were bolted to the gusset using WT $5 \times 11$ sections.

The three test specimens were fabricated using standard shop practices. Since it is essential that none of the members framing into the connection fails before all the data from the gusset plate is acquired, the gusset plates and attachment elements were fabricated from $36 \mathrm{ksi}$ steel while the main framing members were fabricated from $50 \mathrm{ksi}$ steel. E70 electrodes were used for all weldments and A325 High Strength Bolts were used for all bolted attachments. The connection configurations were determined by the advisory panel to represent practical heavy bracing connections. 
The experiments were conducted using the NIST Tri-directional Test Facility (TTF) [11], a permanent structural testing apparatus located in the NIST Structures Division Laboratory. The TTF can subject large structural components to controlled displacements, forces, or both, including translations and rotations in three orthogonal directions. The facility is computer-based with all aspects of the loading of test specimens and the acquisition and reduction of data coordinated and controlled by the operator. The loads are applied by a closed-loop hydraulic system having six independently servo-controlled hydraulic actuators. Lateral forces as large as 200 kips and vertical forces up to 250 kips may be applied to the test specimen.

The testing apparatus consists essentially of two steel crossheads to which the test specimen is attached (see Figure 2.11). The reaction system consists of a structural tie-down floor and two vertical reaction walls (see Figure 2.12). The bottom crosshead is anchored to the tie-down floor and is stationary. The top crosshead is attached to six hydraulic actuators which control its movement. The actuators are in turn attached to either the bottom crosshead or one of the reaction walls. The clear distance between the crossheads is approximately $12 \mathrm{ft}$. and the clear distance between the vertical actuators is approximately $10 \mathrm{ft}$.

Figure 2.13 shows a photo of the tri-dimensional test facility without a test specimen mounted in it. A close-up of the roller support system for the end of the beam is shown in Figure 2.14. A test specimen mounted in the test facility is shown in Figure 2.15. Also, shown in Figure 2.15 is a free-standing steel frame on which instrumentation for measuring displacements was mounted. The columns in each test were laterally braced at the column mid-height (Figure 2.16). Pins at both ends of the lateral brace allowed unrestrained movement of the subassemblage in its plane while providing no 
rotational restraint. The lateral brace was instrumented to determine the load resisted by the brace.

\section{$2.6 \quad$ Instrumentation}

The following data were either recorded directly or computed from recorded data for each of the three tests:

- The applied lateral load

- The lateral frame displacement (top and mid-height of sub-assemblage).

- The axial force, bending moment, and shear distributions in all of the framing members.

- The distribution of stresses in the gusset plate along those edges attached to the framing members.

- The principal mode of failure of each specimen.

The test specimens were instrumented with resistance-type strain gages to record strains and with linear variable differential transformers (LVDT) to record displacements or rotations. A sufficient number of strain gages were applied to determine the axial force and bending moments in all members and the distribution of stress along the connected edges of the gusset plates. The locations of the strain gages are shown in Figures 2.17 and 2.18. LVDT's were located at the center of the upper support pins and at the column midheight to record lateral frame displacements. LVDTs were also located at the center of the bottom pin supports to monitor any base movements. A total of 96 data channels were used to record data form the strain gages and LVDTs. In addition, transducers mounted on the hydraulic actuators were used to measure loads and displacements of the upper crosshead.

All instrumentation was connected to a computer-based analog-to-digital converter. Acquired data were stored on magnetic tape for later processing 
and selected data channels, converted to engineering units, were displayed during the course of a test.

\section{$2.7 \quad$ Test Procedure}

Each specimen was loaded in the plane of the frame as shown in Figure 2.6. Loading of each specimen was conducted in two separate tests as follows:

- Test A - Lateral load was applied so as to produce tension in the upper diagonal. The specimen was loaded until failure occurred and the subassemblage was unable to carry additional load. It was then unloaded. Since yielding and/or buckling occurred in all instances, there was a residual lateral frame displacement when the specimen was fully unloaded.

- Test B - The specimen was loaded in the opposite direction producing compression in the upper diagonal. As in the first test, loading was continued until failure occurred and the subassemblage was unable to carry any additional load. The load was then removed.

Al1 tests were conducted under displacement control. That is, the TTF was given a command to move (displace) the upper crosshead a prescribed amount and the forces required to produce the given displacement were computed and recorded. 


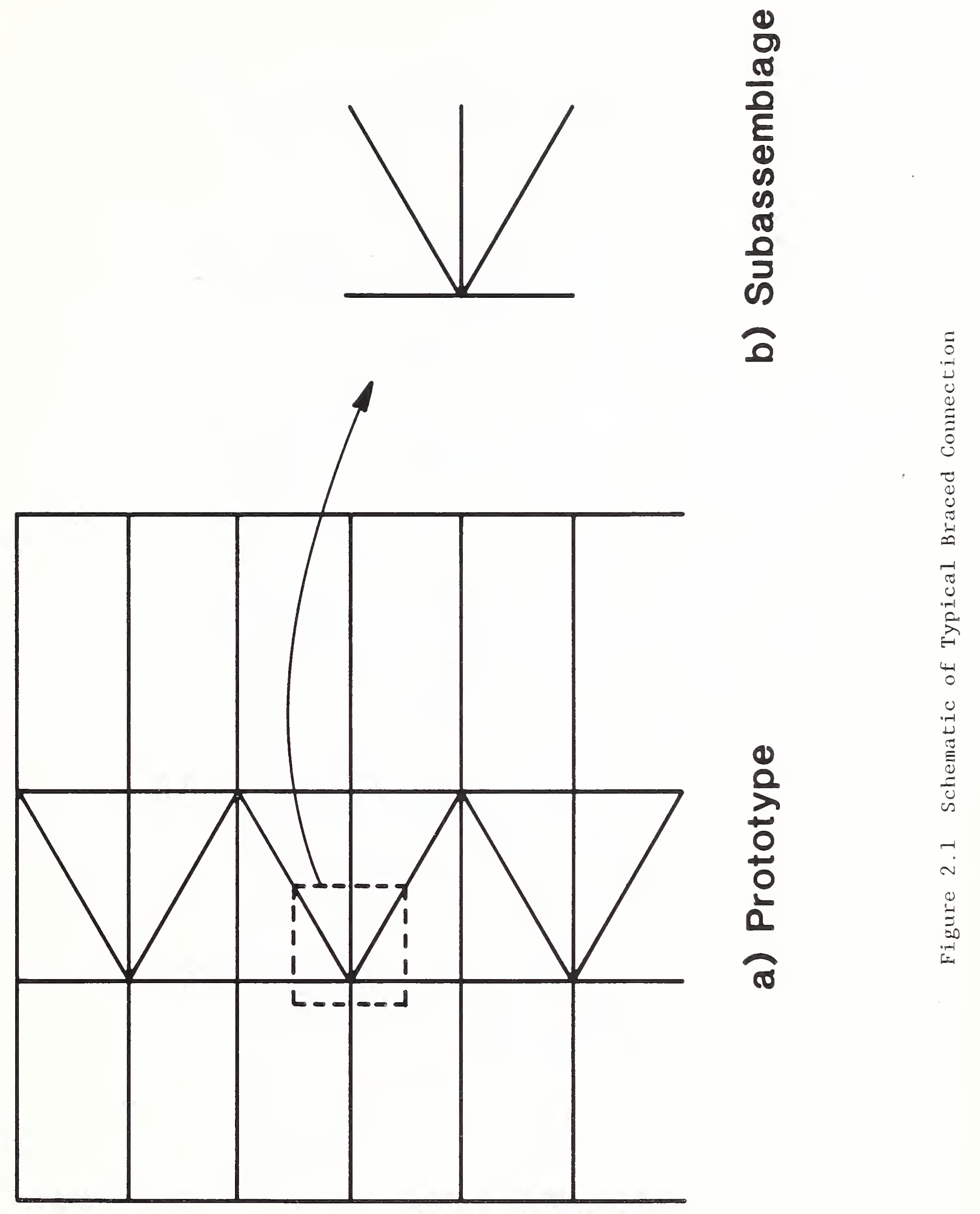




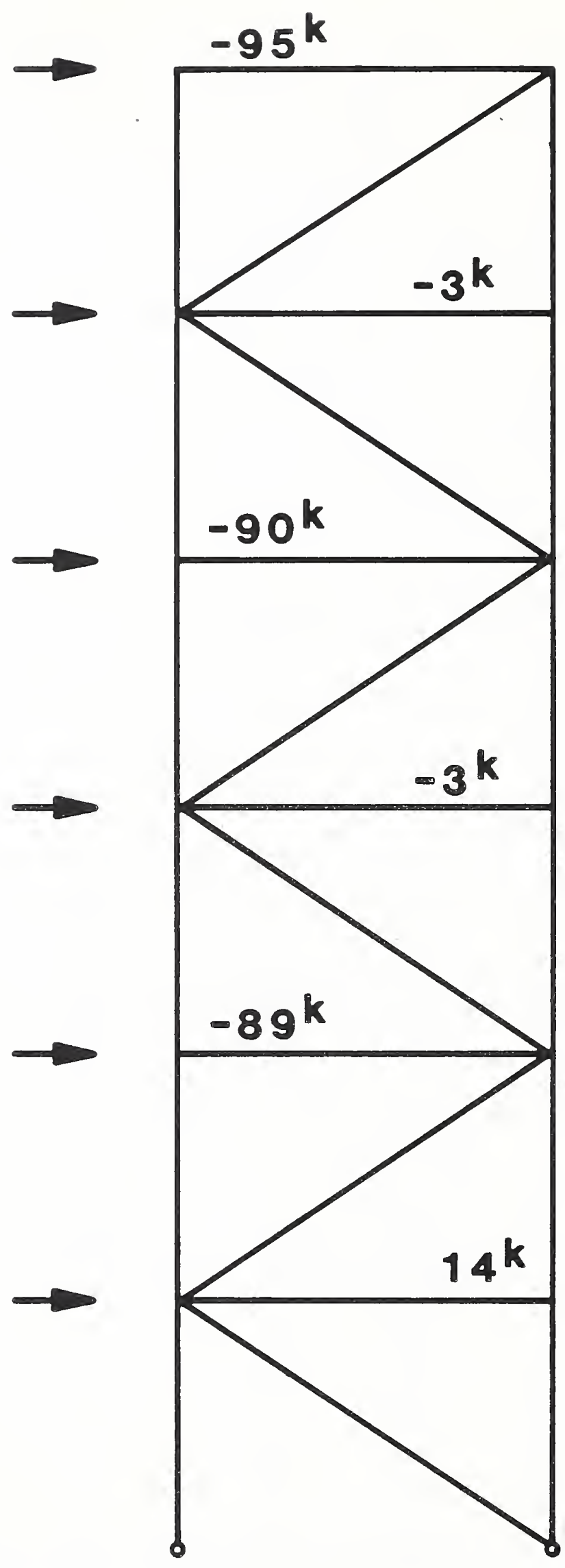

Figure 2.2 - Prototype Beam Axial Loads 


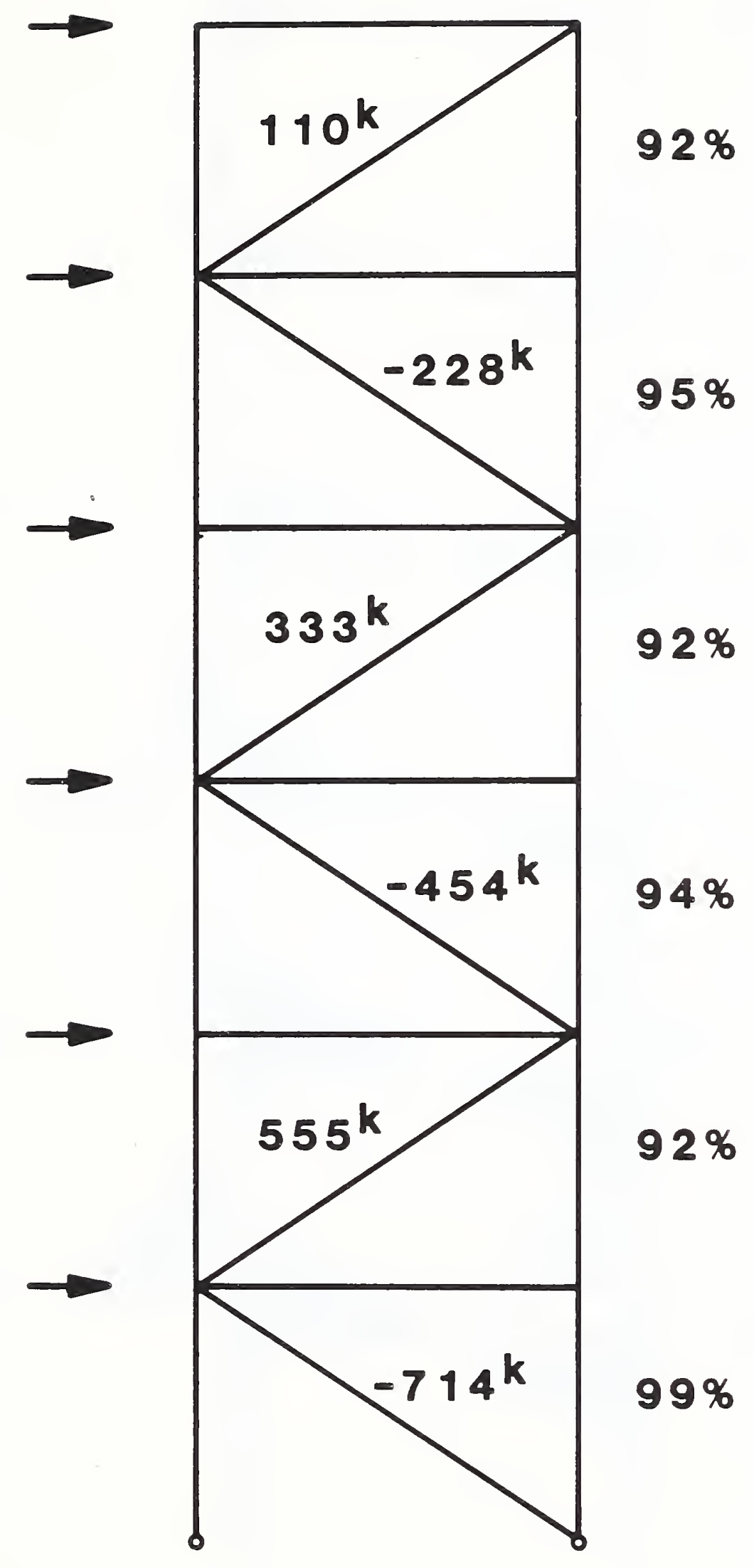

Figure 2.3 - Prototype Diagonal Bracing Loads and Percent of Total Story Shear Carried by Bracing 


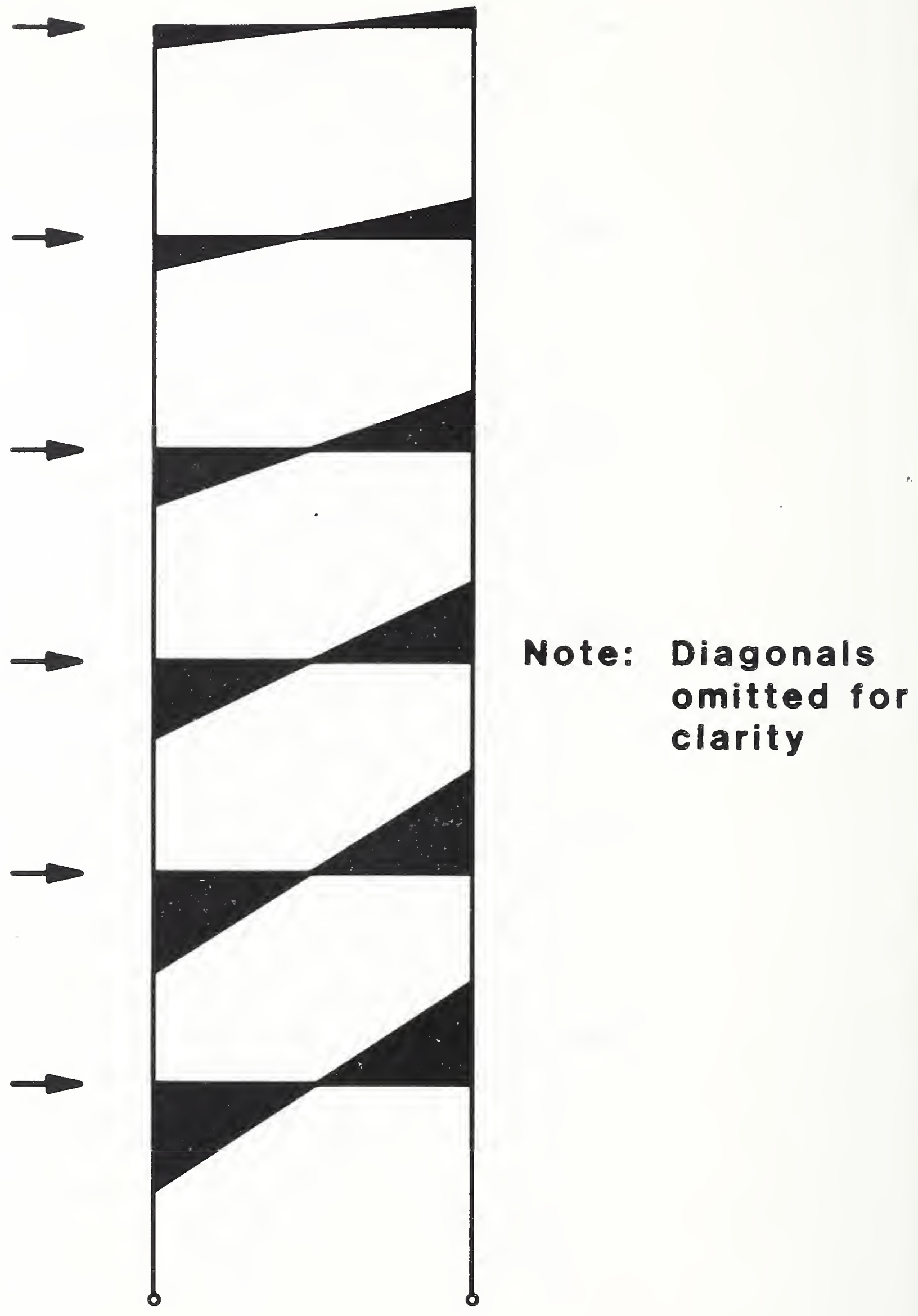

Figure 2.4 - Prototype Beam Moments 


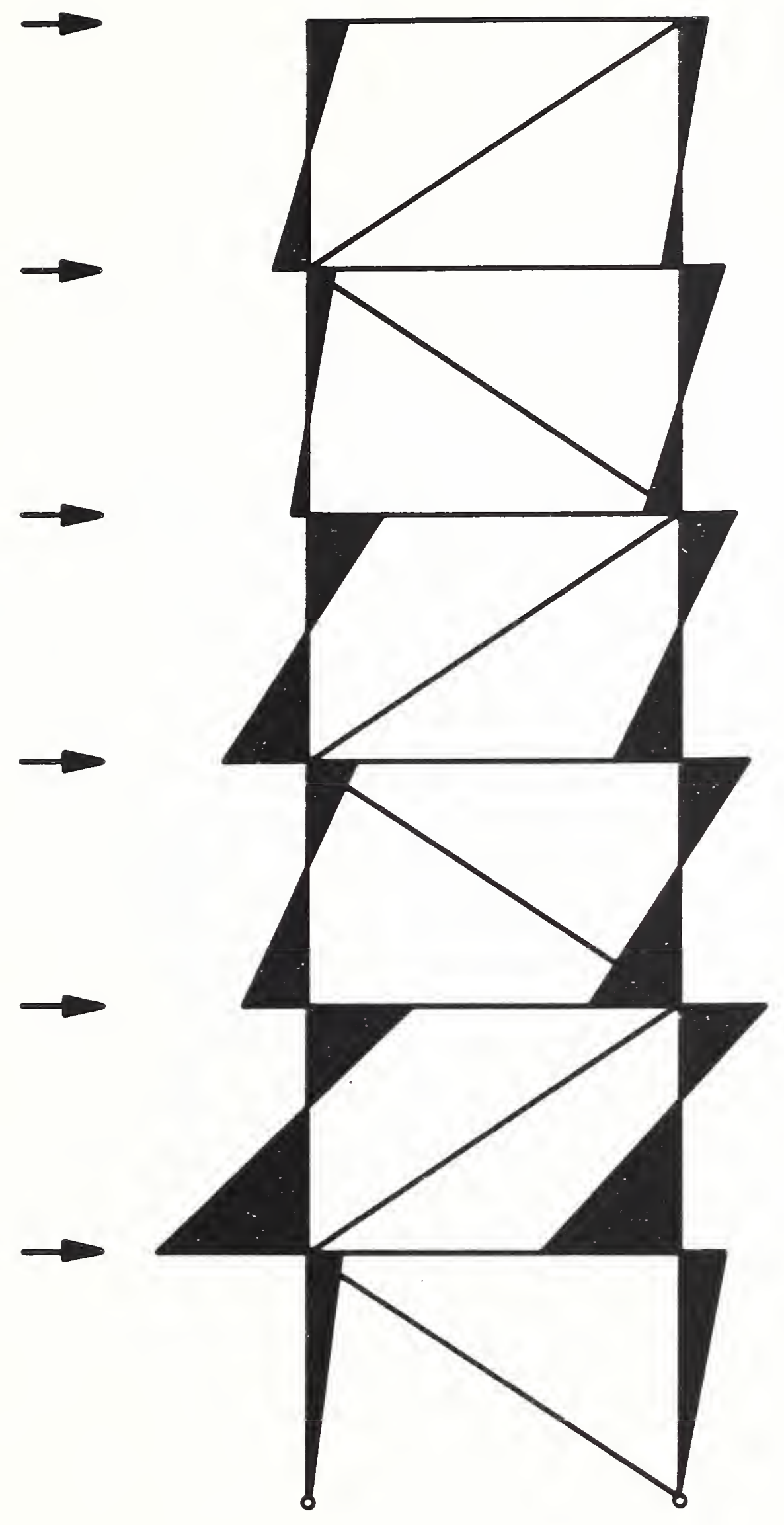

Figure 2.5 - Prototype Column Moments 


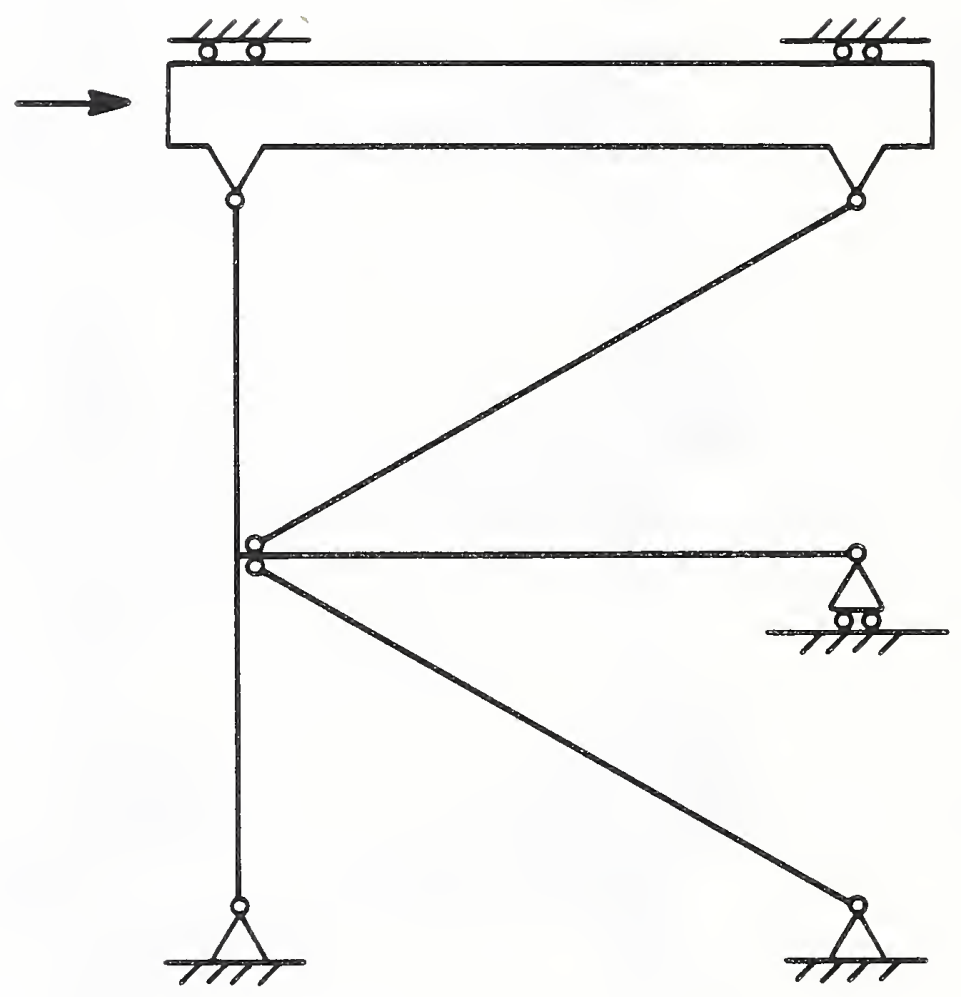

Figure 2.6 - Boundary Conditions for Test Subassemblages 


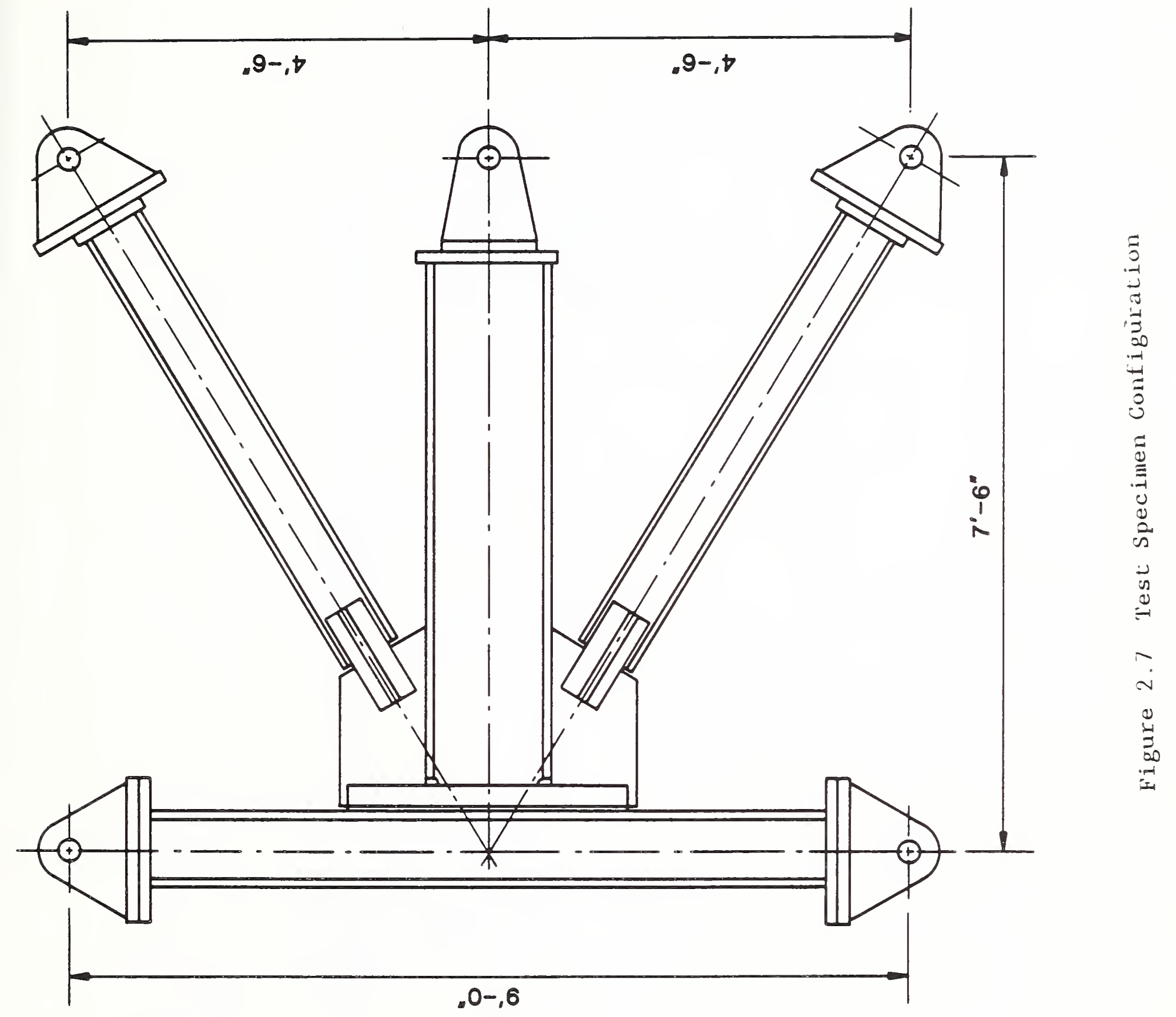




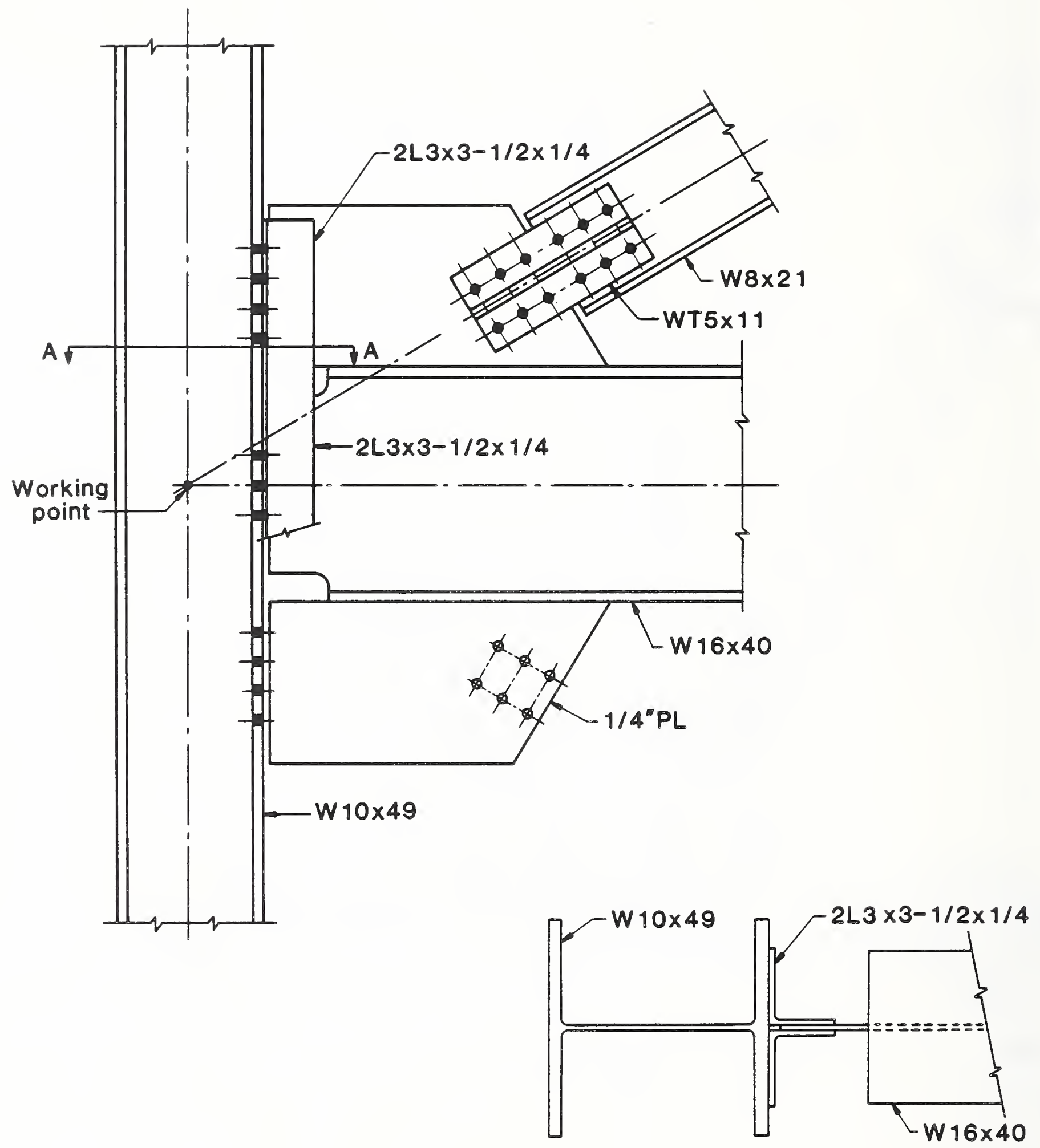

Section A-A

Figure 2.8 - Connection Detail for Test Specimen No. 1 


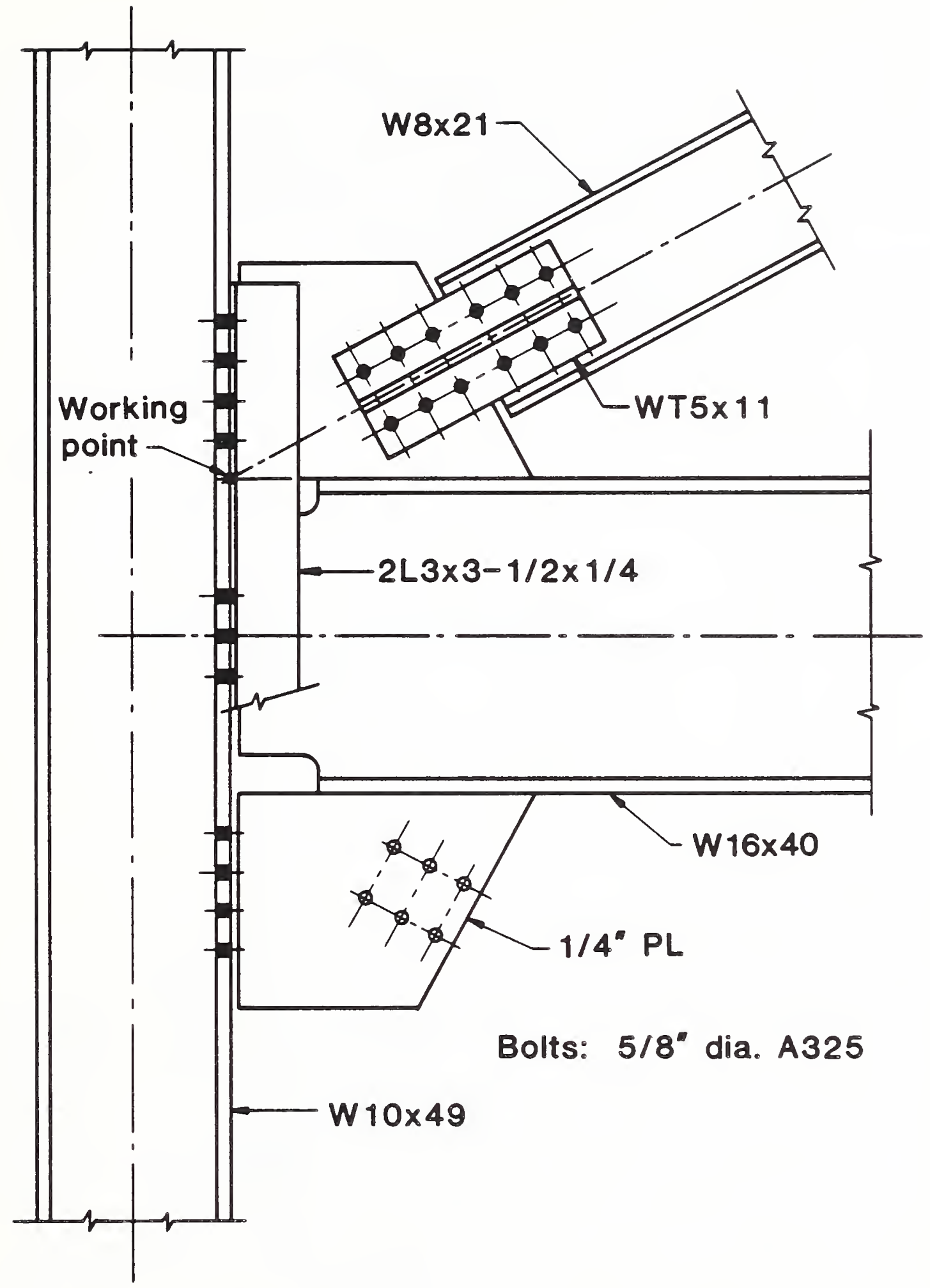

Figure 2.9 - Connection Detail for Test Specimen No. 2 


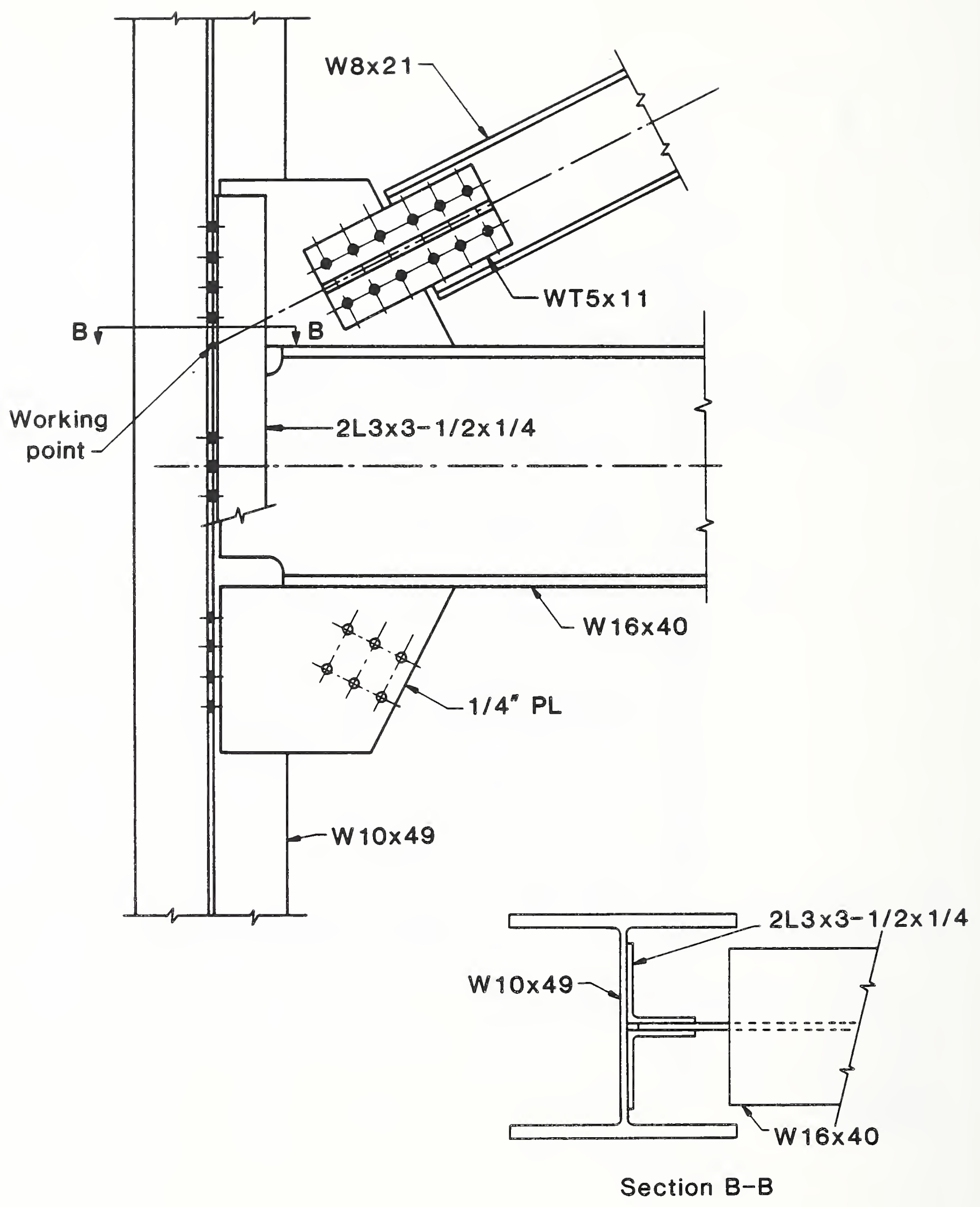

Figure 2.10 - Connection Detail for Test Specimen No. 3 


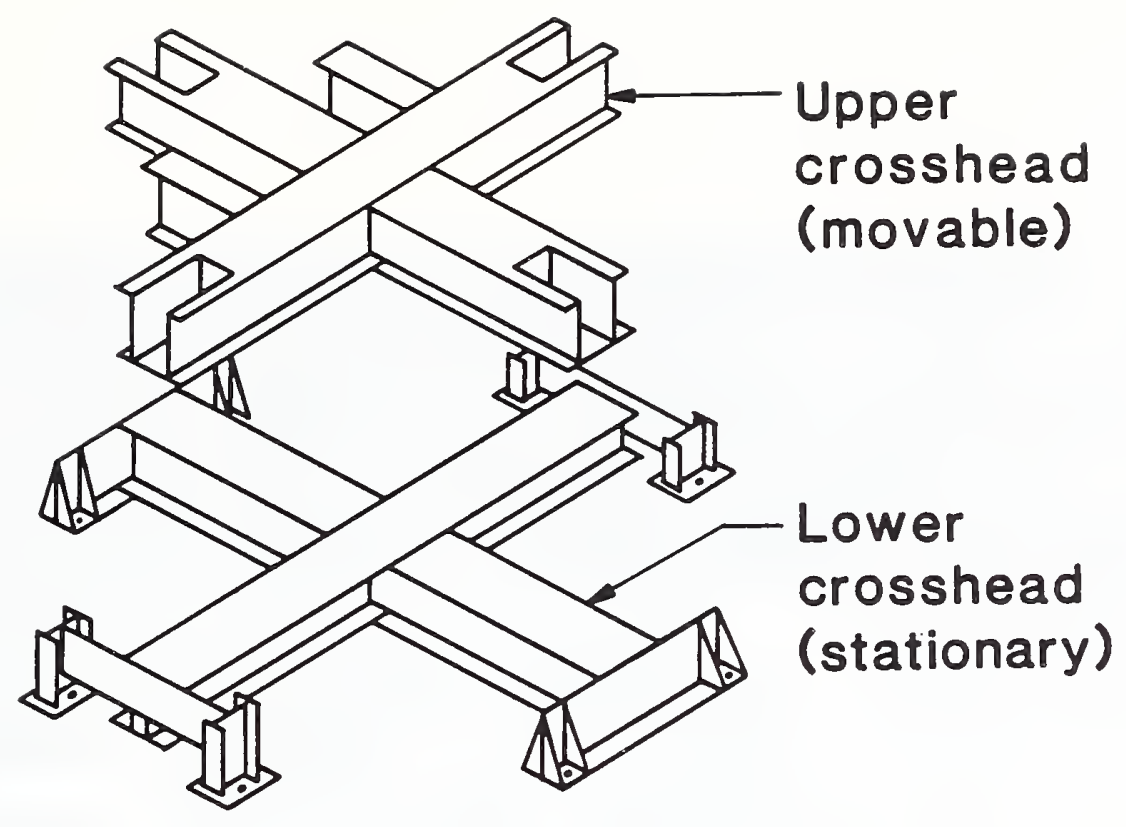

Figure 2.11 - Upper and Lower Crossheads of TTF

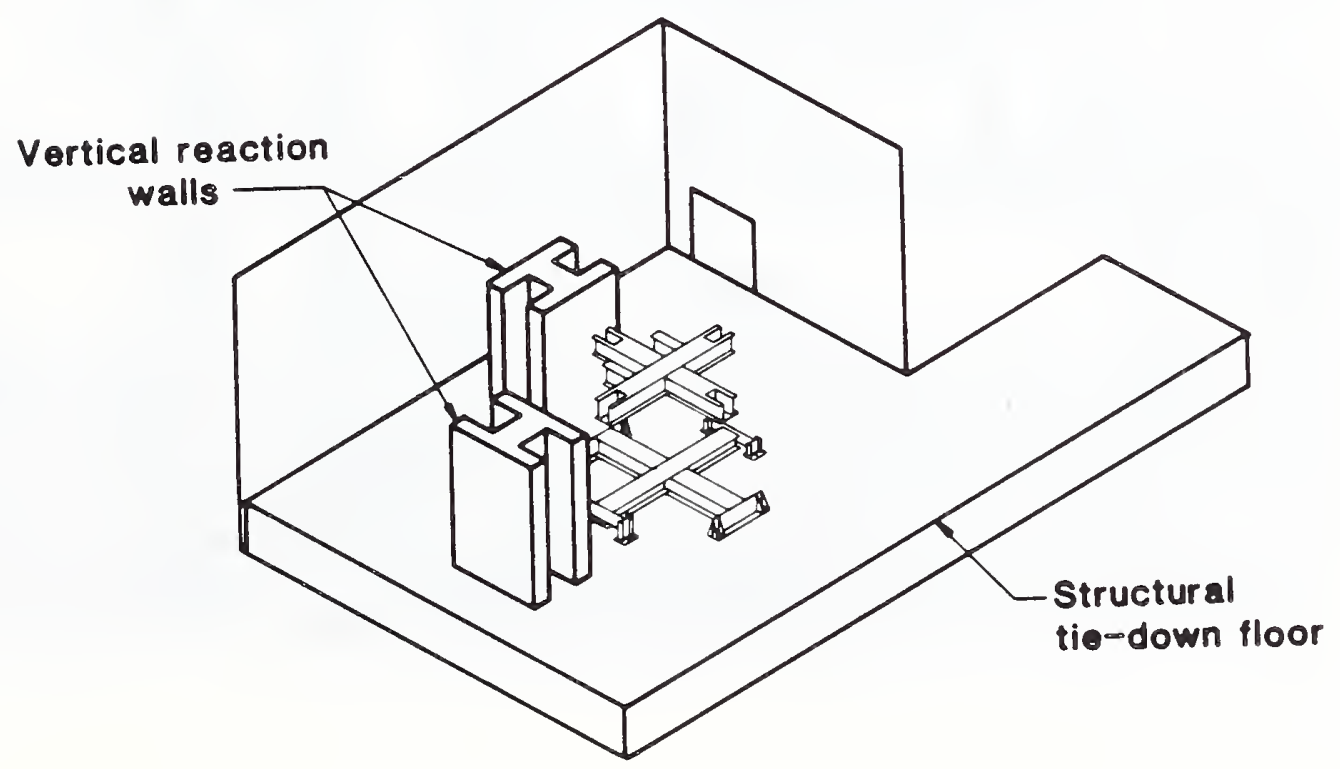

Figure 2.12 - Schematic of NBS Tri-Directional Test Facility 


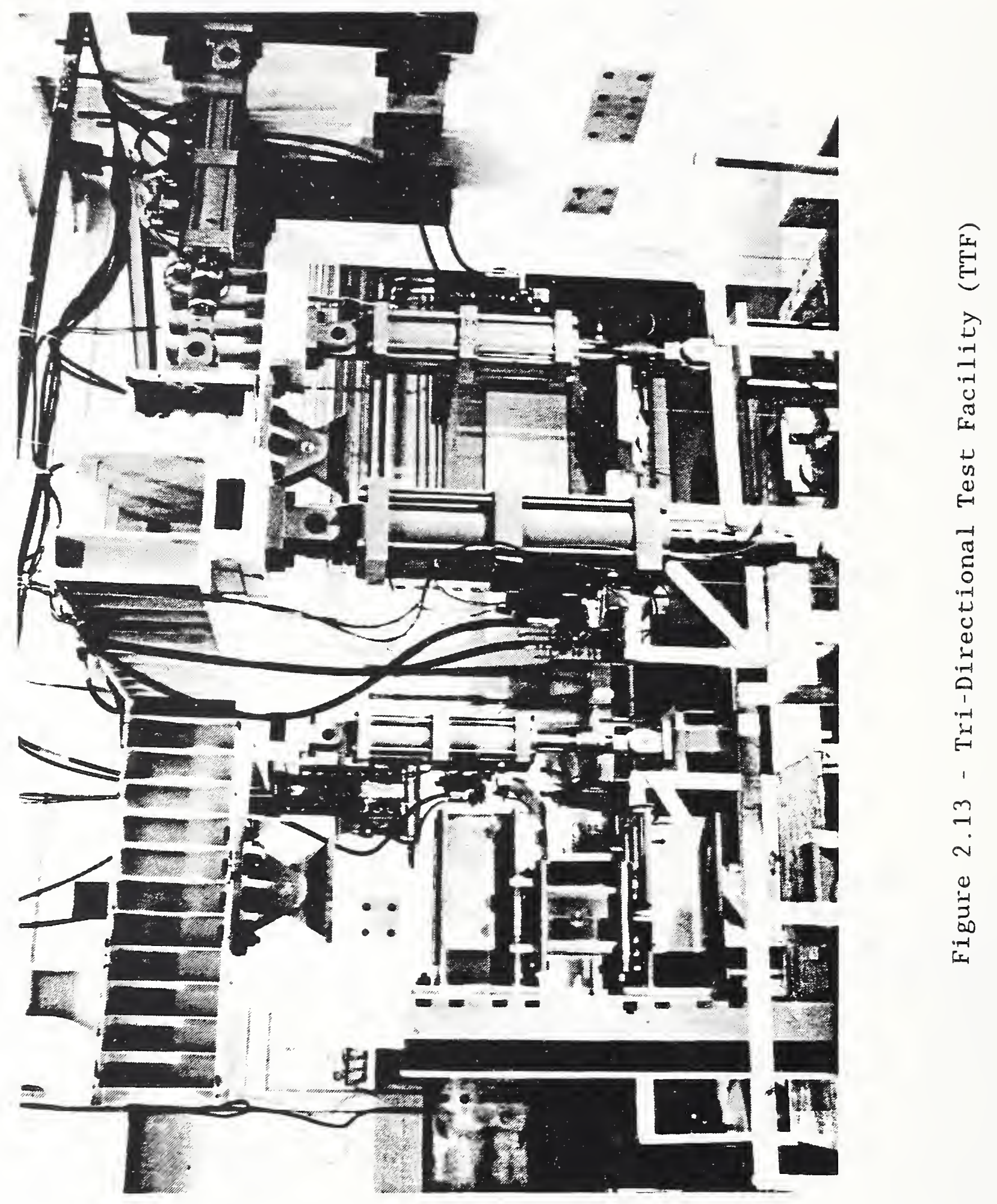



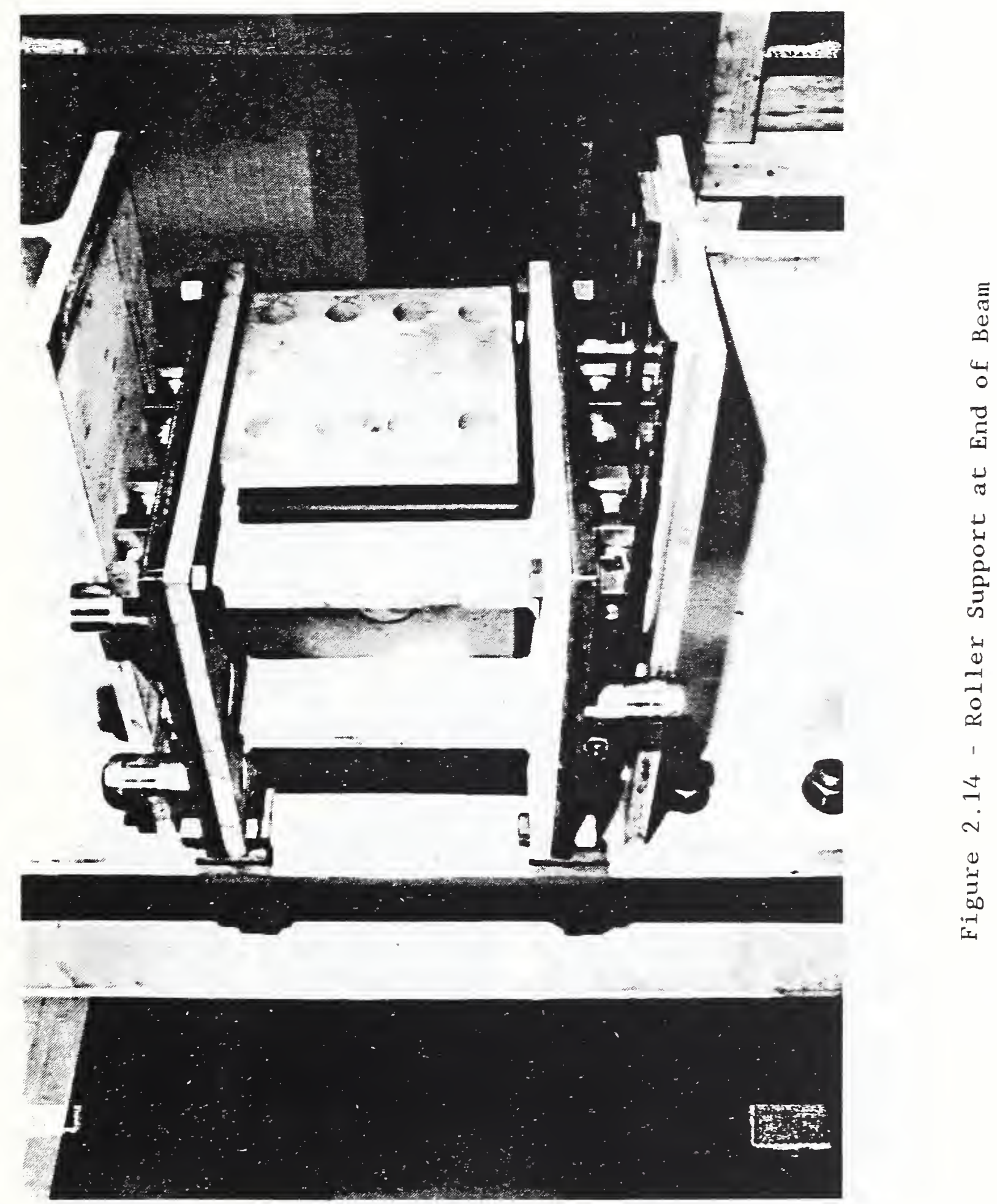


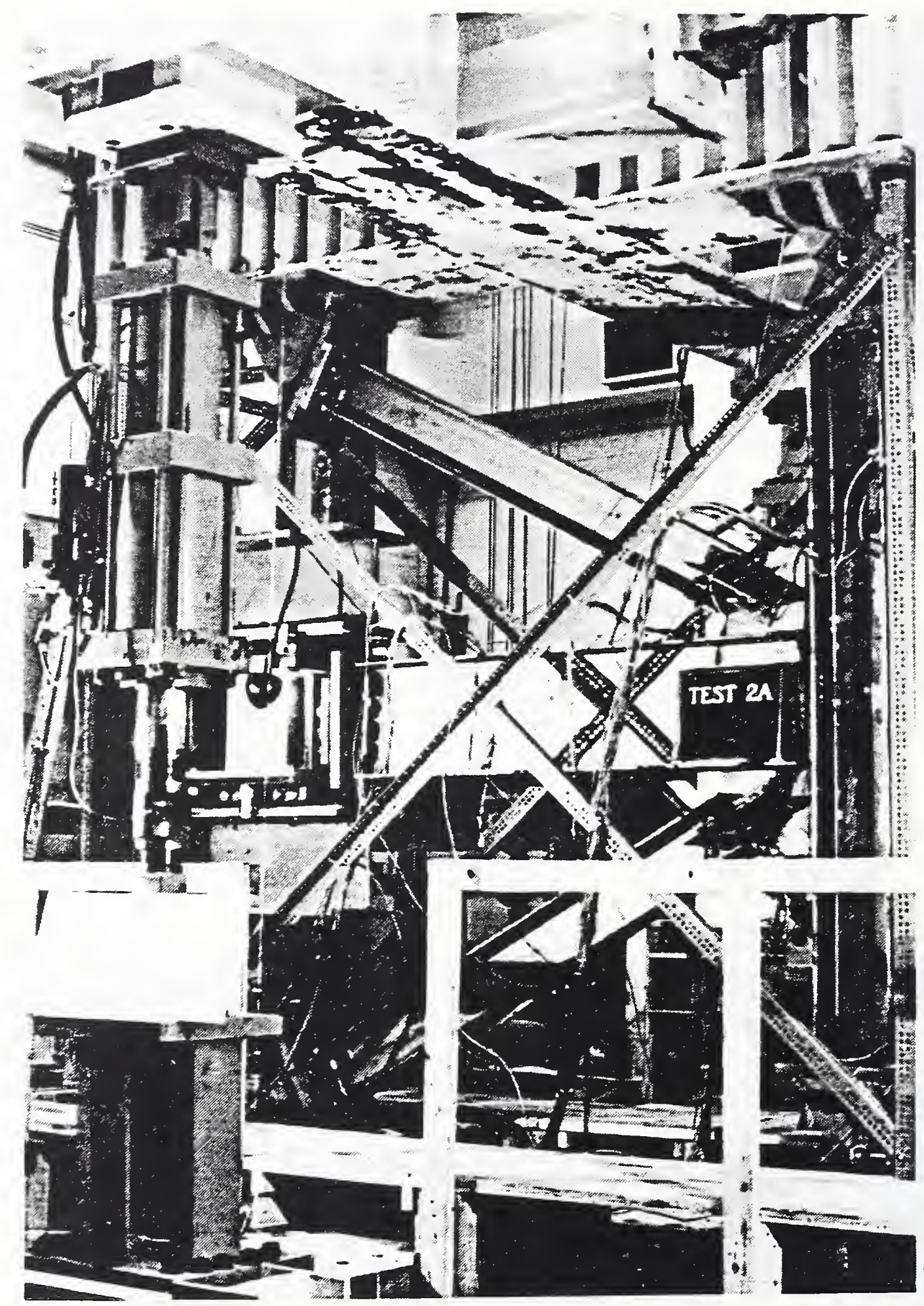

Figure 2.15 - Test Specimen Mounted in the TTF 


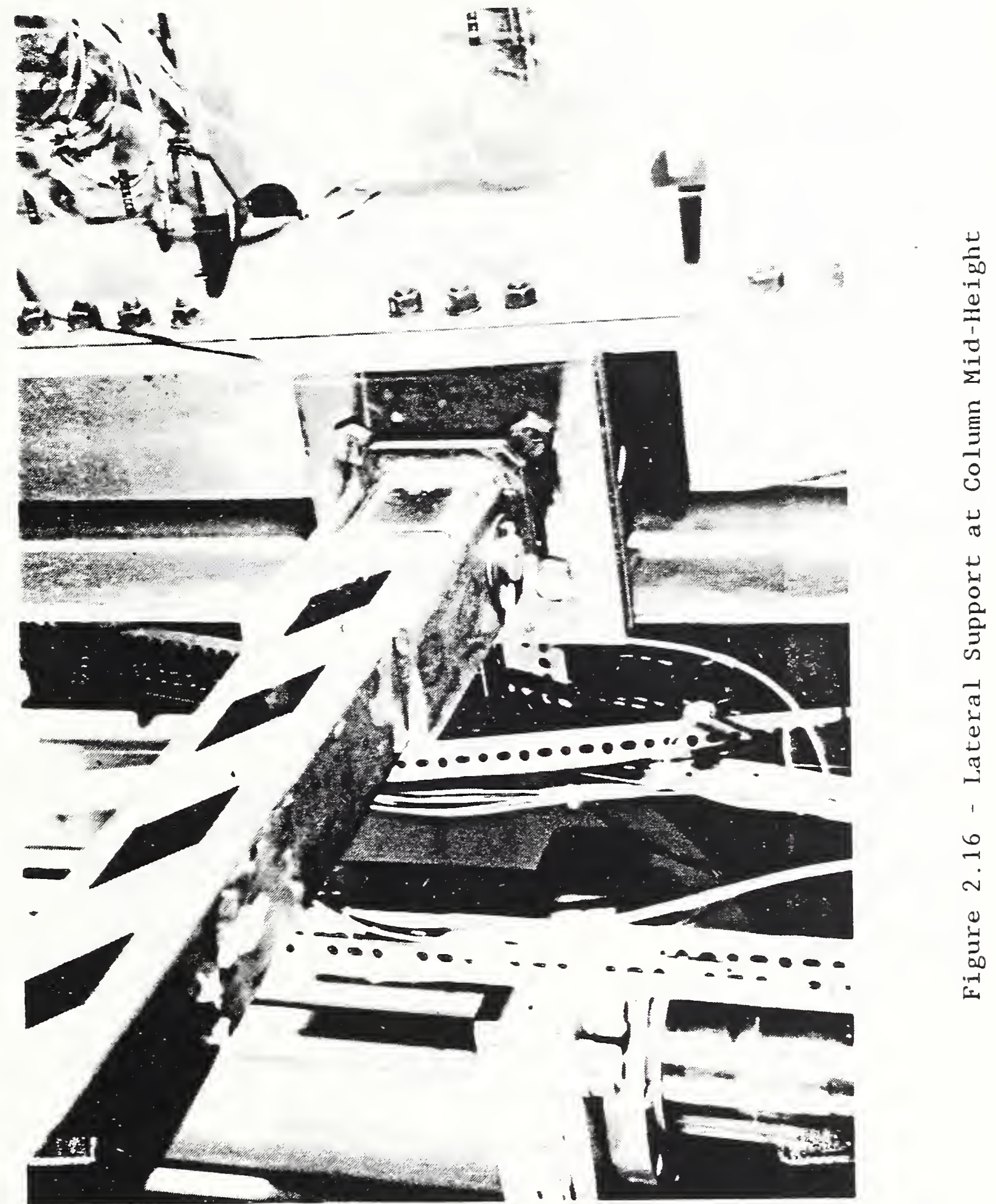




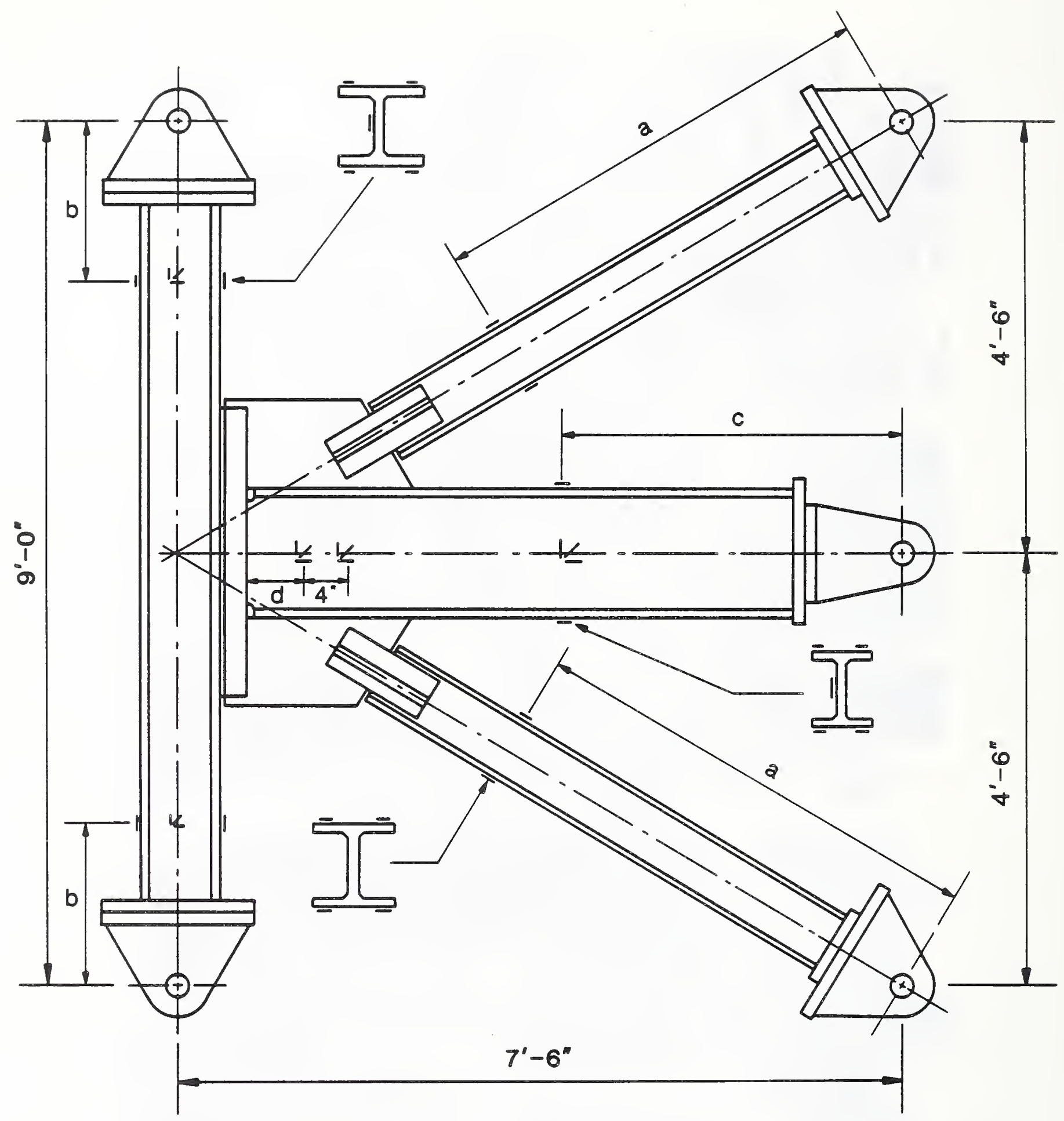

Figure 2.17 - Strain Gage Locations 


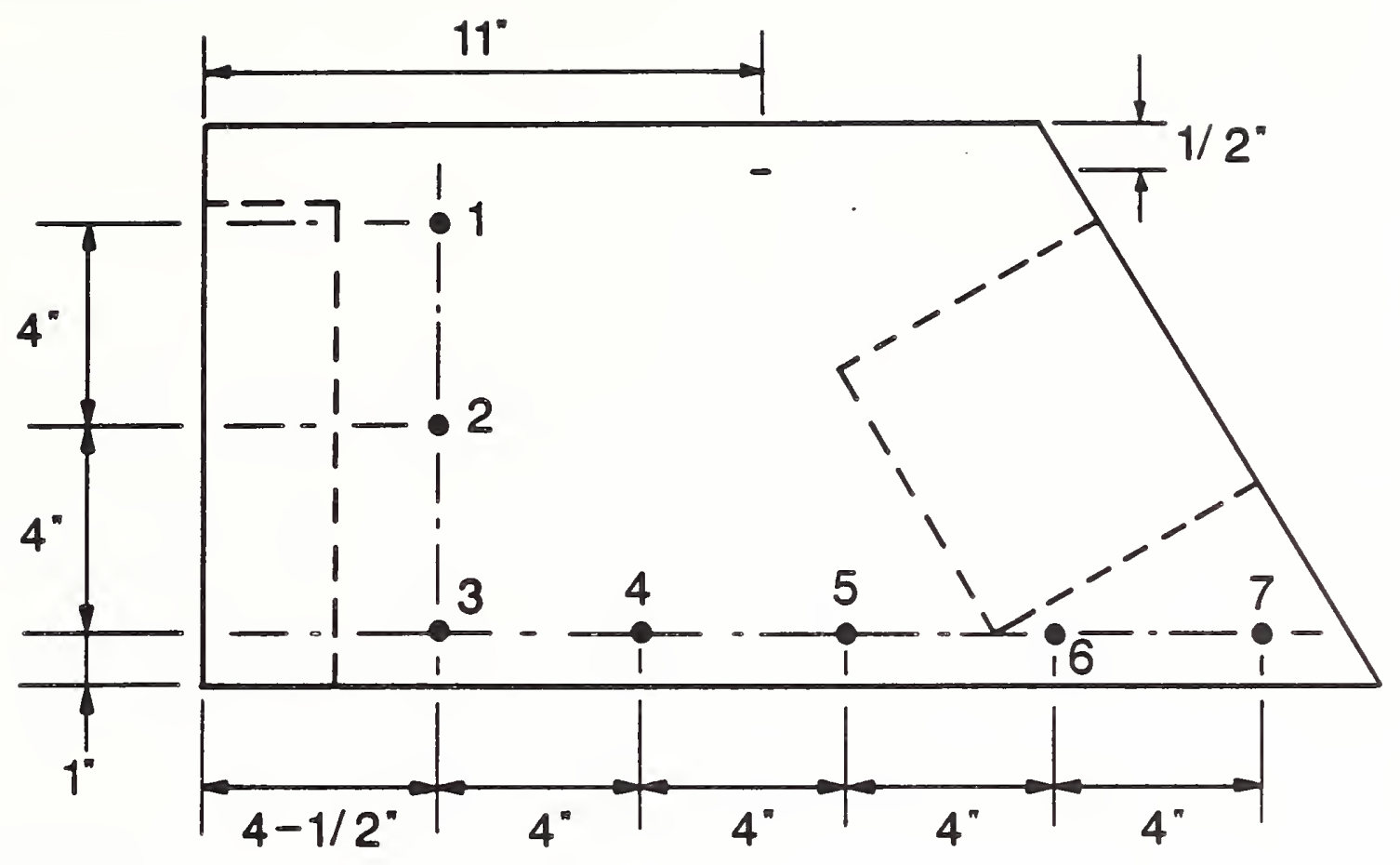

Specimen No. 1

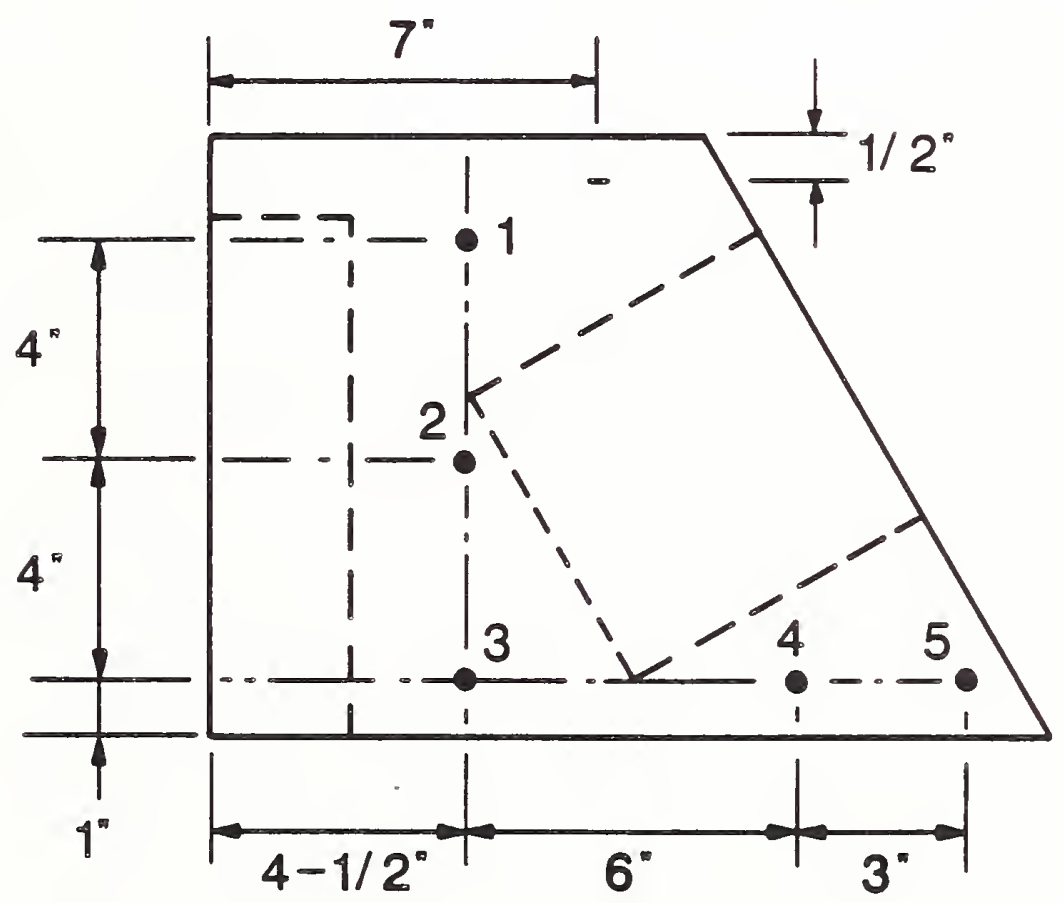

Specimen Nos. $2 \& 3$

Figure 2.18 - Location of Rosette Gages on Gusset Plate 



\subsubsection{Test 1A}

The gusset plates were coated with a brittle lacquer coating on one side and with a whitewash on the other. This was done in an attempt to determine the areas of high stress and patterns of yielding in the gusset plates. The whitewash coating flaked off in pieces rather than crack because the mill scale had been removed by grit blasting during fabrication. Cracks were observed in the brittle coating, however, they were not easily seen due to the size of the cracks and the reflection of light from the glossy coating. As a result, the gusset plates in the later tests were left uncoated.

The load vs. deflection plot for Test $1 \mathrm{~A}$ is shown in Figure 3.1. At a lateral load on the frame of 56 kips, flaking of the whitewash was observed in the lower gusset at the upper corner of the $\mathrm{T}$-section which connects the gusset to the diagonal. At approximately $60 \mathrm{kips}$, first cracking of the brittle coating was observed. Slip of the lower splice between the gusset and the diagonal resulted in a loud bang at a lateral load of 90 kips. A drop in lateral load occurred due to the slip and can be noted in Figure 3.1. A Iinear regression analysis was used to obtain the frame stiffness. Data points up to a lateral load of 50 kips were used and the resulting line was constrained to pass through the origin. A stiffness of $288 \mathrm{kip} / \mathrm{in}$ was found.

Buckling of the lower gusset occurred very suddenly at a lateral load equal to 107 kips. The lateral frame load dropped from 107 kips to 96 kips as shown in Figure 3.1. Thus, the ultimate frame load for Test $1 \mathrm{~A}$ was $107 \mathrm{kips}$ and the mode of failure was buckling of the gusset. The load in the compression (lower) diagonal was 116 kips and the load in the tension (upper) diagonal was 100 kips when the gusset buckled. The corresponding frame displacement was 0.50 in. The buckled lower gusset is shown in Figure 3.2 and a close-up of the cracks in the brittle coating is shown in Figure 3.3 . 
Figure 3.4 shows the load in the two diagonals for Test A. From the figure, it can be seen that the compression diagonal carried a greater load than the tension diagonal. This slight deviation was attributed to the lower crosshead being considerably stiffer than the upper crosshead which deflected under load thereby relieving some of the tension load in the upper diagonal.

As shown in Figure 3.1, the frame was not able to carry any additional load once the gusset buckled. However, as seen in Figure 3.4, the load in the compression diagonal decreased while the load in the tension diagonal increased. Loading was stopped at a maximum load of 96 kips and a corresponding displacement of 0.85 in. Force components in the framing members, calculated from strain measurements, were calculated for three lateral loads: 1) 40 kips, which was within the linear elastic range; 2) 70 kips, which was within the inelastic range but below ultimate; and 3 ) ultimate load, which was different for each specimen. The force components for these three cases are given in Tables $3.1 \mathrm{a}, \mathrm{b}$ and $c$ for the elastic range, inelastic range and ultimate load, respectively. Strains in the lateral brace less than 10 microstrain indicated that the load in the brace was less than one kip which was considered negligible.

\subsubsection{Test $1 \mathrm{~B}$}

The load vs. deflection plot for Test $1 \mathrm{~B}$ is shown in Figure 3.5. Significant slip of the splice between the gusset and diagonals occurred twice in Test 1B; once at a load of approximately 79 kips and again at 92 kips (see Figure 3.5). Lateral displacement of the upper gusset was first noticed at a lateral frame load of approximately 92 kips. At a lateral load of 96 kips and a lateral displacement of 0.72 in, the upper gusset buckled. Thus, the ultimate load for Test 1B was 96 kips and the mode of failure was buckling of the compressed gusset. Unlike Test 1A, buckling of the gusset was not accompanied by a large decrease in load. Some relaxation in load took place when the specimen was held at a fixed displacement for a period of time (such as for data recording and photography). However, the load quickly returned to its previous value upon application of additional displacement. This relaxation in load is not shown in Figure 3.5. The extent of buckling is indicated by the shadow cast by the straightedge on the gusset in Figure 3.6. Note that the value of load 
of 91 kips reported in the figure is a result of the relaxation noted above. The load in the compression (upper) diagonal was 96 kips and the load in the tension (lower) diagonal was 80 kips (see Figure 3.7) when the upper gusset buckled. As seen in Figure 3.5, the frame carried almost no additional load upon further displacement of the frame. Again, the load in the compression diagonal decreased while the load in the tension diagonal increased after the gusset buckled. The maximum post-buckling load for Test 1B was found to be 100 kips at a displacement of 1.09 in. The load in the lateral brace was less than one kip.

\subsection{Test Specimen No. 2}

\subsubsection{Test 2A}

The load vs. deflection plot for Test 2A is shown in Figure 3.8. The frame stiffness from the regression analysis was $258 \mathrm{kip} / \mathrm{in}$. No major slip of the splices occurred in the early part of the test. A sharp drop in lateral load occurred with a slip of one of the splices at a lateral load of approximately 124 kips. As the frame was displaced further and the lateral load increased, the lower gusset buckled suddenly (Figure 3.8).

The lateral displacement corresponding to the buckling load was 0.80 in. The load in the compression (lower) diagonal at buckling was 138 kips and the load in the tension (upper) diagonal was 113 kips. The loads in the diagonals are shown in Figure 3.9. The compression diagonal is shown to carry a greater load than did the tension diagonal. Buckling of the gusset was accompanied by a sudden drop in lateral load as in Test 1A. The load was 117 kips at a displacement of 1.12 in before the specimen was unloaded. The buckled gusset for Test $2 \mathrm{~A}$ is shown in Figure 3.10. The original 0.5 in. gap between the lower gusset and the lower diagonal had closed at this point (Figure 3.11) as a result of slip of the splice and rotation of the diagonal. Any further displacement would have caused the edge of the gusset to be loaded by the flange of the diagonal brace. Force components in the framing members are given for the linear elastic range, inelastic range, and ultimate load in 
Tables $3.1 \mathrm{a}, \mathrm{b}$ and $\mathrm{c}$, respectively. Again, strain in the lateral brace was insignificant.

\subsubsection{Test $2 \mathrm{~B}$}

Slip of the splices with accompanying drop in lateral load occurred several times during this test with the earliest slip occurring at a lateral load of 83 kips. Incipient buckling of the lower gusset plate was noted at a lateral load of 132 kips and a frame displacement of $1.54 \mathrm{in.}$ The load in the compression diagonal was 148 kips and in the tension diagonal 114 kips.

The lateral load had peaked and was decreasing when the testing machine malfunctioned and the test had to be stopped. The test was not resumed after repairs were made since it was felt that no further information needed to be obtained. The load vs. deflection plot for Test 2B is shown in Figure 3.12 and the load in the diagonals is shown in Figure 3.13. The irregularities in Figure 3.12 and Figure 3.13 are a result of numerous occurrences of slip of the splices.

\subsection{Test Specimen No. 3}

\subsubsection{Test $3 \mathrm{~A}$}

As in the previous tests, slip of the splices occurred in Test $3 \mathrm{~A}$ with the earliest slip occurring at a lateral load of 80 kips. The load vs. deflection plot is shown in Figure 3.14. The initial slope of load vs. deflection plot was $240 \mathrm{kip} / \mathrm{in}$ as obtained from a regression analysis.

During the test two dial gages were added at mid-height of the column to measure out-of-plane distortions of the column web. The maximum measured displacement of the column web was 7 thousandths of an inch and was considered negligible. The lateral load reached a peak value of 122 kips and then dropped suddenly to approximately $83 \mathrm{kips}$. The displacement corresponding to the maximum lateral load was 1.00 in. The load in the compression diagonal 
was 139 kips and the load in the tension diagonal was 125 kips at the maximum lateral load.

No buckling of the lower (compression) gusset plate was observed. However, noticeable distortion of the upper (tension) gusset and a widening of the gap between the upper diagonal and gusset were noted. Figure 3.15 shows the gap between the end of the upper diagonal and the edge of the gusset plate after the lateral load had peaked at 122 kips and then fallen to 83 kips. The lateral load continued to drop without attaining a stable value as the frame was displaced further. The specimen was unloaded at this point. The maximum displacement of the frame was 1.18 in. The load vs. deflection plot and diagonal load plot for Test $3 \mathrm{~A}$ are shown in Figure 3.14 and Figure 3.16, respectively.

After Test 3B had been completed and the diagonals had been removed, the reason for the inability of the frame to carry additional load in Test $3 \mathrm{~A}$ was apparent. The tension gusset was torn along the lower bolt line and the upper bolt line and lower bolt row showed obvious signs of yielding. The bolt holes were also elongated (Figure 3.17). Thus, the ultimate load for Test $3 \mathrm{~A}$ was 122 kips and the mode of failure was tearing of the gusset plate.

\subsubsection{Test 3B}

Many slips of the splices occurred in this test as indicated by the sudden drops in load shown in Figure 3.18. The two dial gages measuring lateral displacement of the column web indicated a maximum movement of 0.07 in. Buckling of the upper gusset, Figure 3.19, occurred at a lateral load of 103 kips, a frame displacement of 2.26 in and a load in the compression diagonal of 88 kips. The load in the tension diagonal was equal to 122 kips. A plot of the lateral load vs. axial loads in the diagonal bracing is shown in Figure 3.20. The frame was displaced to a maximum displacement of 1.17 in before the specimen was unloaded. It was necessary to unload at this point because the gap between the upper diagonal and the gusset had closed and the diagonal was resting against the gusset as seen in Figure 3.21. Further loading of the frame would not have yielded any relevant results. 
After testing of all the specimens, coupons were cut out from each of the members from all three specimens and tension tests were performed on the coupons in accordance with ASTM Standard A 370 [12]. The coupons from the gusset were obtained from the shaded area shown in Figure 3.22 which was between the legs of the two angles and should have experienced little or no stress during the tests. The results from the tensile tests are given in Table 3.2. A typical stress-strain plot for the gusset plate is shown in Figure 3.23. The average yield stress of the gusset plates was $46.7 \mathrm{ksi}$.

\subsection{Comparisons Between Tests}

\subsubsection{Concentric vs. Eccentric Bracing Connection (Test 1A vs. Test 2A)}

The connection with eccentric brace loading and compact gusset plate (Specimen No. 2) had a capacity of 123 kips as compared to the connection without eccentric loading (Specimen No. 1) which had a capacity of 107 kips. This is a 108 increase in buckling load capacity. The stiffness of specimen No. 1 was found to be greater than that for specimen No. 2 (288 vs. $258 \mathrm{kip} / \mathrm{in}$ ).

The global member force components in the $\mathrm{X}$ and $\mathrm{Y}$ directions were comparable for both tests for similar frame loads. The moment diagrams for Tests $1 \mathrm{~A}$ and $2 \mathrm{~A}$ are shown in Figures 3.24 and 3.25 , respectively. The moments in these figures correspond to a lateral load of 70 kips. The moments in the diagonals are not included because they are negligible in comparison with the moments in the column and beam. Two observations can be made regarding the moments in the framing members. The first is that the beam carries a significant moment regardless of the assumed beam end condition (in this case the beam was assumed to be pinned). This is because the gusset plates produce a nearly fixed condition for the beam-to-column connection. The second observation is that the moment produced by the force in the diagonal bracing members acting eccentric to the intersection of the framing member centroidal axes is distributed to the beam and column. This moment is distributed roughly in 
proportion to the ratio of moment of inertia to length ( $I / L$ ) of the members framing into the connection as shown in Figure 3.26 .

\subsubsection{Strong-Axis vs. Weak-Axis Column Connection (Test 2A vs. Test 3A)}

While the ultimate load for both tests was practically the same, the failure mode of the gusset was different for the two tests. The gusset attaching the compression diagonal buckled in Test $2 \mathrm{~A}$ while the gusset attaching the tension diagonal tore in Test 3A. The tearing of the gusset in Test $3 \mathrm{~A}$ was likely a result of the rotation allowed by the connection due to the flexibility of the column web which increased the load in the tension diagonal. From Section 3.3.1, the loads in the compression diagonals were 138 kips and 139 kips for Test $2 \mathrm{~A}$ and $3 \mathrm{~A}$, respectively. The loads in the tension diagonals were 113.4 kips and 125 kips for Test $2 \mathrm{~A}$ and Test $3 \mathrm{~A}$, respectively. The stiffness of the frame in Test $2 \mathrm{~A}$ was $258 \mathrm{kip} /$ in compared with $240 \mathrm{kip} / \mathrm{in}$ for Test $3 \mathrm{~A}$.

Again, for equal frame loads in the elastic range (Table 3.1a), the member loads in the $X$ and $Y$ directions and the moments in the beams were comparable in both tests. Also, in the elastic range, the moment in the compression diagonal in Test $3 \mathrm{~A}$ was greater than that in Test $2 \mathrm{~A}$. However, at the buckling load (Table 3.1C), the moment in the beam in Test 3A was larger than in Test 2A. The moments corresponding to a lateral load of 70 kips for Test $3 \mathrm{~A}$ are shown in Figure 3.27. As can be seen, the moment produced by frame action as well as the moment produced by the eccentricity of the bracing loads was carried almost exclusively by the beam. Apparently, the thin column web was not sufficiently stiff to mobilize the column flanges in resisting the moments. 
Table 3.1a - Force Components, Elastic Range 1

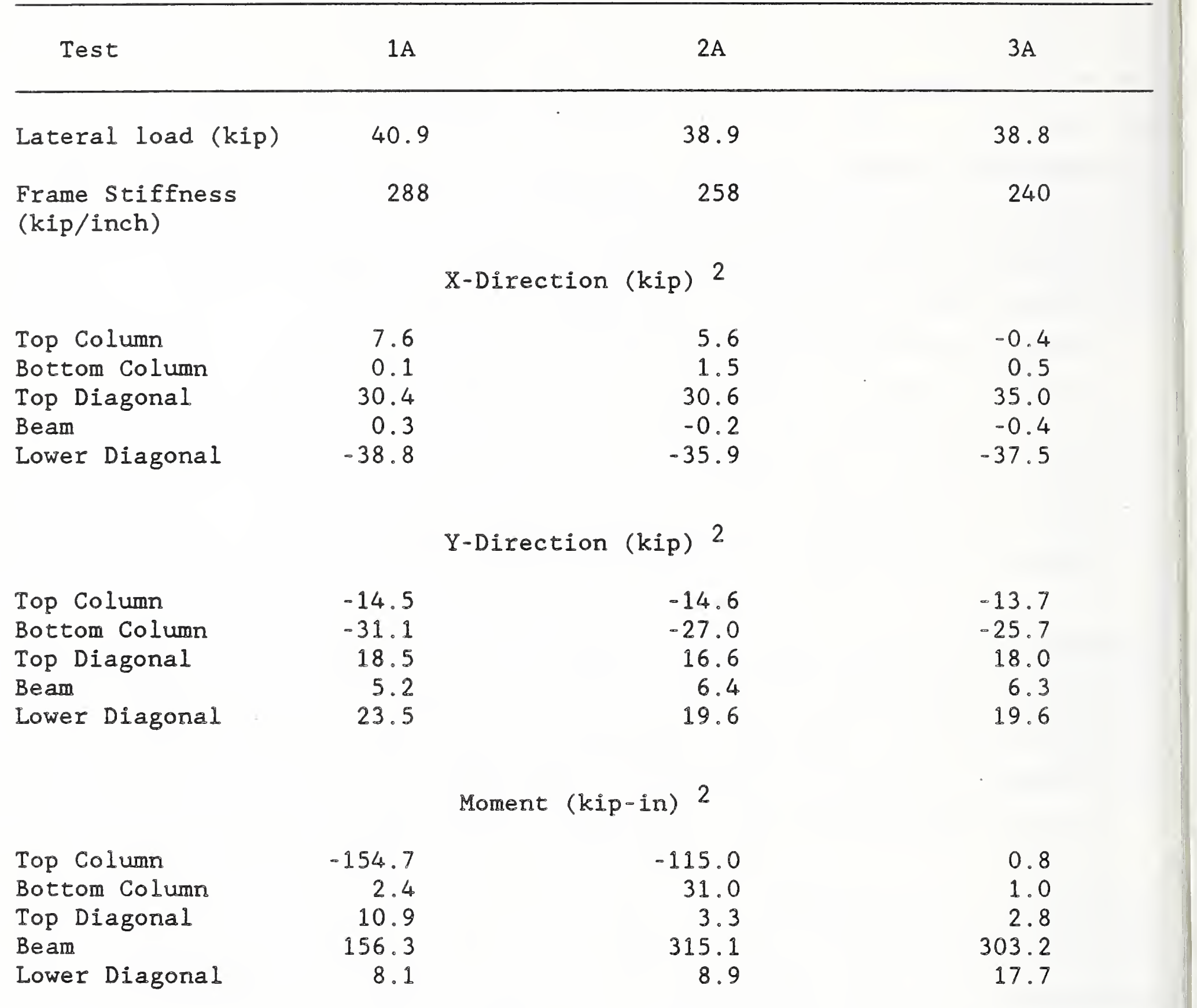

1 Loads at gage location. See Figure 2.14a

2 Sign convention:

+ value = positive $X$-direction, right hand coordinate system

+ value $=$ positive $Y$-direction, right hand coordinate system

+ value $=$ counter - clockwise moment 
Table 3.1b Force Components, Inelastic Range 1

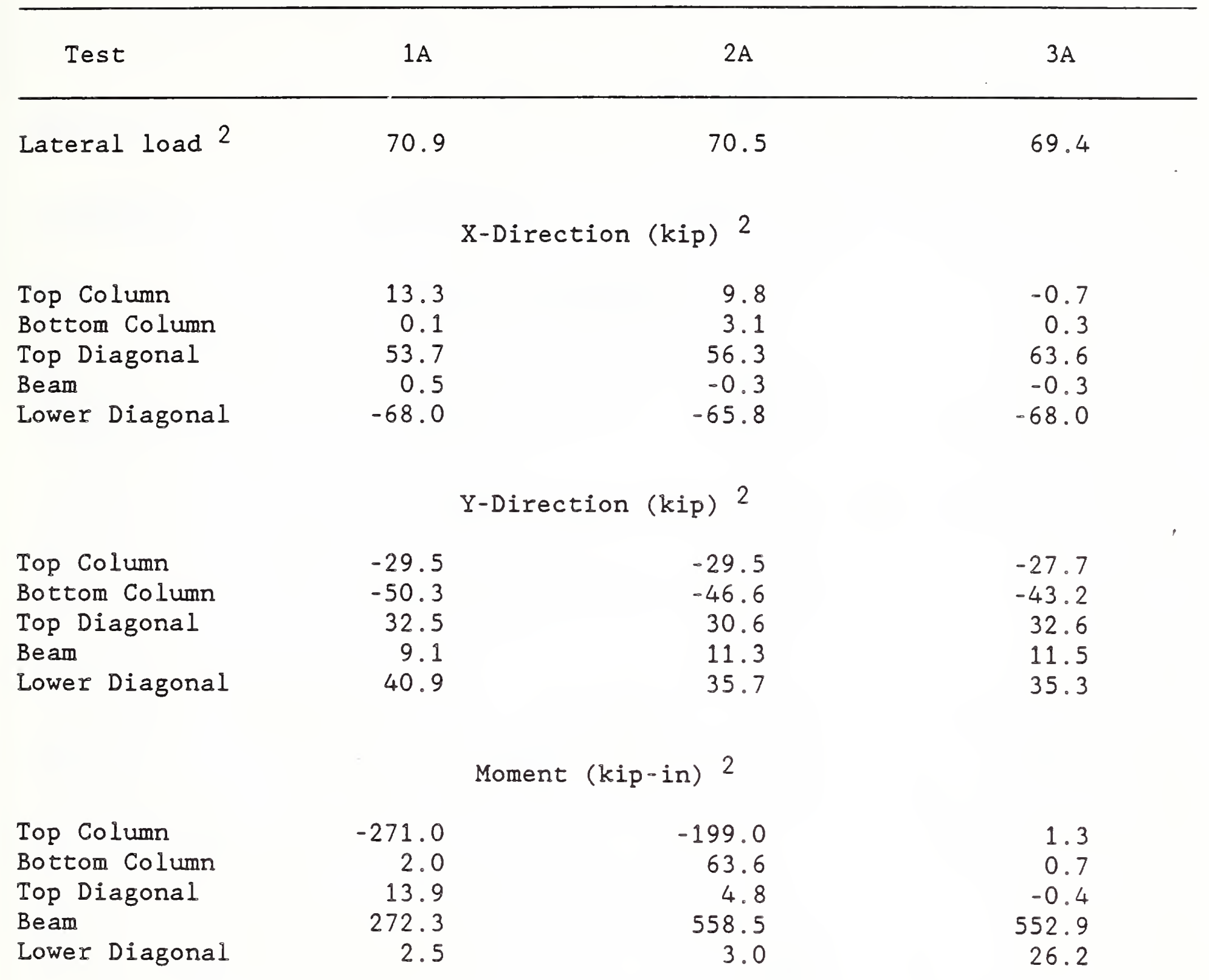

1 Loads at gage location. See Figure $2.18 \mathrm{a}$

2 Sign convention:

+ value $=$ positive $X$-direction, right hand coordinate system

+ value $=$ positive $Y$-direction, right hand coordinate system

+ value $=$ counter-clockwise moment 
Table 3.1c - Force Components at Ultimate Frame Capacity

Test
$1 \mathrm{~A}$

107.0

(buckling)
$2 \mathrm{~A}$

$3 \mathrm{~A}$
Ult. Capacity (kip)

(mode of failure) (buckling)

$$
\mathrm{X} \text {-Direction (kip) }{ }^{2}
$$

123.0

(buckling)
122.0

(tearing)
Top Column

Bottom Column

Top Diagonal

Beam

Lower Diagonal
17.5

$-3.4$

85.6

0.2

$-99.6$
17.9

11.0

99.7

$-0.5$

$-121.7$
$-0.1$

0.0

111.0

0.0

$-123.8$

\section{Y-Direction (kip) 2}

Top Column

Bottom Column

Top Diagonal

Beam

Lower Diagonal
$-48.3$

$-73.2$

51.6

14.5

59.4
$-50.7$

$-82.4$

54.1

18.1

65.2

Moment (kip-in) 2

$-356.0$

$-70.2$

11.4

434.7

$-20.2$
$-365.0$

224.9

6.8

896.4

$-33.8$
$-46.2$

$-80.0$

57.1

21.1

62.6
Beam

Lower Diagonal
Bottom Column

Top Diagonal
Top Column

$-20$

2


Table 3.2 Material Properties

Specimen

$F_{\mathrm{u}}$

(lbs)
Cross Sectional

Area

$\left(\right.$ in $\left.^{2}\right)$

of Elongation

Column:

$\begin{array}{lllll}\text { Test } 1 & 63 & - & 0.281 & 39.1 \\ \text { Test } 2 & 61 & 21,400.0 & 0.281 & 43.7 \\ \text { Test } 3 & 55 & 21,350.0 & 0.278 & 40.6\end{array}$

Beam:

Test 1

63

$19,550.0$

0.252

40.6

Test 2

63

$19,700.0$

0.253

40.6

Test 3

61

$18,550.0$

0.253

40.6

Diagonal:

Test 1

Test 2

Test 3
61

60

60
$15,050.0$

$15,150.0$

$15,200.0$
0.189

0.190

0.189
34.4

34.4

34.4

Top Gusset Plate:

$\begin{array}{lllll}\text { Test } 1 & 47 & 8,460.0 & 0.115 & 34.4 \\ \text { Test 2 } & 41 & 8,440.0 & 0.114 & 34.4 \\ \text { Test } 3 & 47 & 8,310.0 & 0.114 & 28.1\end{array}$

Bottom Gusset Plate:

$\begin{array}{lllll}\text { Test } 1 & 47 & 8,465.0 & 0.114 & 31.3 \\ \text { Test 2 } & 49 & 8,360.0 & 0.115 & 34.4 \\ \text { Test } 3 & 49 & 8,470.0 & 0.115 & 34.4\end{array}$

Tee Sections:

Coupon 1

Coupon 2

Coupon 3

Coupon 4
49

50

49

52
$7,100 \cdot 0$
$7,120.0$
$8,350.0$
$8,380.0$

0.103

0.103

0.115

0.115
34.4

34.4

34.4

34.4 


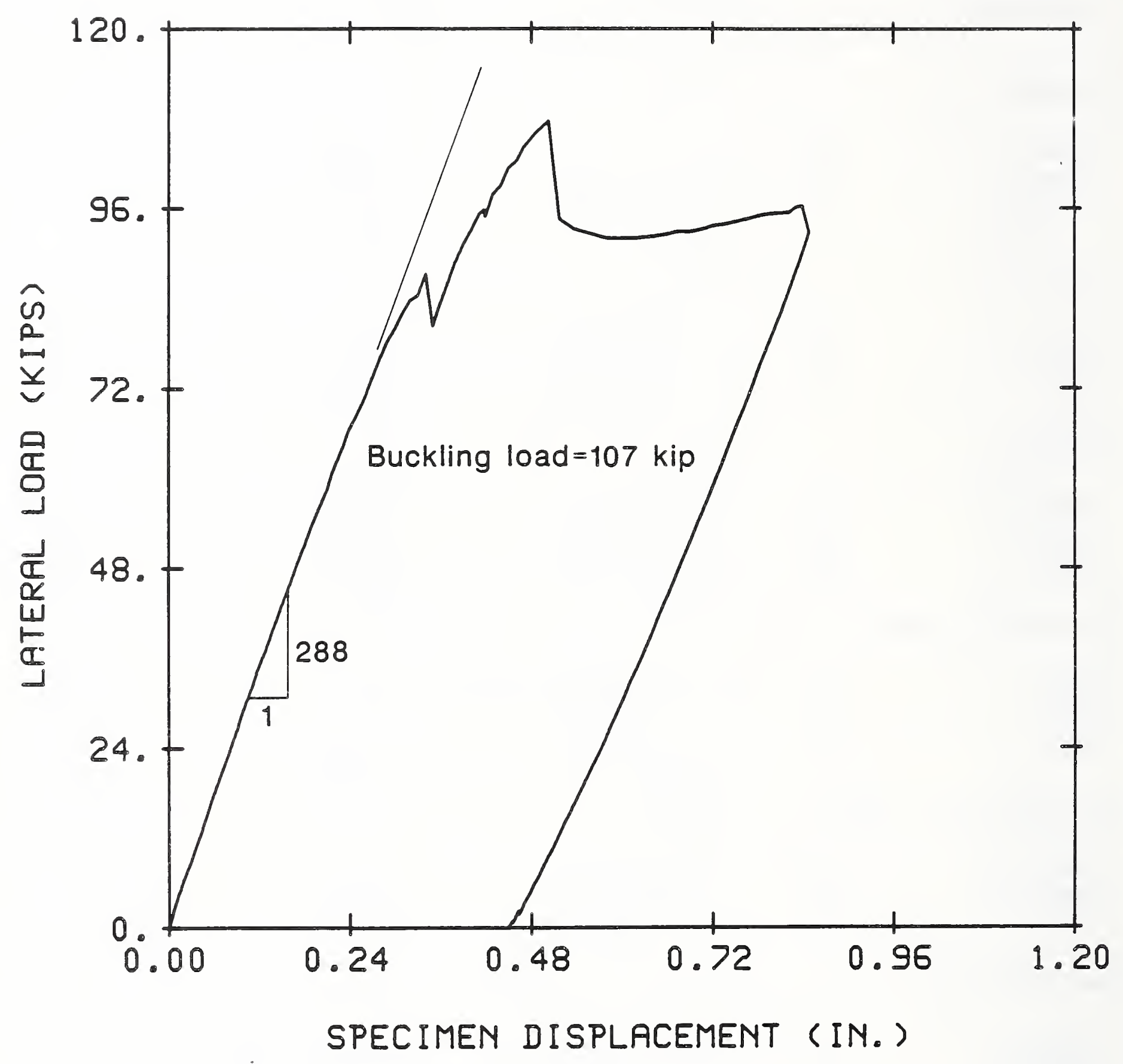

Figure 3.1 - Load vs. Deflection, Test 1A 


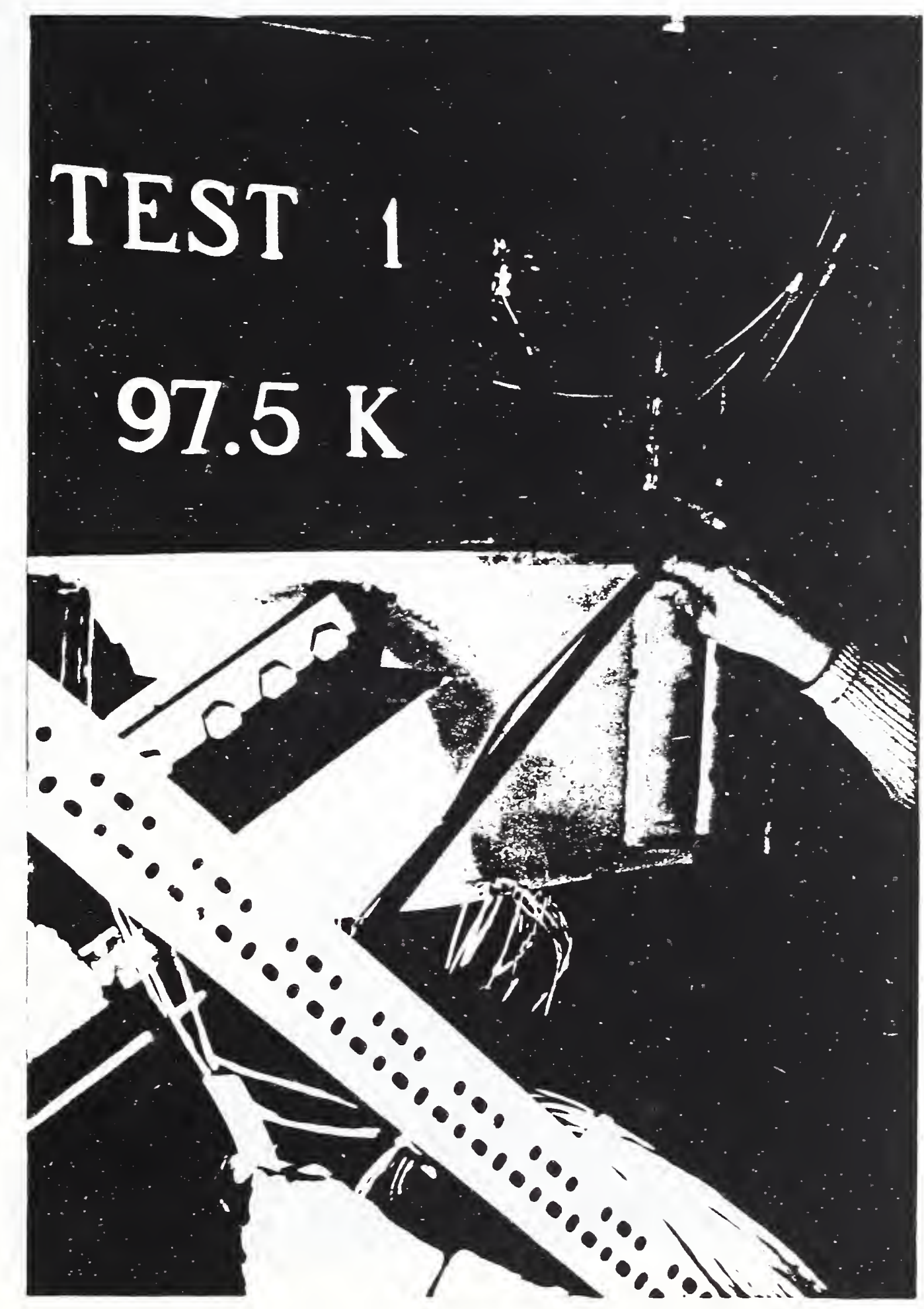

Figure 3.2 - Buckled Lower Gusset Plate, Test 1A 


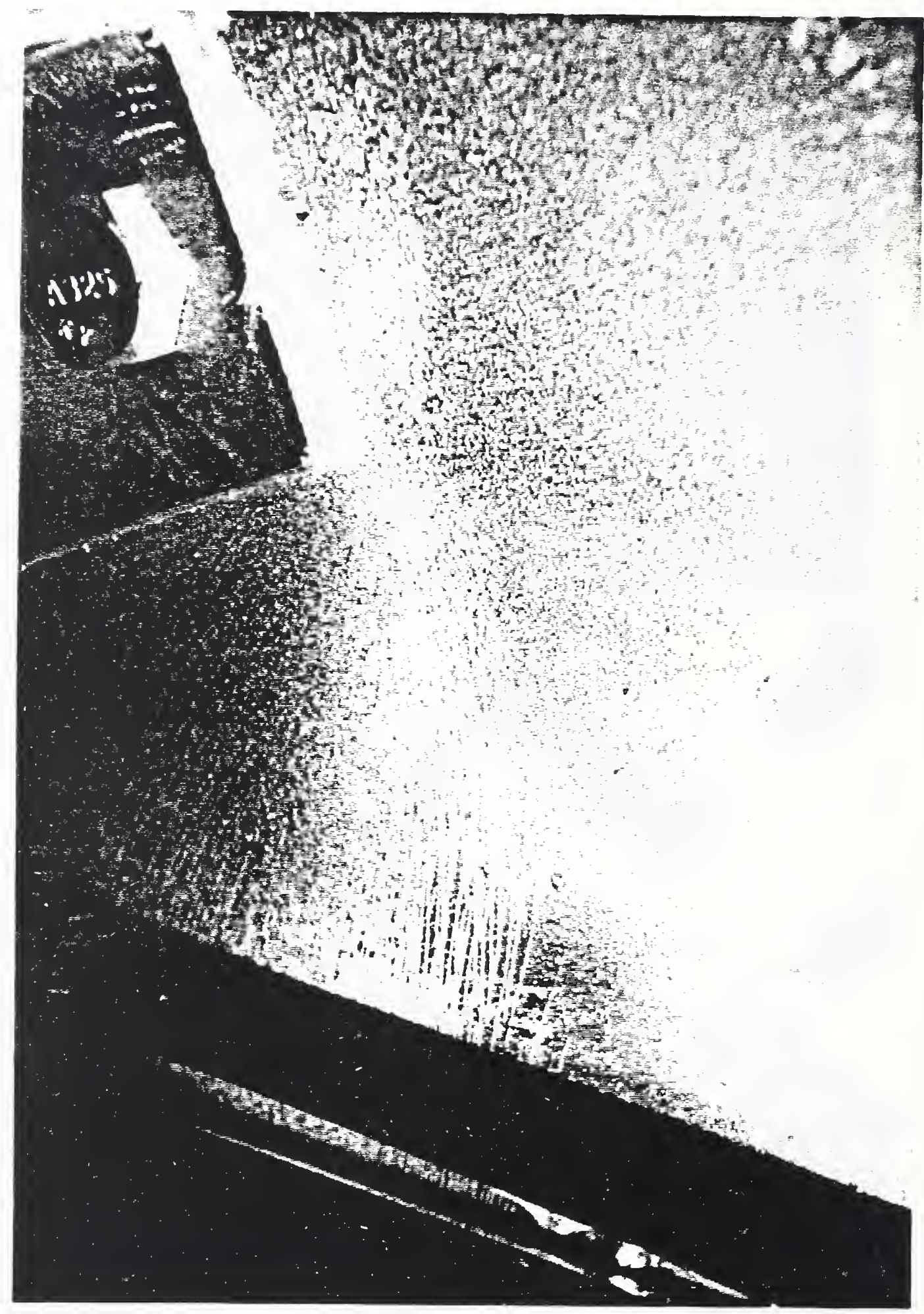

Figure 3.3 - Cracks in Brittle Coating on Lower Gusset, Test 1A 


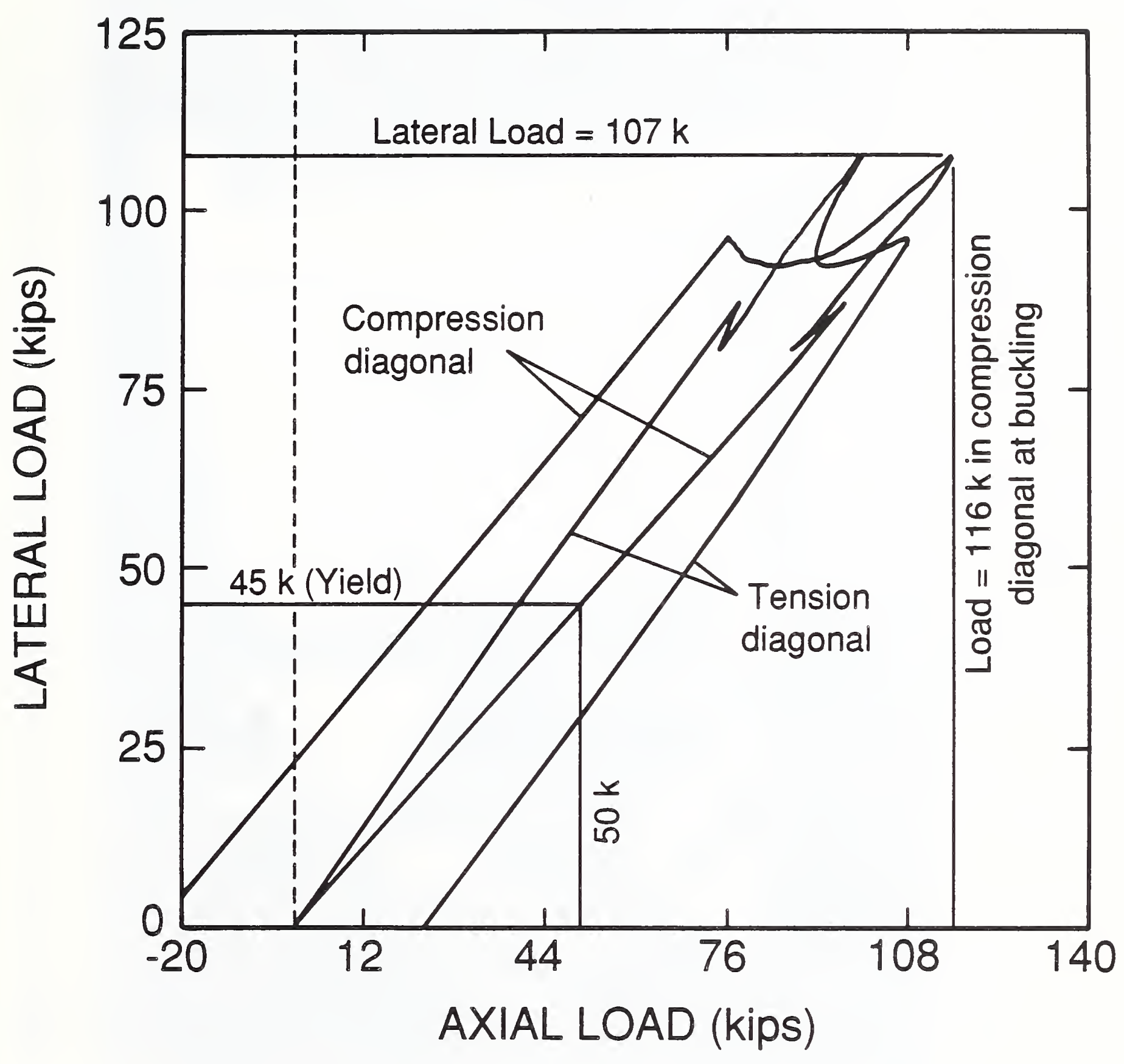

Figure 3.4 - Lateral Load vs. Axial Loads in Diagonal Bracing, Test $1 \mathrm{~A}$ 


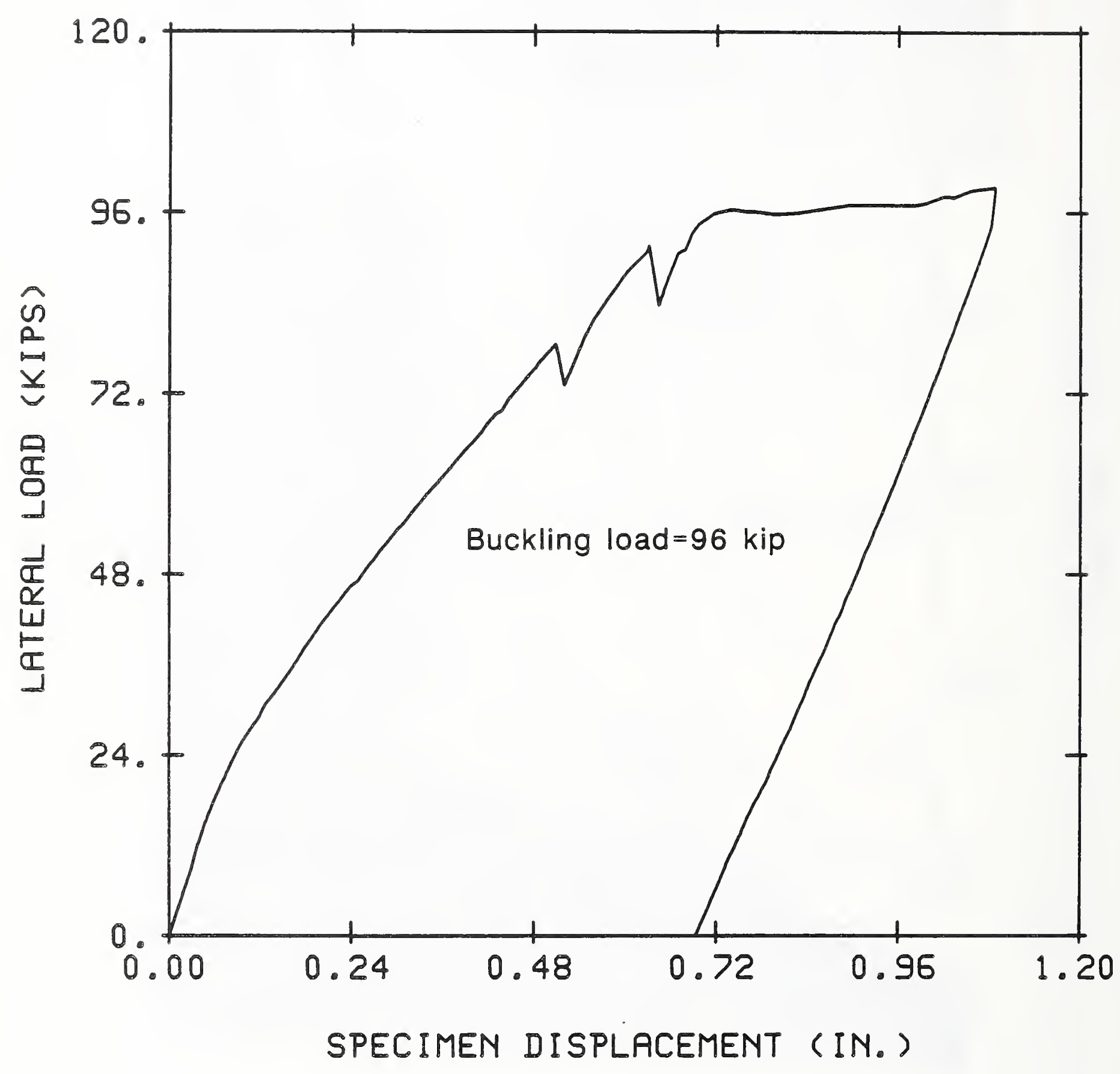

Figure 3.5 - Load vs. Deflection, Test 1B 


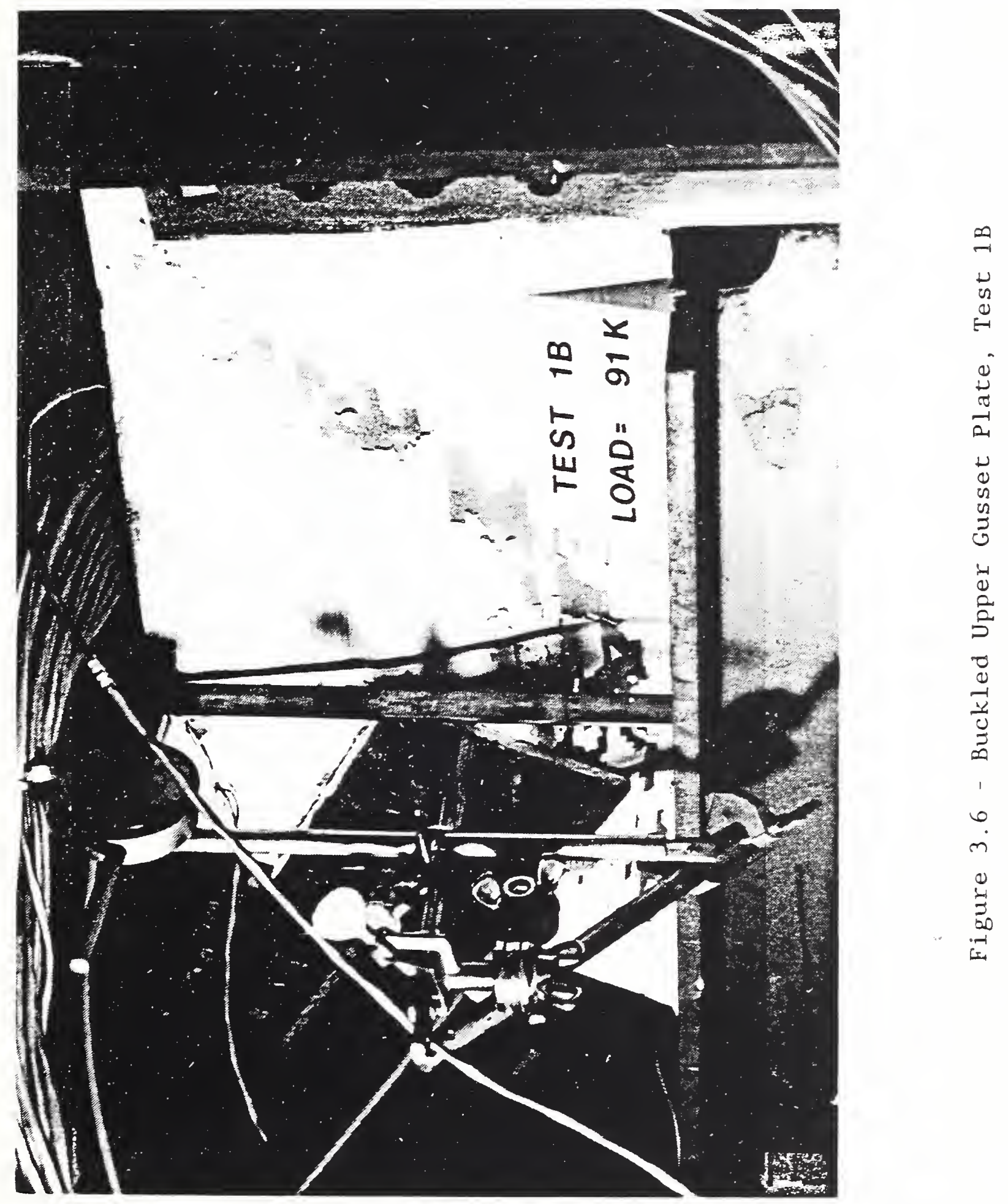




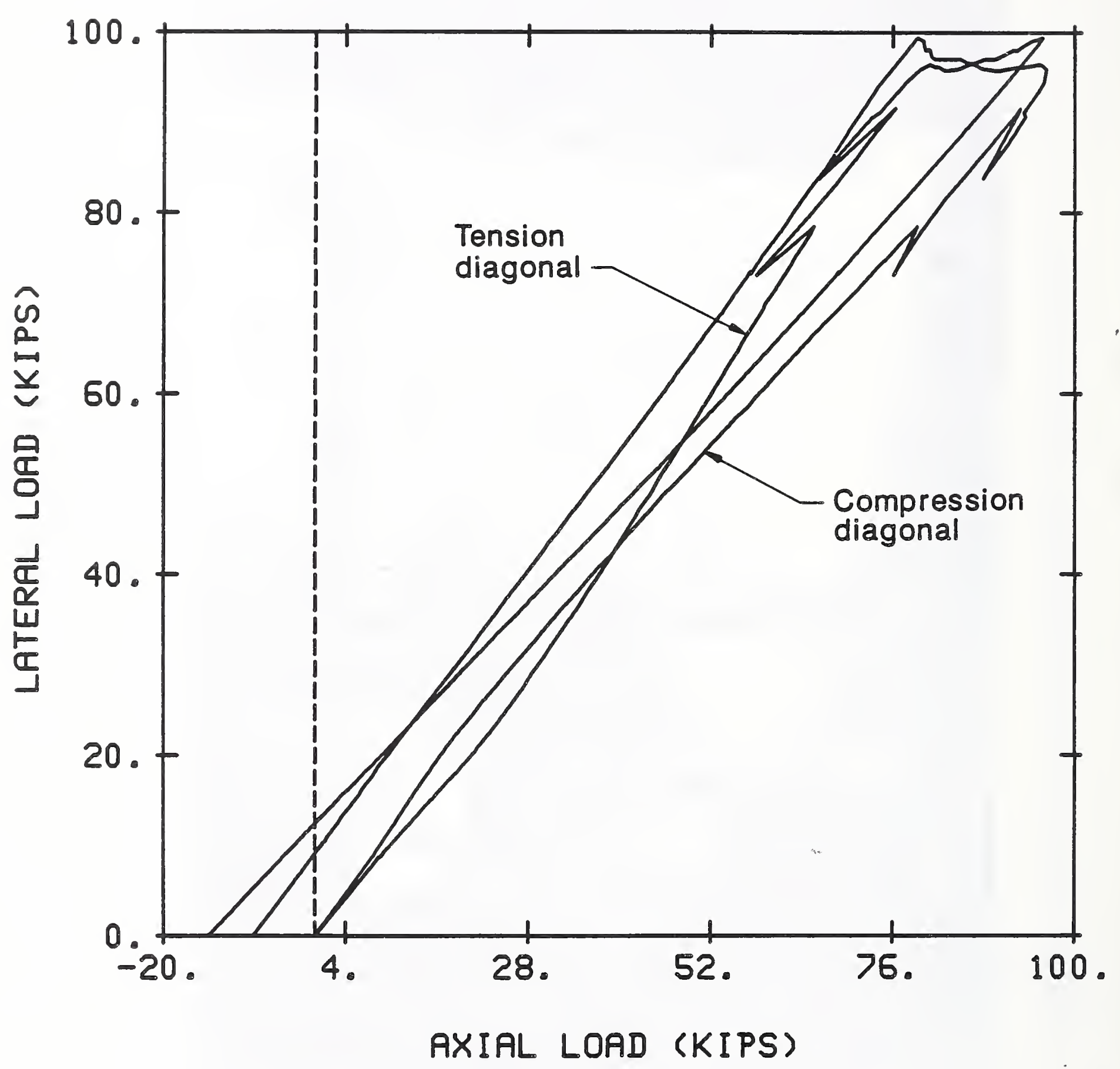

Figure 3.7 - Lateral Load vs. Axial Loads in Diagonal Bracing, Test $1 B$ 


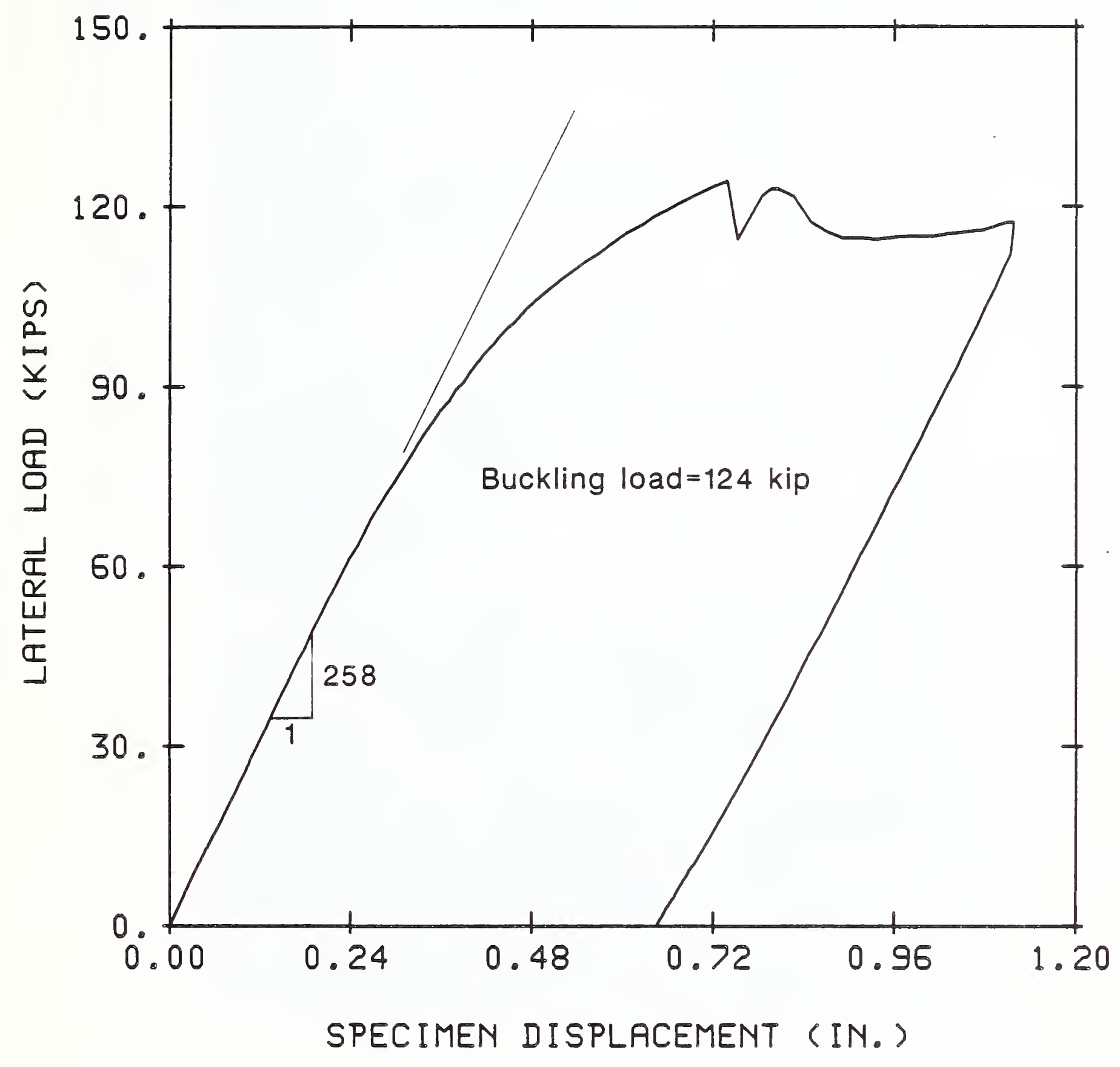

Figure 3.8 - Load vs. Deflection, Test 2A 


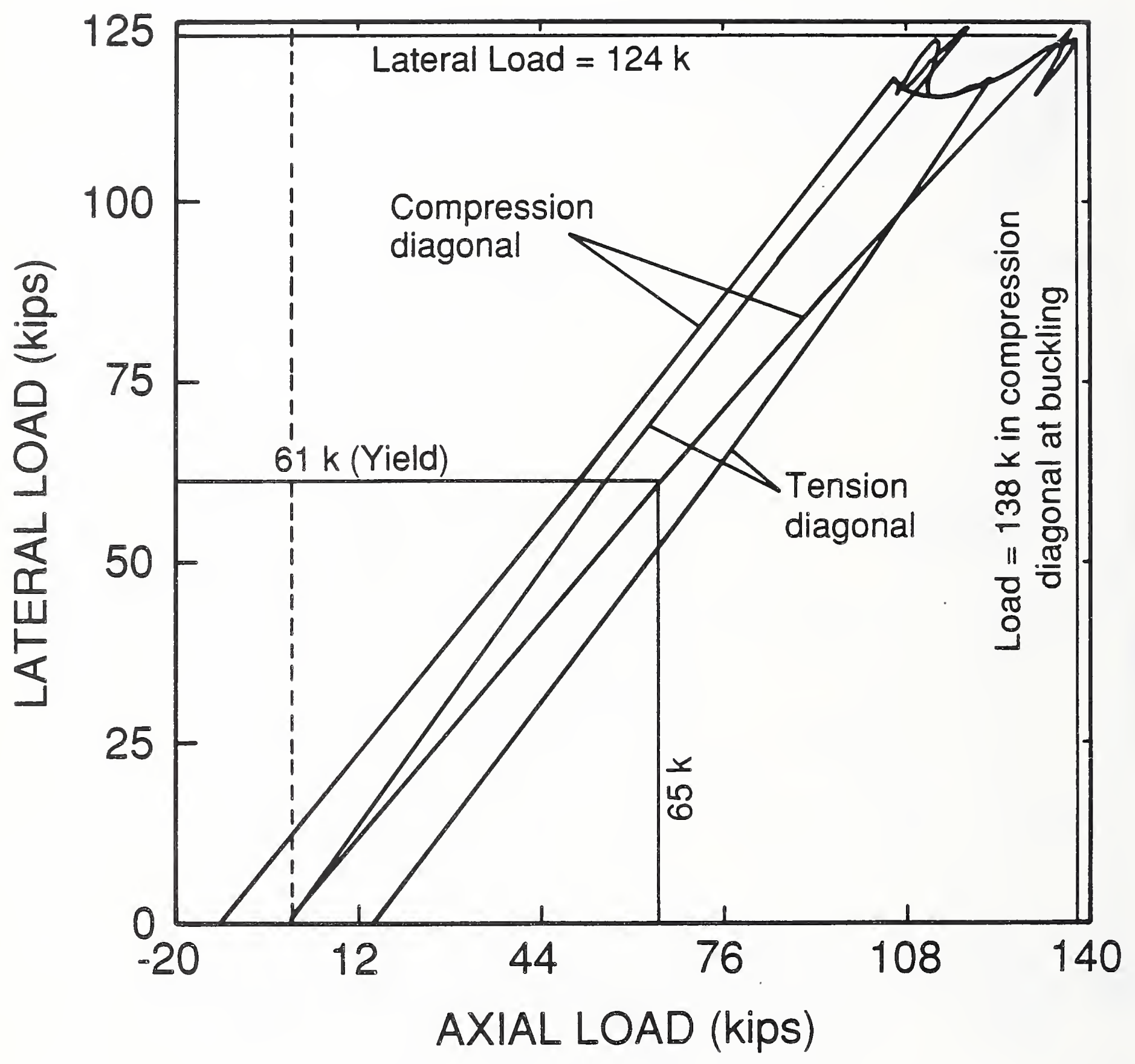

Figure 3.9 - Lateral Load vs. Axial Loads in Diagonal Bracing, Test $2 \mathrm{~A}$ 


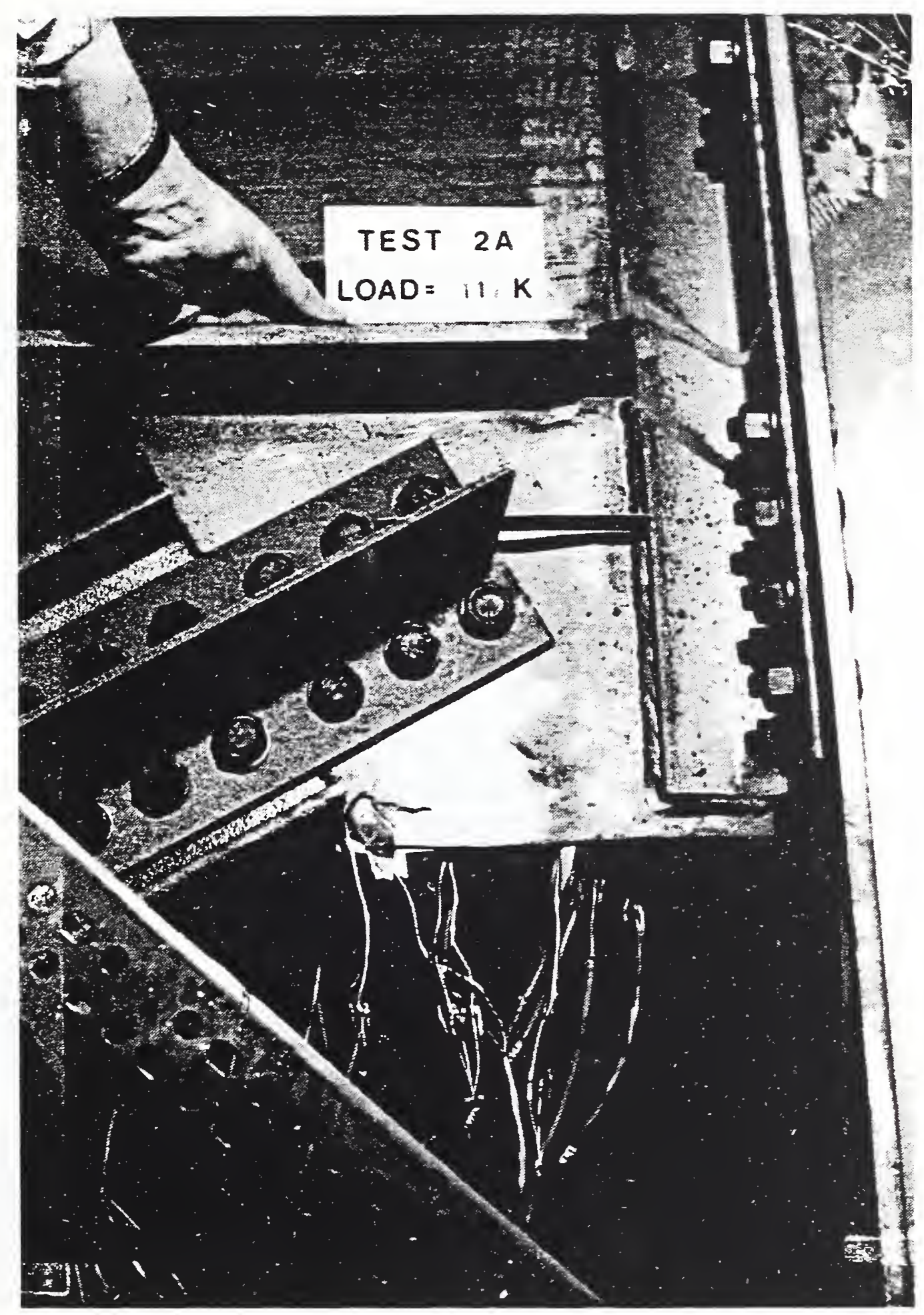

Figure 3.10 - Buckled Lower Gusset Plate, Test 2A 


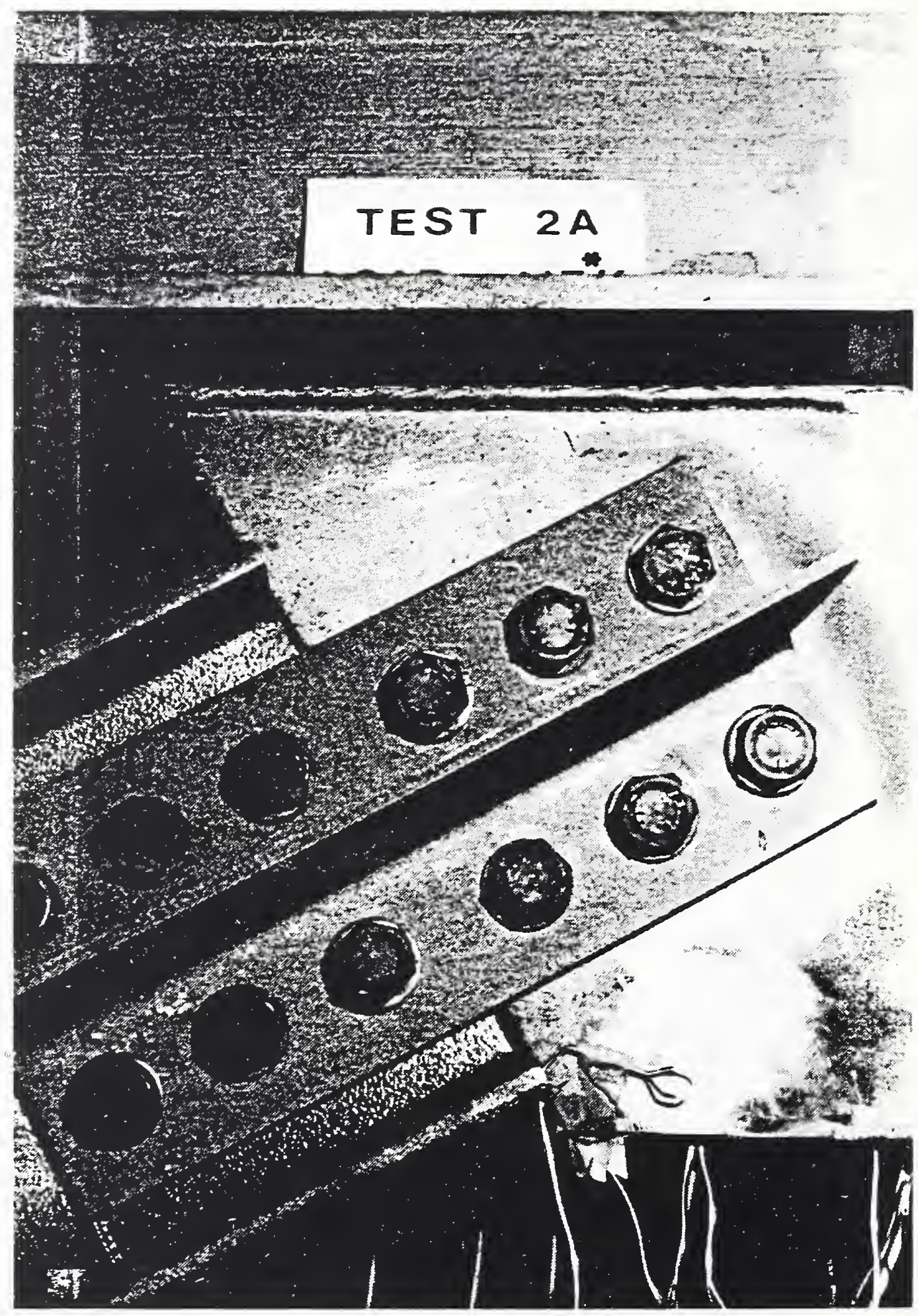

Figure 3.11 - View of the Closed Gap Between the Lower Gusset and the Diagonal 


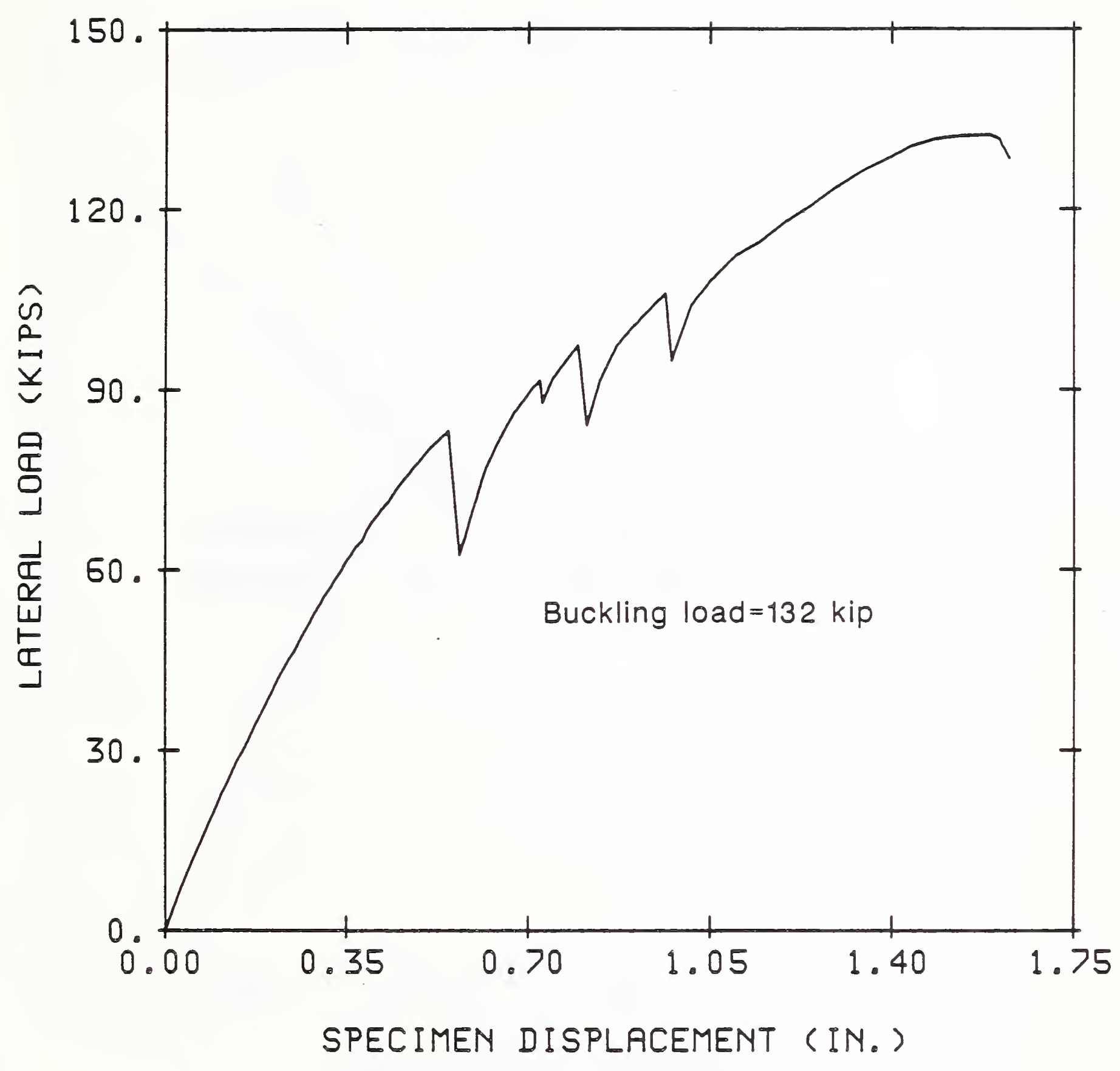

Figure 3.12 - Load vs. Deflection, Test 2B 


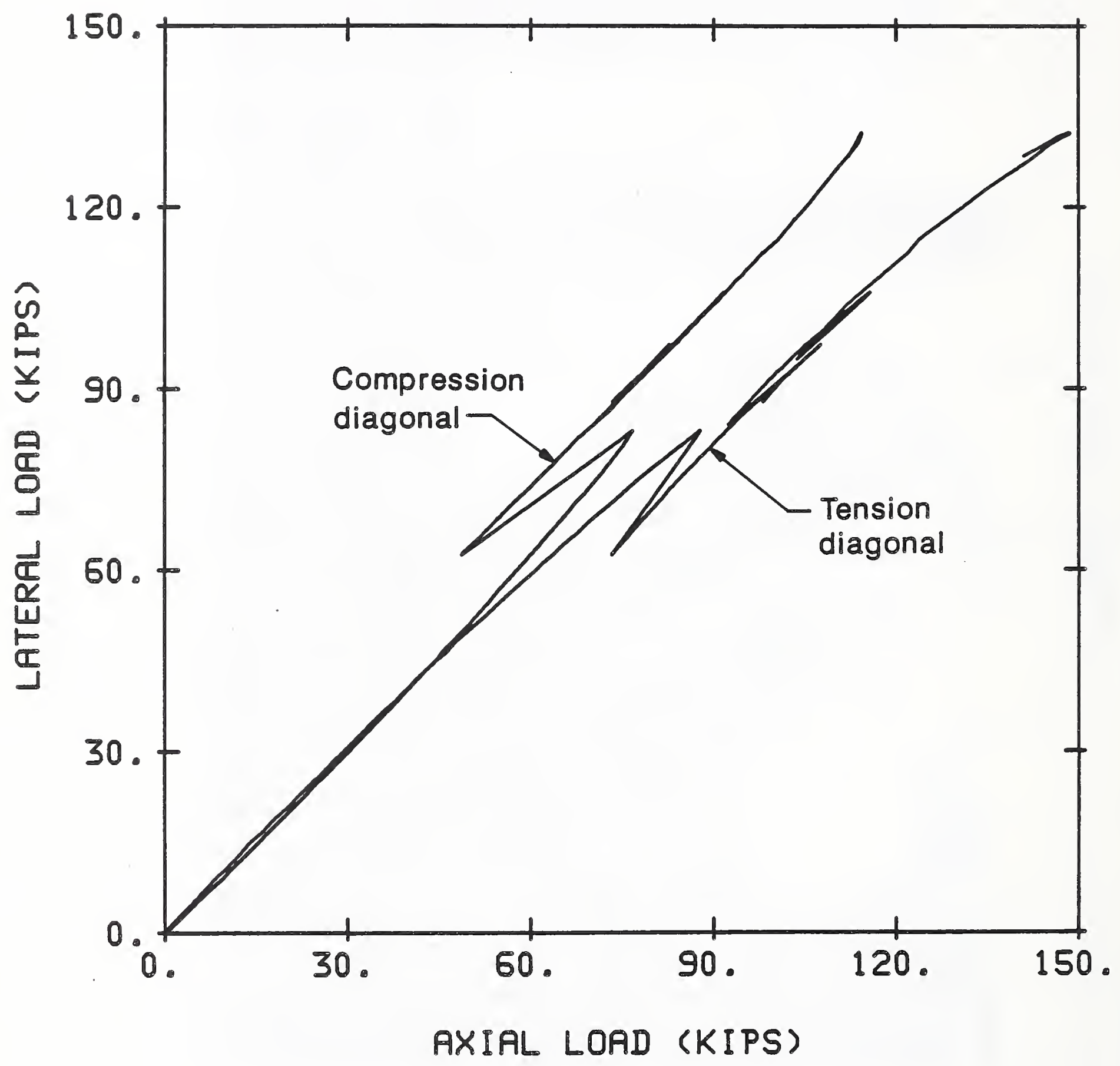

Figure 3.13 - Lateral Load vs. Axial Loads in Diagonal Bracing, Test 2B 


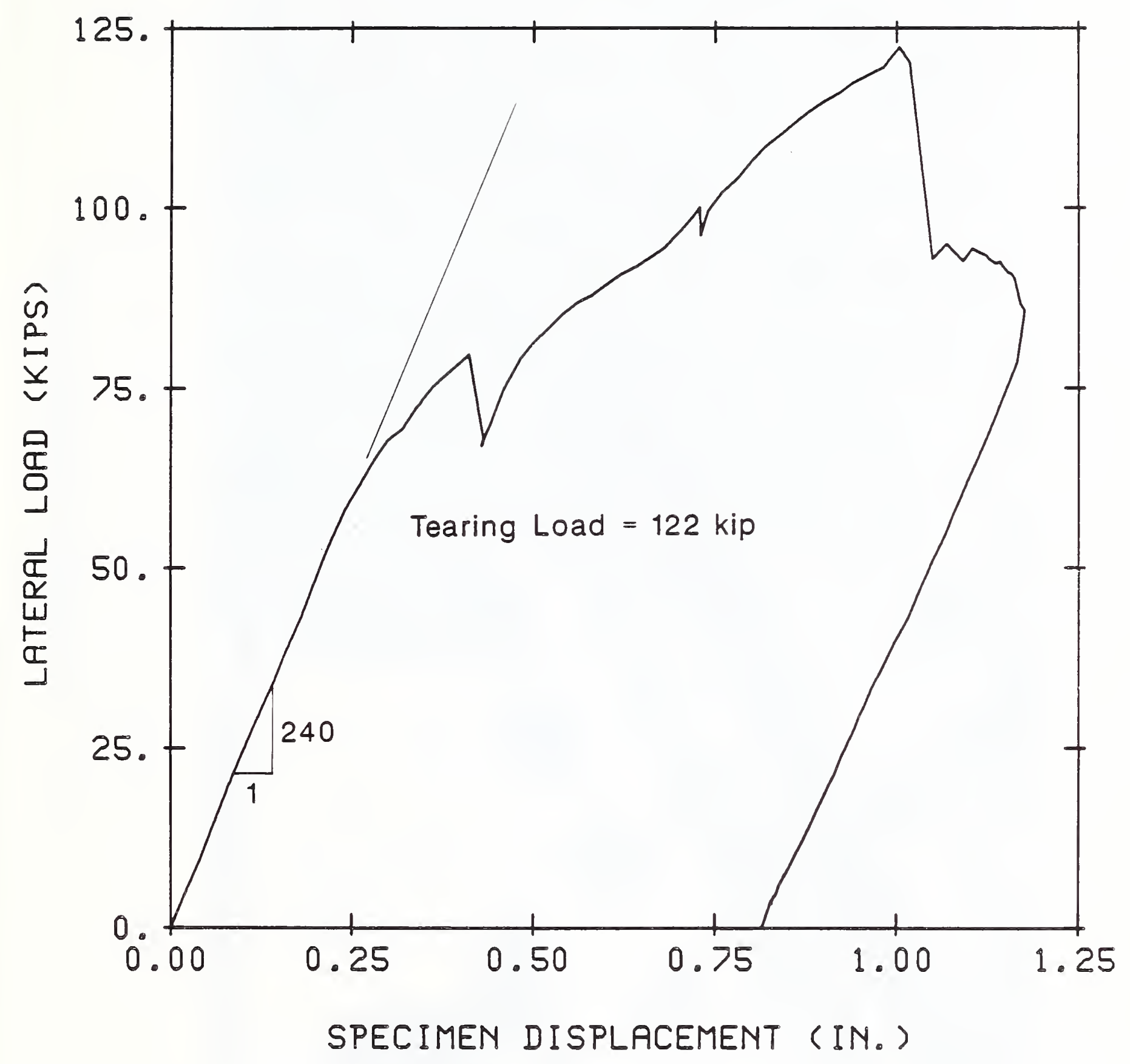

Figure 3.14 - Load vs. Deflection, Test 3A 


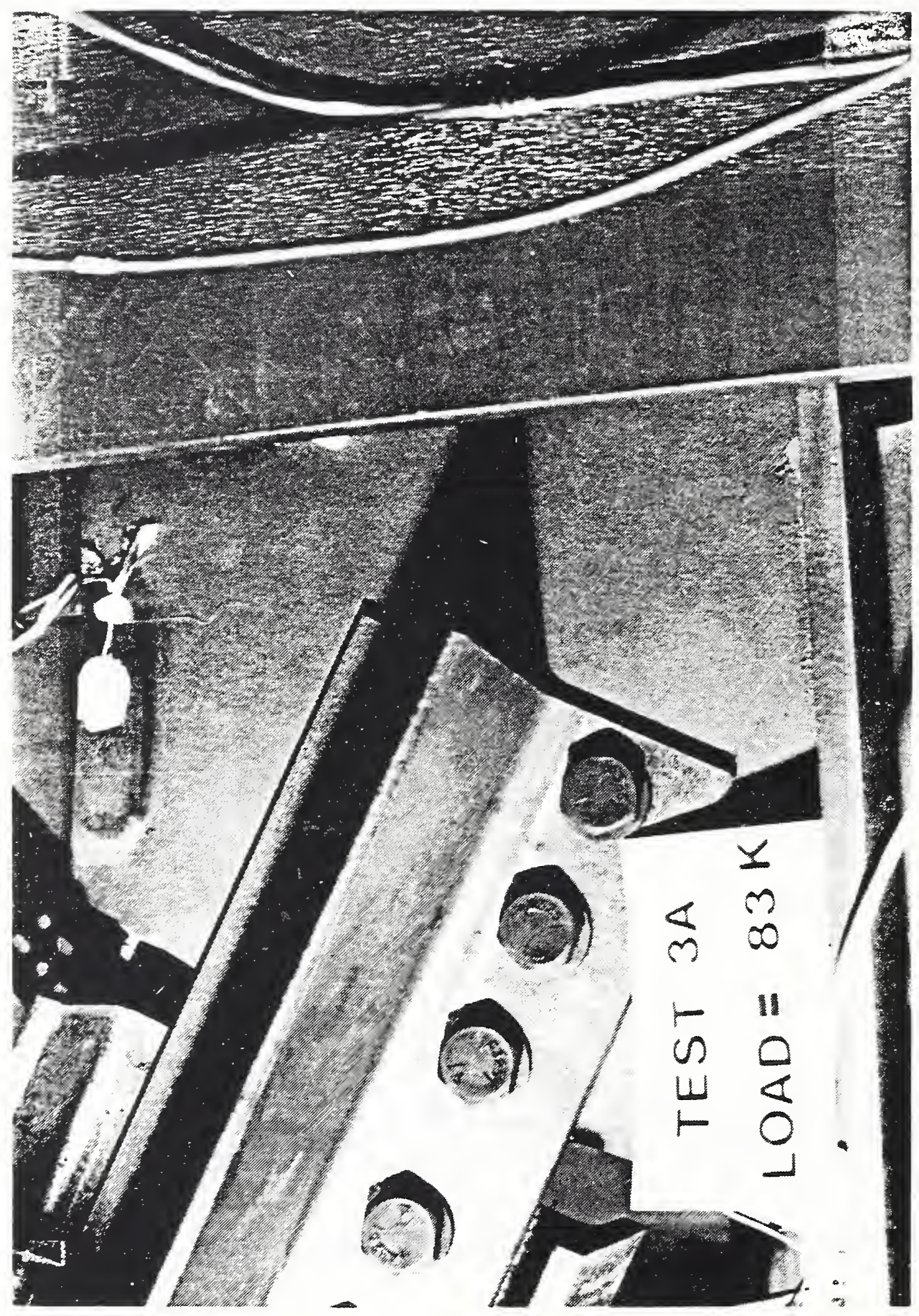

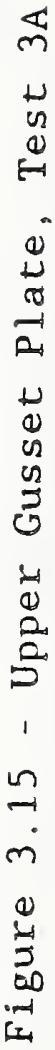




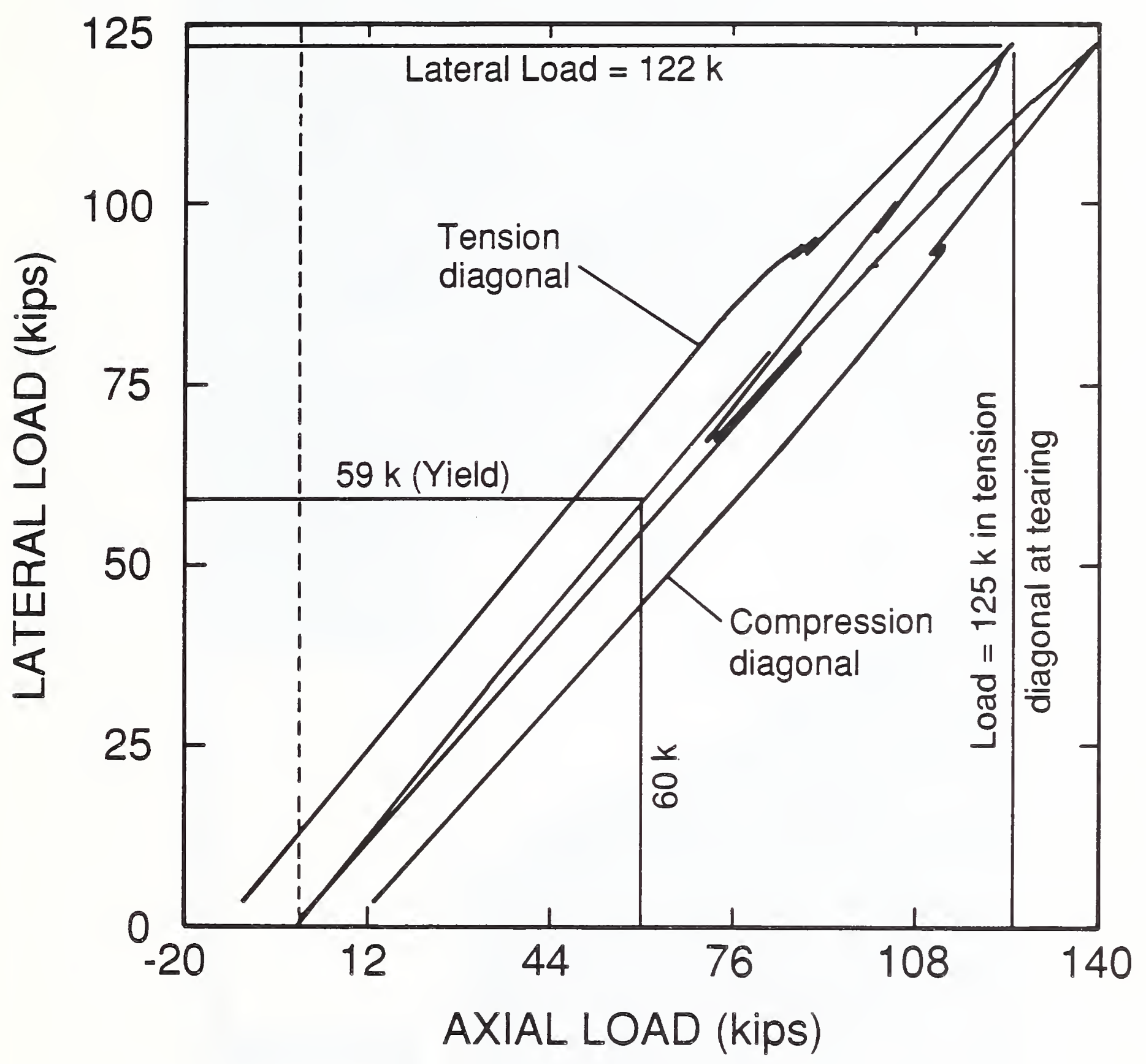

Figure 3.16 - Lateral Load vs. Axial Loads in Diagonal Bracing, Test $3 \mathrm{~A}$ 


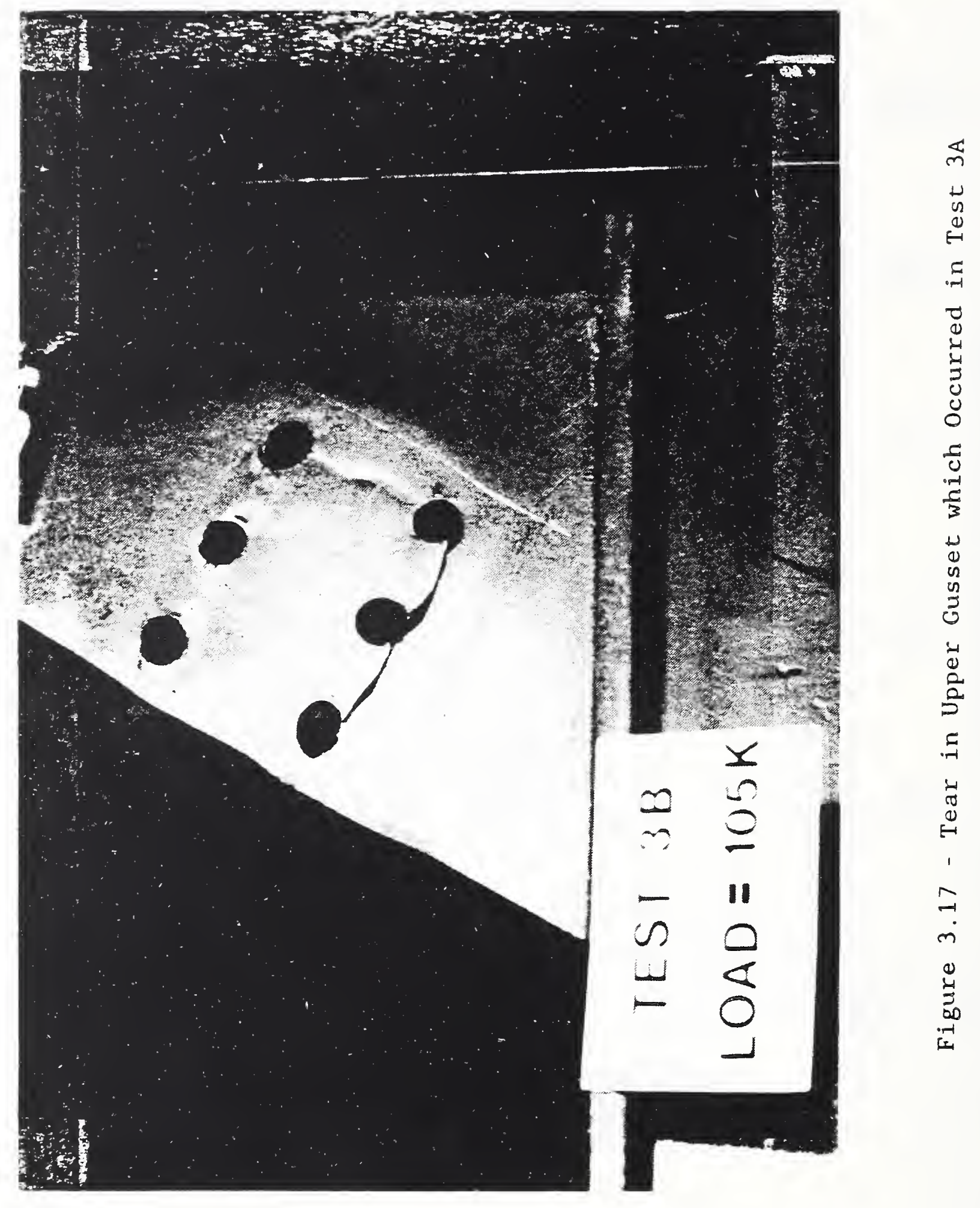




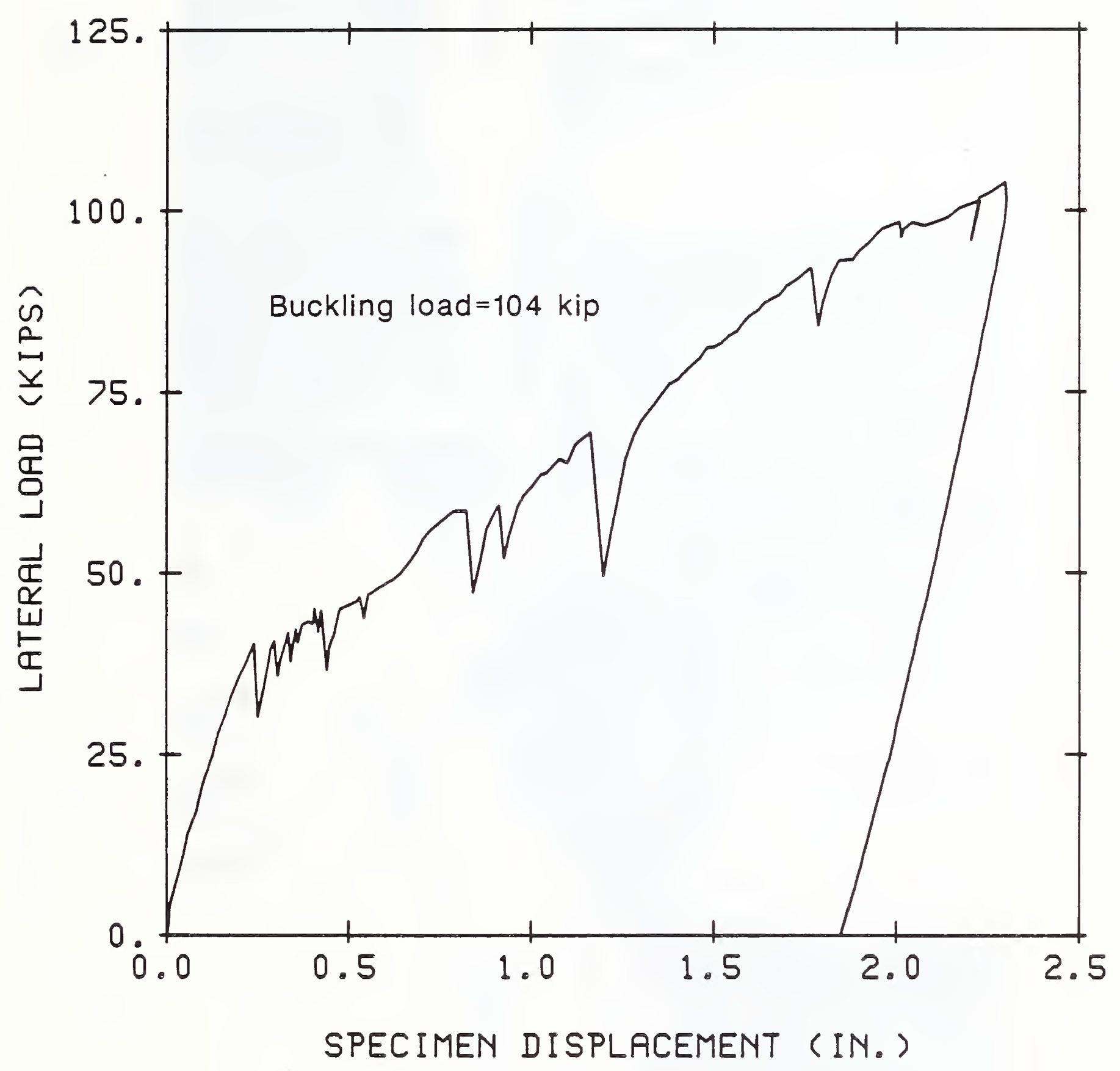

Figure 3.18 - Load vs. Deflection, Test 3B 


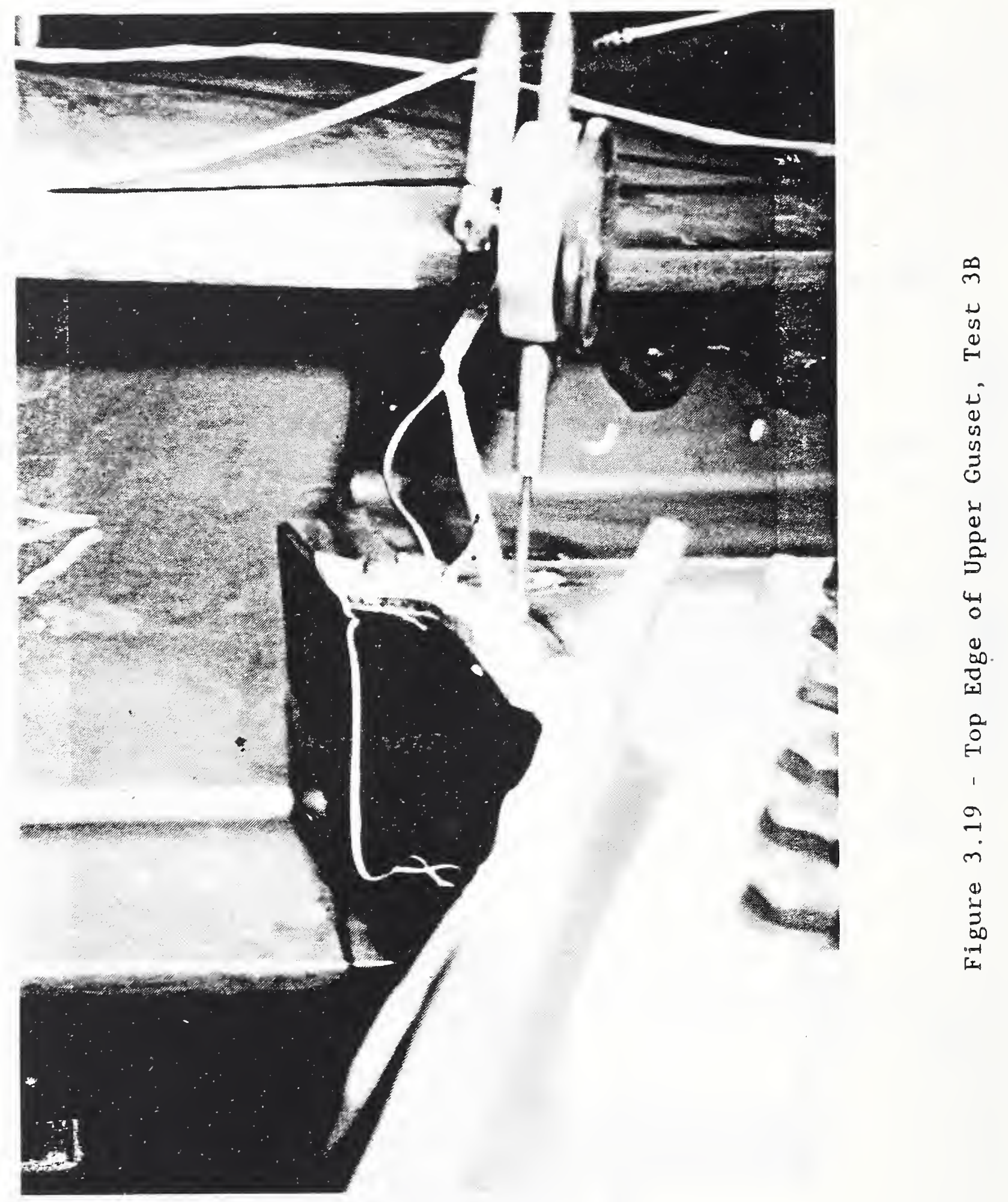




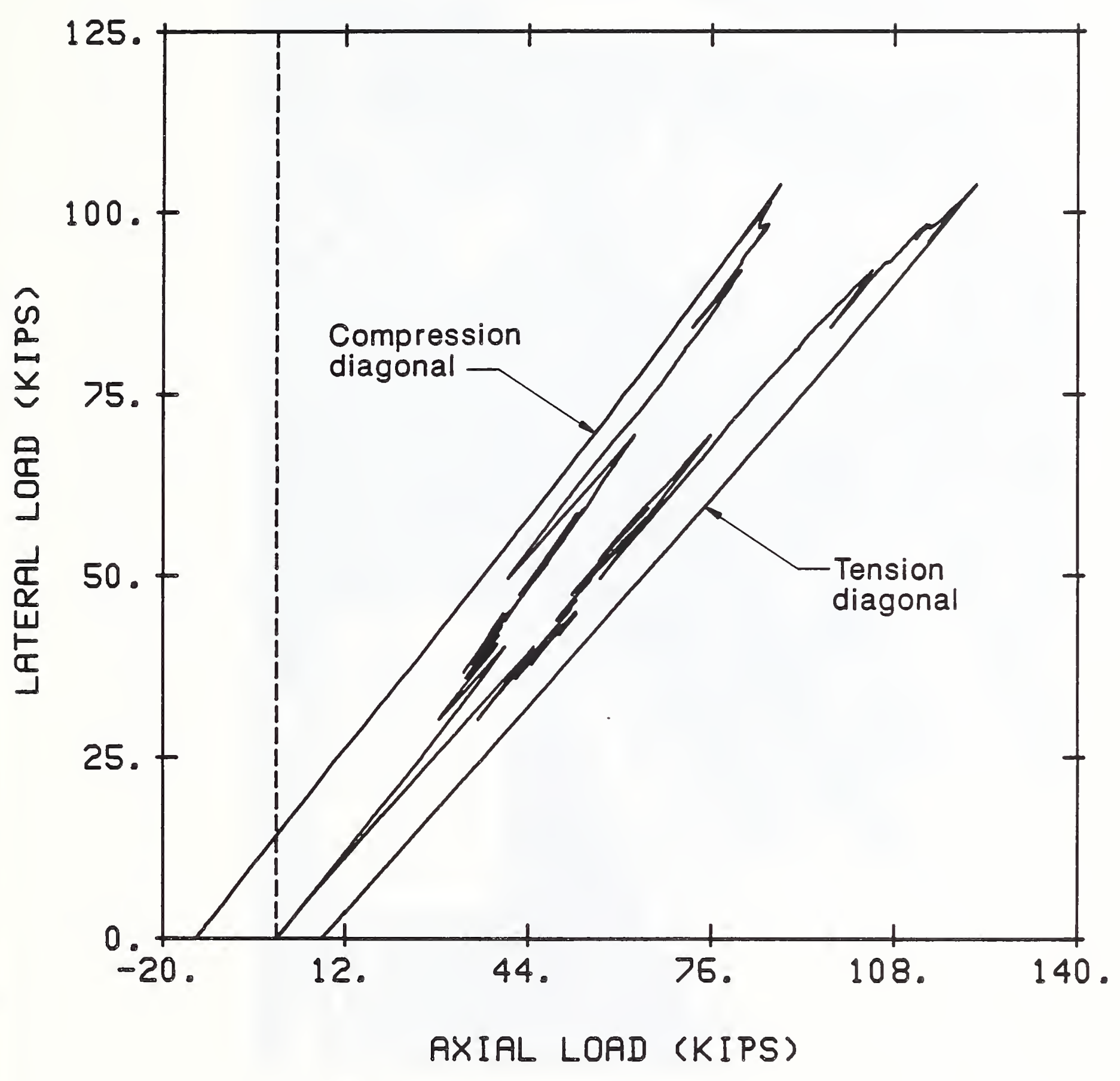

Figure 3.20 - Lateral Load vs. Axial Loads in Diagonal Bracing, Test 3B 


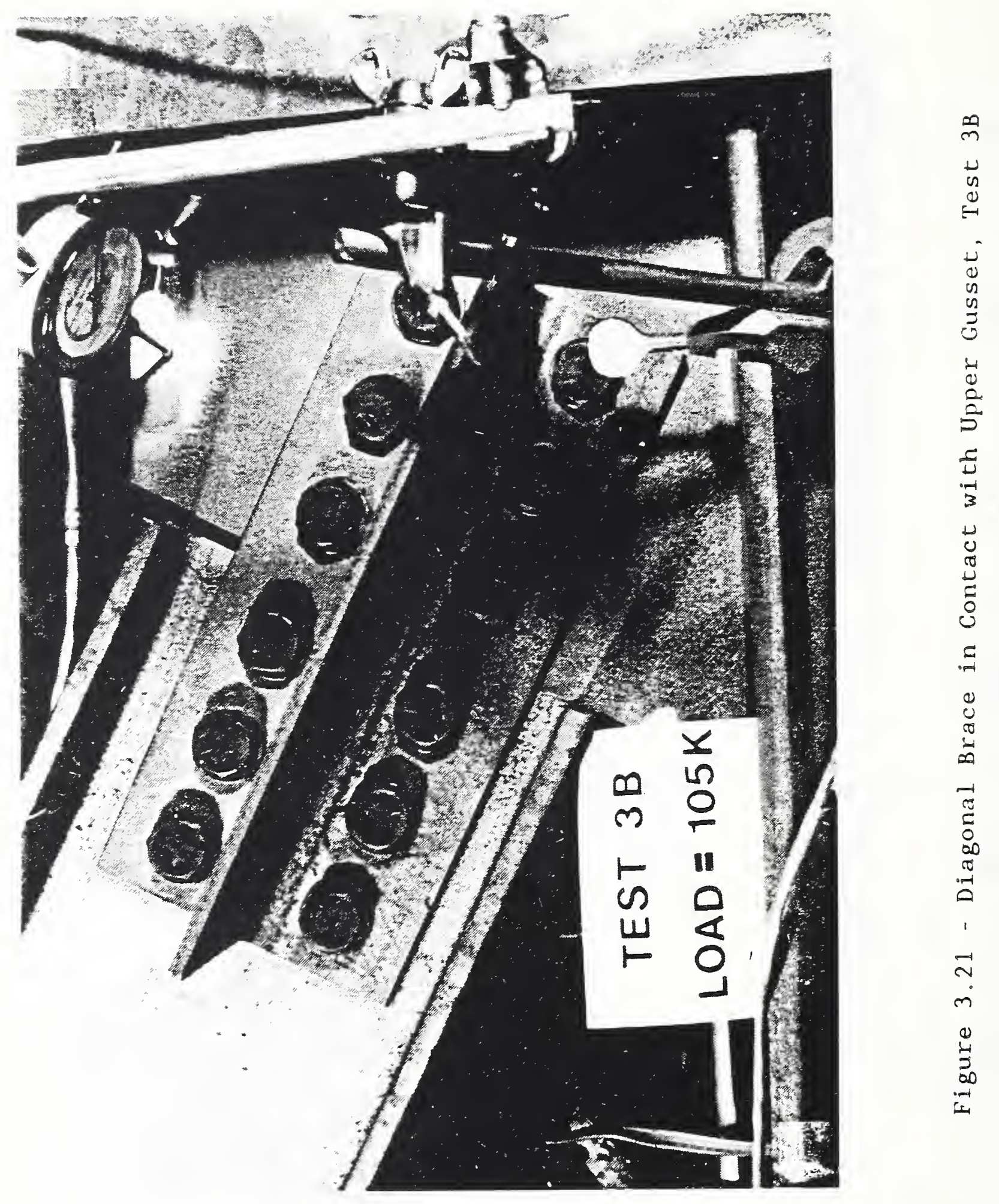



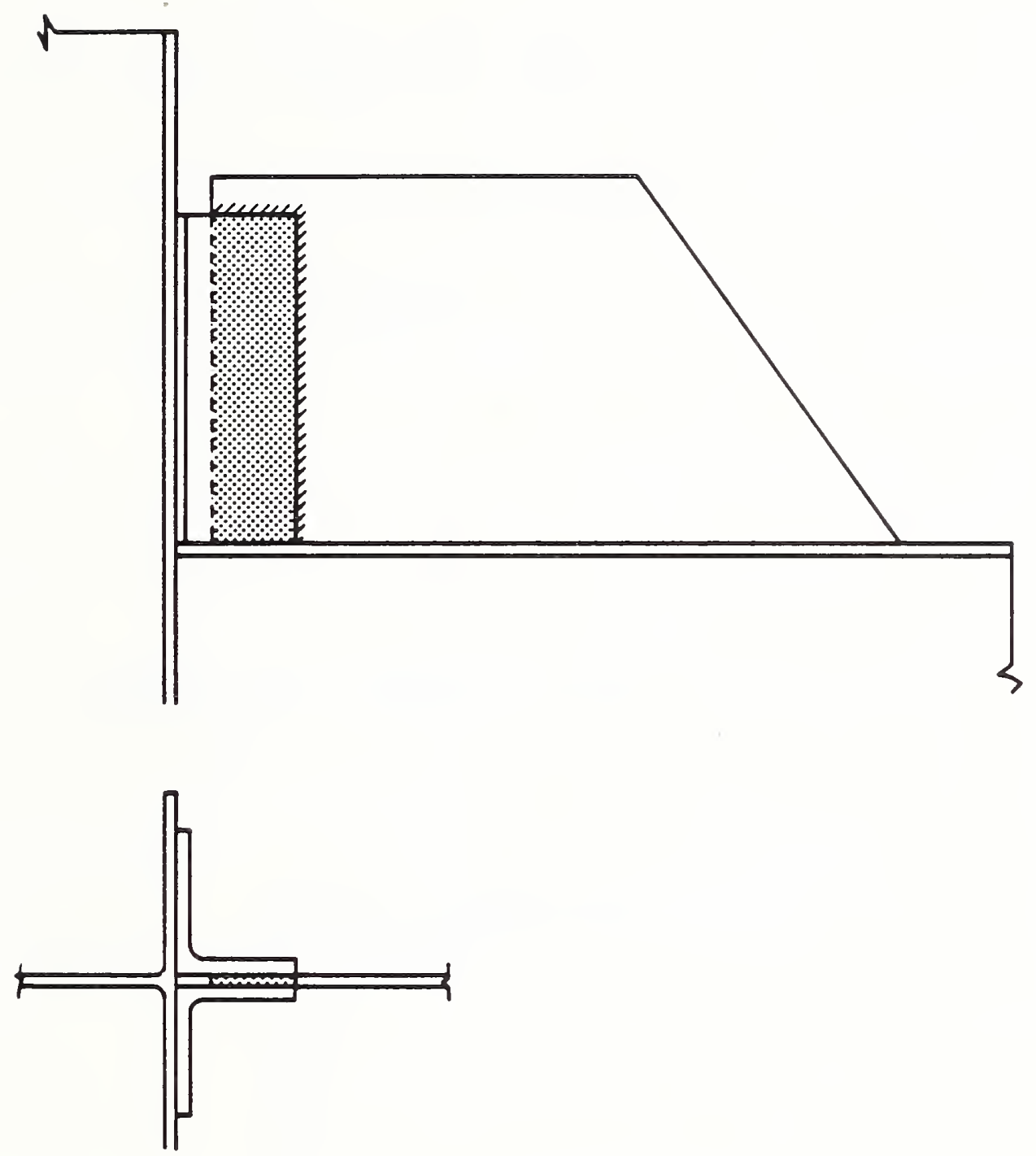

Shaded area on gusset shows location from which test coupons were obtained

Figure 3.22 - Location of Tensile Test Coupons in Gusset Plates 


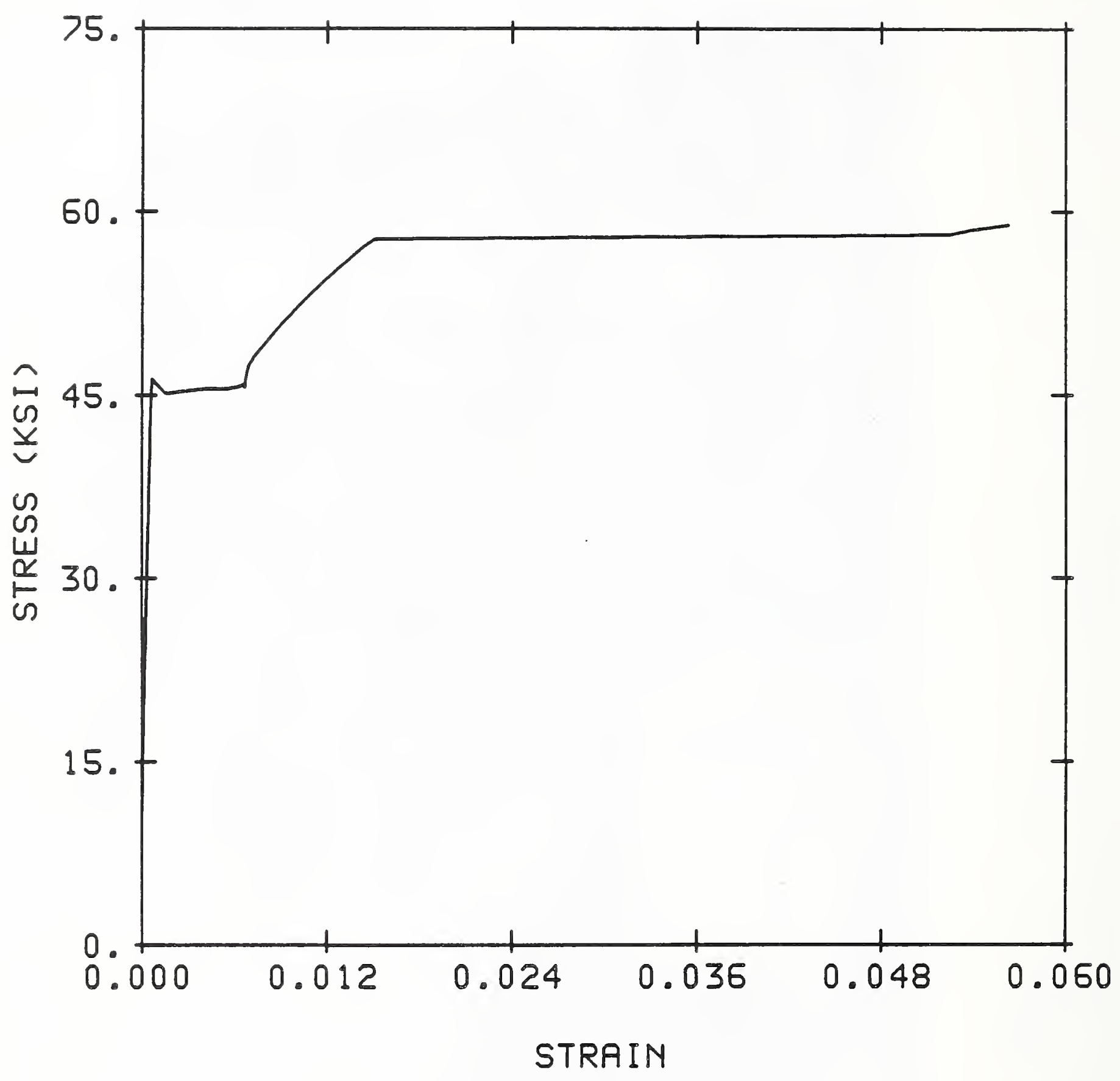

Figure 3.23 - Stress - Strain Curve for Upper Gusset, Specimen No. 1 - $64-$ 


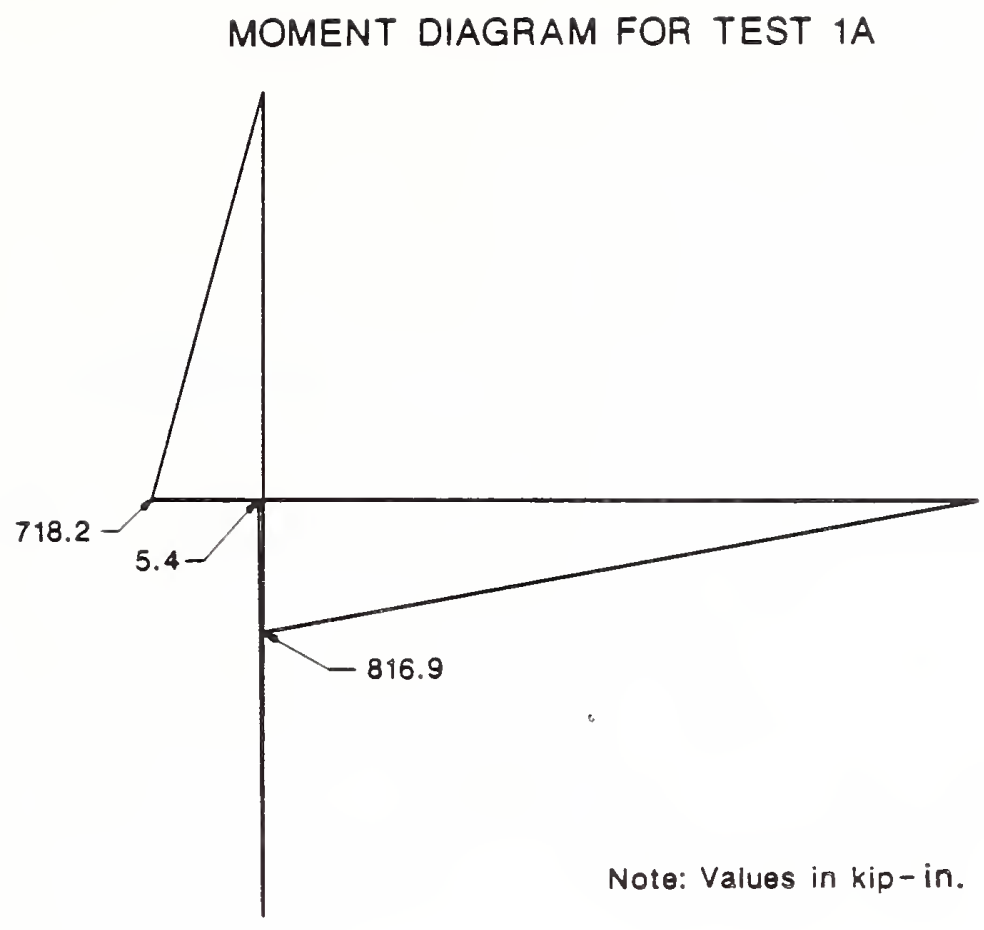

Figure 3.24 - Moment Diagram for Test $1 \mathrm{~A}$

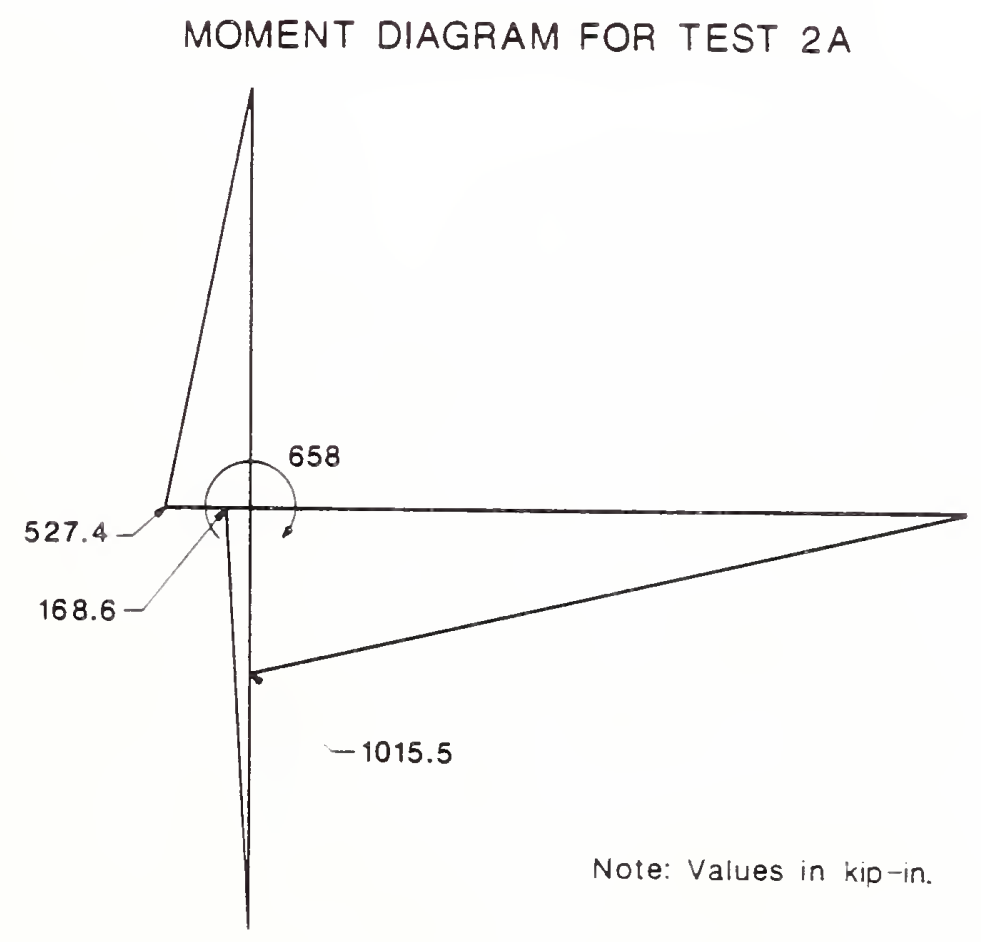

Figure 3.25 - Moment Diagram for Test 2A 


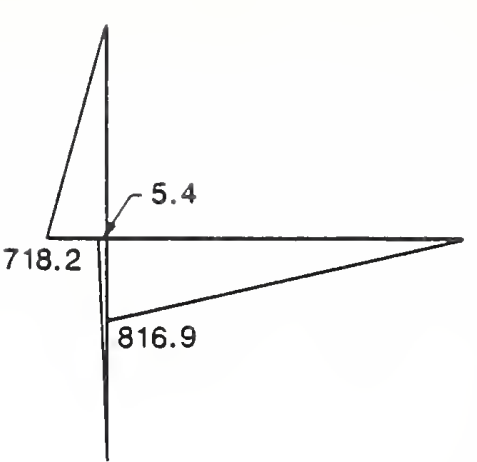

Test 1A

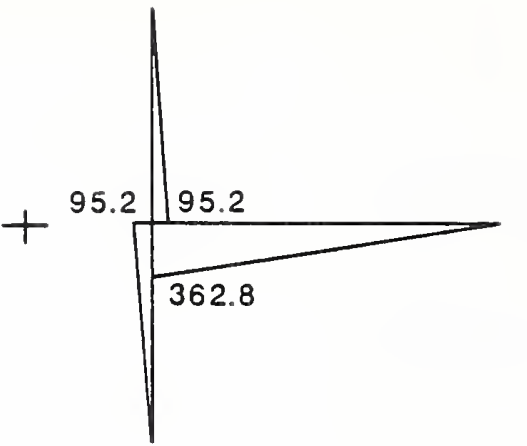

Eccentric Moment from Test $2 \mathrm{~A}$

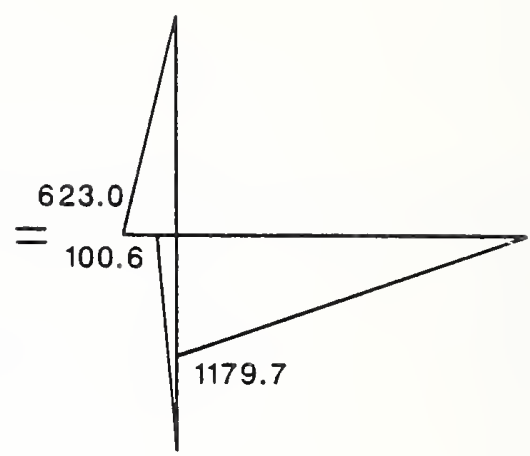

Predicted for Test $2 \mathrm{~A}$

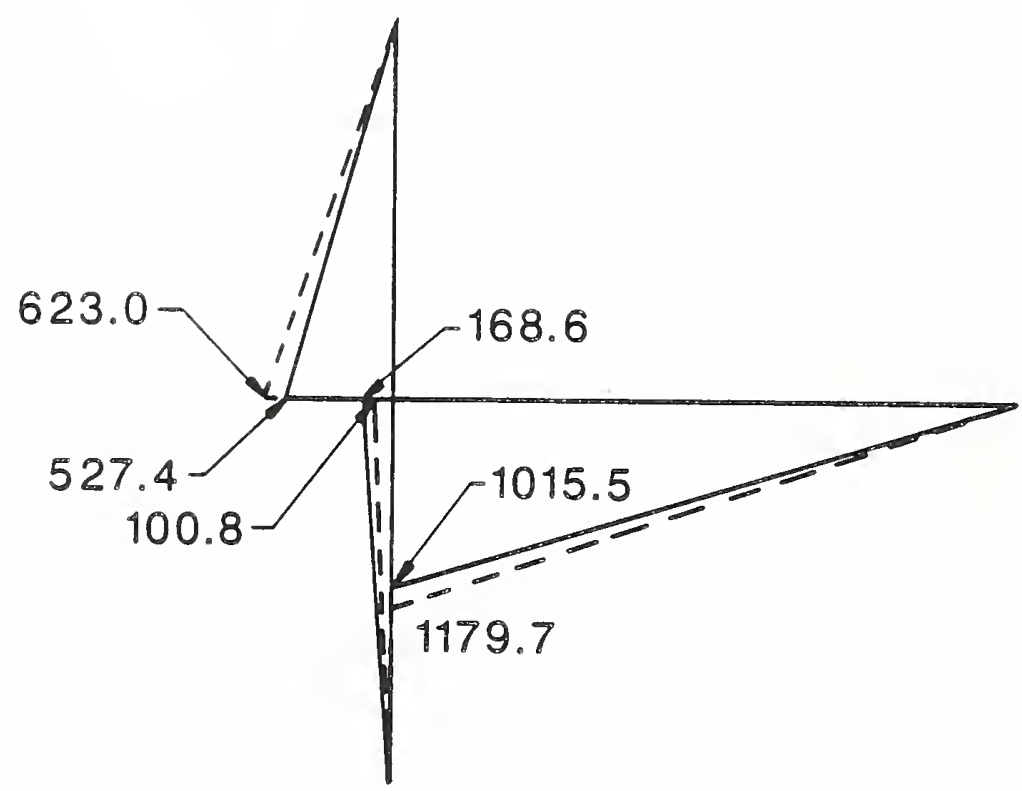

- Measured values

- - Predicted values

NOTE: Values in kip-in.

Figure 3.26 - Predicted and Experimental Moments for Test 2A 


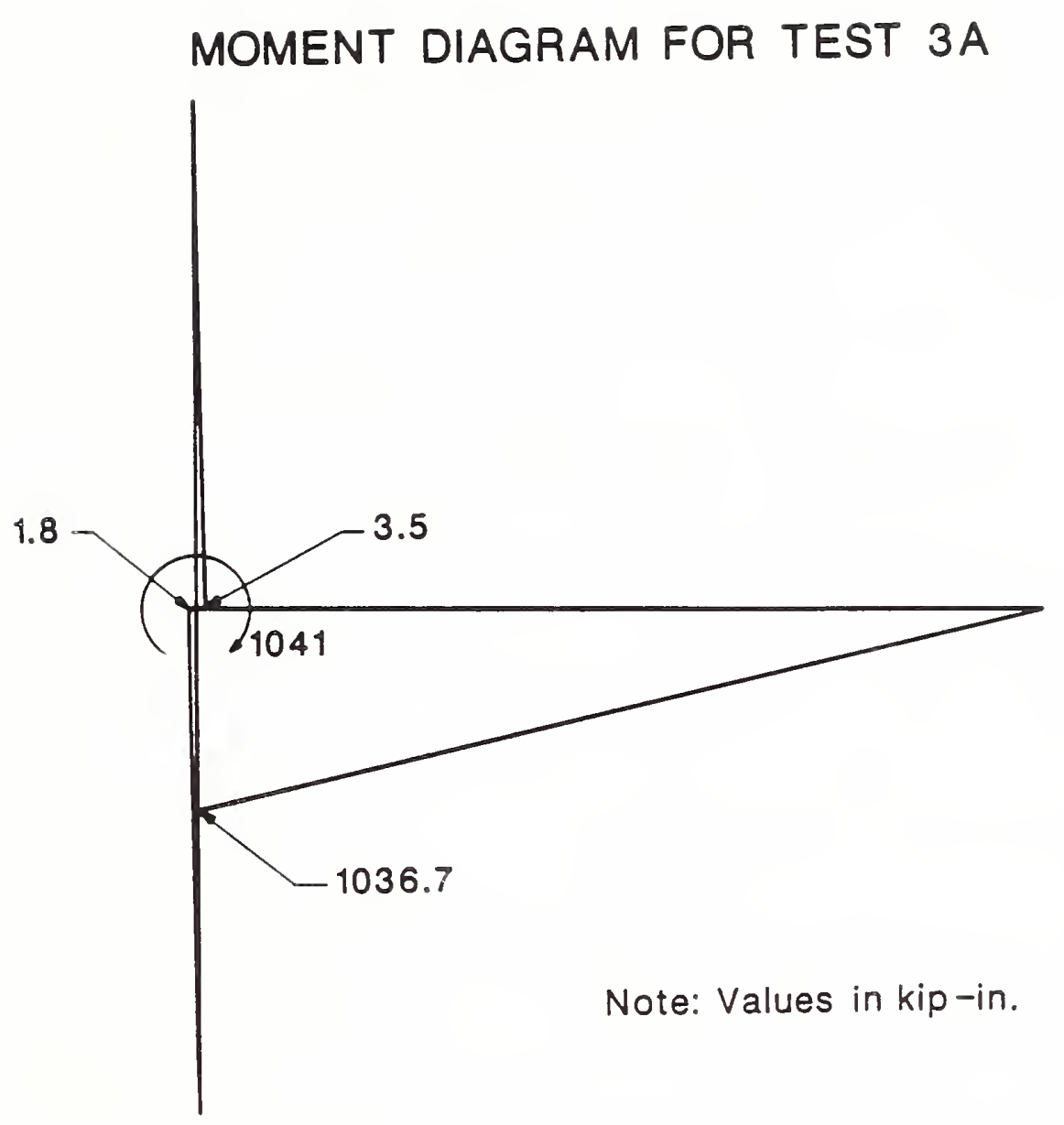

Figure 3.27 - Moment Diagram for Test 3A 
The Whitmore criterion, mentioned in section 1.2, will be used in the discussion of experimental results. The Whitmore criterion, developed in 1952, is applicable to bolted connections in tension. This criterion provides a means by which a gusset plate may be designed (bolt pattern and plate thickness chosen) for a given tension load. Application of the Whitmore criterion involves constructing what is sometimes referred to as the whitmore section (see Figure 4.1). This section is defined as the length of the line passing through the last row of fasteners and extending to the intersection of the lines drawn from the first fasteners at a $30^{\circ}$ angle from the line of the fasteners. The Whitmore criterion states that yielding occurs when the direct stress on the Whitmore section exceeds the tension yield stress of the gusset plate material. The direct stress is the tension load divided by the product of the Whitmore section and the plate thickness.

\subsection{Comparison of Analytical and Experimental Results}

Fung and Richard [8] performed an inelastic finite element analysis of each of the NBS test specimens using a computer code developed by Richard at the University of Arizona. A summary of their results is given in Table 4.1. The results reported are the applied lateral frame load for which three criteria are met: the whitmore yield load which is described in section 4.1, "first yield" which is the lateral load at which the effective stress in the gusset first reaches the yield stress of $36 \mathrm{ksi}$, and "general yield" which is the lateral load at which the effective stress in the gusset exceeds $36 \mathrm{ksi}$ in many elements and is representative of the load corresponding to the relatively flat portion of the load vs. deflection curve. The effective stress is defined as

where,

$$
\sigma_{\text {eff }}=\left(\sigma_{1}^{2}+\sigma_{2}^{2}-\sigma_{1} \sigma_{2}\right)^{1 / 2}
$$

$$
\sigma_{1}, \sigma_{2}=\text { principal stresses }
$$


To compare experimental and computed capacities, it is necessary to interpret the experimental results presented in Chapter 3 to determine the load at which yielding occurs. Several definitions will be used here. The onset of yielding will be defined as the point at which the load deflection curve becomes nonlinear. To establish this point, a linear regression technique was used to produce a "best fit" straight line through the data points below a lateral load of 50 kips. The resulting line, or initial tangent stiffness, was then drawn on the experimental load vs. deflection plot, and the point of departure from linearity chosen by observation. Figures $4.2,4.3$ and 4.4 show the load vs. deflection plot, initial tangent stiffness and yield load for Series A tests of Specimens 1, 2 and 3, respectively. The values determined from this procedure are reported in Table 4.1 and are labeled "Nonlinearity of Load-deflection Plot." Note that the departure from linearity reported here should be interpreted as a lower bound on the yield load.

Two alternate definitions of yielding of the gusset plates are reported to allow direct comparison with analytical results reported by Fung and Richard [8]. First yield is defined as the lateral load on the test specimen at which the effective stress in the gusset is computed to be greater than 36 ksi at any strain rosette. A yield stress value of $36 \mathrm{ksi}$ is used in this calculation, rather than the measured yield stress of the gusset plates, to permit a comparison with analytical results which used a value of $36 \mathrm{ksi}$.

Finally, general yield is defined as the load at which the effective stress, computed from rosette strains, exceeds $36 \mathrm{ksi}$ at a majority of the rosettes. It should be pointed out that the rosette gages were located along the bottom of the gusset (Figure 2.14) and the maximum stress in the gusset is likely to be at the end of the diagonal brace and not captured by the rosettes. Thus, the experimental values of first yield and general yield should be considered to be upper bounds. Values for first yield and general yield are given in Table 4.1 for all three specimens.

A comparison can be made between the analytical results reported by Fung and Richard [8] and the experimental results reported herein by referring to Table 4.1. Both the Whitmore yield and first yield determined from the departure from linearity of the load vs. deflection curve appear to predict the onset of 
yield in specimen Nos. 2 and 3. The comparison is not as close for specimen No. 1. However, the analytically determined yield load, ranging between 65 kips for the Whitmore yield load and 78 kips for first yield, falls between the values of 45 kips and 87 kips determined from experimental results. General yield as determined by experiment was higher than that predicted analytically for all three specimens. Since the actual yield stress of the gusset plate material was higher than the assumed yield stress, one would expect a higher observed general yield for all three specimens.

Contour plots of the effective stress in the gussets for the three specimens were reported in Reference [8]. Reproductions of these plots with the experimental stress values superimposed on them are shown in Figures 4.5 through 4.7. The stresses in these figures correspond to an applied frame load equal to the Whitmore yield load; that is 65 kips, 62 kips and 60 kips for Tests $1 \mathrm{~A}, 2 \mathrm{~A}$ and $3 \mathrm{~A}$, respectively. As seen in the figures, the experimental values and the analytical values agree very well. It would therefore appear that the inelastic finite element analyses predict the state of stress in the gusset accurately.

\subsection{Design Capacities}

The test specimens were designed using standard design practice and the design guidelines developed by Williams and Richard [4] for the attachment of the gusset to the beam and column. The gusset plate capacity in tension was determined by applying the Whitmore criterion which gave a value of 41.4 kips as shown in Table 4.2. (Design philosophies are discussed in the following paragraphs and calculations are presented in Appendices A and B). Buckling of the gusset was checked using the procedure described by Thornton [6] and was found to be 30.9 kips. The design of the gusset-to-column attachment was based on Williams and Richard's equations and the AISC procedure for bolt capacity in combined shear and tension for the clip angles. The capacity of the gusset-to-column attachment was 74.8 kips. To allow comparisons to be made between the test specimens, the gusset plate thickness, clip angles, bolts, weld size, etc. were the same for all three test specimens. 
Design capacities of the test specimens using various other methods are presented here. The calculations were made by Dr. William Thornton. A summary of Thornton's calculations is presented in this section in Tables 4.2 through 4.4. Detailed calculations for Specimen No. 1 are presented in Appendix A. This section briefly discusses the methods used in determining the brace capacities. The capacities were "back-calculated" as the member sizes, weld and fastener sizes, and number of fasteners were known quantities. The calculations were based on the material yield strength of $F_{y}=36 \mathrm{ksi}$ and ultimate strength of $F_{u}=58 \mathrm{ksi}$.

\subsubsection{Capacity of Gusset Plate}

For a given number of fasteners and gusset plate thickness, the capacities for the gusset plate were determined using standard methods based on the AISC Specification [13]. The bolts used to connect the brace to the gusset were checked for bearing and double shear. The gusset, brace and splice were also checked for tearout as described in the commentary of Reference [13]. Yielding of the gusset plate was computed using Whitmore's yield criteria as described in section 4.1. The buckling capacity of the gusset was determined using the method outlined in Reference [6] and illustrated in Appendix A.

\subsubsection{Methods to Distribute Brace Loads}

Three different methods were used to compute the distribution of the load in the diagonal brace to the beam and column. The first was that of Williams and Richard [4] using the following equations:

$$
\begin{array}{ll}
\mathrm{R}_{\mathrm{B}}=\mathrm{P}[1.4 \mathrm{a} /(\mathrm{a}+\mathrm{b})-0.1] & \\
\theta_{\mathrm{B}}=0.6 \theta & \text { for } \theta \leq 45^{\circ} \\
\theta_{\mathrm{B}}=27+[8.5-20 \mathrm{a} /(\mathrm{a}+\mathrm{b})](45-\theta) & \text { for } \theta>45^{\circ} \\
\mathrm{H}_{\mathrm{B}}=\mathrm{R}_{\mathrm{B}} \cos \theta_{\mathrm{B}} & \\
\mathrm{V}_{\mathrm{B}}=\mathrm{R}_{\mathrm{B}} \sin \theta_{\mathrm{B}} & \\
\mathrm{H}_{\mathrm{C}}=\mathrm{H}-\mathrm{H}_{\mathrm{B}} & \\
\mathrm{V}_{\mathrm{C}}=\mathrm{V}-\mathrm{V}_{\mathrm{B}} &
\end{array}
$$


where,

$$
\begin{aligned}
& \mathrm{P}=\text { Brace load } \\
& \mathrm{H}=\text { Horizontal component of the brace load } \\
& \mathrm{V}=\text { Vertical component of the brace load } \\
& \theta=\text { Angle that the brace makes with the horizontal axis } \\
& \mathrm{R}_{\mathrm{B}}=\text { Resultant of the beam forces } \\
& \mathrm{H}_{\mathrm{B}}=\text { Horizontal force on beam } \\
& \mathrm{V}_{\mathrm{B}}=\text { Vertical force on beam } \\
& \mathrm{H}_{C}=\text { Horizontal force on column } \\
& \mathrm{V}_{C}=\text { Vertical force on column } \\
& \mathrm{a}=\text { Length of gusset plate } \\
& \mathrm{b}=\text { Width of gusset plate }
\end{aligned}
$$

A diagram showing these forces is given in Figure A.2 in Appendix A. Williams and Richard's method is based on results obtained from inelastic finite element analyses. The effect of different gusset geometries is included in this method.

Another method used to distribute the brace load to the beam and column was proposed by Thornton [14]. Thornton's model is shown in Figure B.1 in Appendix $B$ and his equations are as follows:

$$
\begin{aligned}
& \mathrm{H}_{\mathrm{B}}=(\alpha / \mathrm{r}) \mathrm{P} \\
& \mathrm{V}_{\mathrm{B}}=\left(e_{\mathrm{B}} / \mathrm{r}\right) \mathrm{P} \\
& \mathrm{V}_{\mathrm{C}}=(\beta / \mathrm{r}) \mathrm{P} \\
& \mathrm{H}_{\mathrm{C}}=\left(\mathrm{e}_{\mathrm{C}} / \mathrm{r}\right) \mathrm{P} \\
& \mathrm{M}_{\mathrm{B}}=\mathrm{V}_{\mathrm{B}}(\alpha-a) \\
& \mathrm{M}_{\mathrm{C}}=\mathrm{H}_{C}(\beta-\mathrm{b})
\end{aligned}
$$

where,

$$
\begin{aligned}
r= & \sqrt{\left(\alpha+e_{c}\right)^{2}+\left(\beta+e_{b}\right)^{2}} \\
\alpha= & \frac{K^{\prime} \tan \theta+K(a / b)^{2}}{D} \\
\beta= & \frac{K^{\prime}-K \tan \theta}{D} \\
\theta= & \text { Angle that the brace makes with the vertical axis } \\
a, b= & \text { Centroids of the horizontal and vertical fastener } \\
& \text { groups, respectively }
\end{aligned}
$$




$$
\begin{aligned}
\mathrm{K} & =\mathrm{e}_{\mathrm{b}} \tan \theta-\mathrm{e}_{\mathrm{c}} \\
\mathrm{K}^{\prime} & =\mathrm{a}[\tan \theta+(\mathrm{a} / \mathrm{b})] \\
\mathrm{D} & =\tan ^{2} \theta+(\mathrm{a} / \mathrm{b})^{2} \\
\mathrm{e}_{\mathrm{b}} & =\text { Depth of beam } / 2 \\
\mathrm{e}_{\mathrm{c}} & =\text { Depth of column } / 2
\end{aligned}
$$

This method is presented in Appendix B and will therefore not be discussed here. In general, Thornton's model predicts capacities similar to those predicted using Williams and Richard's method. However, it has the advantage that it satisfies moment equilibrium which Williams and Richard's method does not.

The AISC procedure to distribute the brace load to the beam and column is that outlined for heavy bracing connections in Reference [10]. In this procedure, the gusset-to-column connection is typically designed for the vertical component of the brace load and the gusset-to-beam connection is designed for the horizontal component of the brace load (shear) and a moment equal to the shear multiplied by half the beam depth. The equations for this method are, then:

$$
\begin{aligned}
& \mathrm{H}_{B}=\mathrm{H} \\
& \mathrm{V}_{B}=0 \\
& \mathrm{H}_{C}=0 \\
& \mathrm{~V}_{C}=\mathrm{V} \\
& \mathrm{M}_{B}=\mathrm{V}(\mathrm{d} / 2)
\end{aligned}
$$

where the above variables have been defined previously with the exception of,

$$
\begin{aligned}
M_{B} & =\text { Moment in the beam } \\
d & =\text { Depth of the beam }
\end{aligned}
$$

The working point for this procedure is at the corner of the gusset. Although this arrangement introduces an eccentric moment to the connection, the design of the beam and column do not account for this moment as it is considered to have "secondary" effects for small brace loads. 
4.3.3 Capacity of Gusset-to-Beam Attachment

Once the forces distributed to the beam are known, using any of the methods discussed above, the capacity of the attachments can be determined. The capacity of the gusset-to-beam weld was computed taking into account combined shear and tension if applicable. The capacity of the gusset plate in shear and tension was also determined.

\subsubsection{Capacity of Gusset-to-Column Attachment}

The weld attaching the clip angles to the gusset was subjected to an eccentric shearing force. The capacity of this weld was found using the tables in Reference [13]. The clip angles were subjected to prying action, and the capacity against this mode of failure was determined using the method proposed by Thornton in Reference [6]. The shear capacity of the clip angles and the capacity of the gusset plate in shear and tension were also computed.

Capacities of the bolts used to join the gussets to the column were also determined using AISC's methods. Two such procedures to design fasteners subjected to shear and tension are outlined in Reference [10] and referred to as Case I and Case II. The basic assumptions of these two cases are 1) that the stress in the fasteners varies linearly from the neutral axis of the fastener group, and 2) that the shear stress is equal for all fasteners in a fastener group. The difference between the two cases is in the location of the neutral axis. The neutral axis for Case II is assumed to be at the center of gravity of the fastener group while the neutral axis for Case $I$ is assumed to be located at a distance equal to one-sixth of the total bracket depth from the bottom of the bracket. As stated in Reference [10], Case II is a more conservative approach than in Case $I$.

\subsubsection{Capacity of the Beam-to-Column Attachment}

The shear force at the end of the beam was computed by summing the vertical forces from the upper and lower gusset. The clip-to-beam web weld was subjected to this same shearing force plus a moment due to the eccentricity of 
the shear force. Bolts to the column were checked in single shear and bearing. The capacity of the beam web was checked for shear and bending.

\subsection{Comparison Between Experimental and Design Capacities}

In this section, a comparison is made between the capacities computed using various design approaches and the experimental results reported herein. Only the capacities corresponding to the following failure modes are compared:

- Bolt capacity in clip angles-to-column connection

- Buckling of the gusset plate

- Yielding of the Whitmore section

- Tearout of the gusset plate

These failure modes produced the four lowest design capacities (see Tables 4.2 through 4.4).

The capacities presented are forces in the diagonal member. Margins of safety are computed by dividing the experimental capacity by the computed capacity. Note that, if the gusset failed by buckling, then the margins of safety reported for yielding and tearout are actually lower bounds - - in other words, the margin of safety is, as a minimum, equal to the reported value. Minimum margins of safety are identified by an asterisk. Two margins of safety are given. The first is computed using the yield capacity defined by the departure from linearity of the load vs. deflection curve. The second is computed using the measured ultimate capacity. These two factors are useful in interpreting the experimental results in terms of both strength and serviceability.

4.4.1 Bolt Capacity in Clip Angles-to-Column Connection

As seen from Tables 4.2 through 4.4, the capacity of the test specimens was limited by the axial capacity of the bolts attaching the clip angles to the column. The brace capacity, as governed by the clip angles, was approximately 18 kips. Compared to measured capacities of $116 \mathrm{kips}$ and 138 kips for Tests $1 \mathrm{~A}$ and $2 \mathrm{~A}$, respectively which failed by gusset buckling, and 125 kips for Test 
$3 \mathrm{~A}$ which failed by gusset tearing, the design capacity of the brace of 18 kips for the clip angles is extremely conservative. This finding is further reinforced by the lack of visible signs of distress or prying of the clip angles, even after extensive buckling of the gusset. One possible explanation for this is that forces on the gusset-to-column attachment resulting from frame action ("rigid" beam-to-column connection provided by the gusset plates), tended to oppose the forces resulting from the diagonal bracing. For instance, in Test $A$, the top brace was in tension which produced tension on the upper gusset-to-column connection. However, the beam-to-column connection, being very rigid, produced compression in the upper gusset at the gusset-to-column attachment as frame action contributed to resisting the applied lateral load. These two forces tended to cancel. The limiting capacities of the three specimens tested were not related to failure of the clip angles. Hence, the capacity due to this mode of failure is not included in the following discussions.

\subsubsection{Buckling of the Gusset Plate}

The brace-to-gusset capacity was limited by buckling as computed using Thornton's method. This can be seen from Tables 4.2 to 4.4 in which the computed buckling capacity ranges between 30.9 kips and 34.8 kips. Table 4.5 presents a comparison between computed design capacities and measured capacities for buckling of the gusset plate. For specimen No. 1, it is seen that the margin of safety with respect to ultimate capacity is 3.8 . If the yield load is used, the margin of safety is 1.6. Since excessive deflections can result once yielding begins, this may be regarded as a serviceability limit. For specimen No. 2, the buckling capacity was computed to be 34.8 kips. If the buckling load of 138 kips is used as the limiting capacity, the margin of safety is 4.0. The margin of safety for yielding is 1.9. Since Specimen No. 3 failed by tearout before it failed by buckling, the buckling strength was at least as great as the tearout strength. As a result, the margin of safety computed for buckling should be considered to be a lower bound or minimum margin of safety. For specimen No. 3, the value reported in Table 4.5 for the minimum margin of safety against buckling is 3.6 . 
4.4.3 Yielding of the Whitmore Section

Design of the gusset plate using the Whitmore yield criterion is essentially the same as design against tearout. Indeed, both design methods are based on the gusset plate thickness and the arrangement (spacing and pitch) of bolt holes. In design practice, one would not need to check both the Whitmore yield criterion and tearout.

Table 4.6 presents a comparison between computed design capacities and measured capacities for yielding of the whitmore section. The computed Whitmore yield load (load in the diagonal brace) is $41.4 \mathrm{kips}$. It is seen that, for specimen No. 3, the margin of safety for ultimate capacity is 3.0 . The margin of safety against yielding for specimen No. 3 is 1.4 .

\subsubsection{Tearout of the Gusset Plate}

The computed design capacity based on gusset tearout is 45.4 kips which is close to the capacity of 41.4 computed for yielding of the Whitmore section. Indeed, specimen No. 3 failed by gusset tearout. In this section, experimental results will be compared with several methods for computing tearout capacity. In addition to the method already presented (AISC-ASD), three methods for block shear tearout will be compared to experimental results.

The design of a gusset plate based on the block shear concept is a recent development. Block shear failure became a concern when the allowable bearing stress for bolted connections was increased from $1.35 \mathrm{~F}_{\mathrm{y}}$ to $1.50 \mathrm{~F}_{\mathrm{u}}$. Hardash and Bjorhovde [5] conducted a series of tests at the University of Arizona to determine the ultimate capacity of a tension connection. Based on their work and on results of similar studies conducted at the University of Alberta and the University of Illinois, Hardash and Bjorhovde proposed the following equations:

$$
R_{n}=F_{u} S_{\text {net }}+1.15 F_{\text {eff }}(1)(t)
$$


where,

$$
\begin{aligned}
F_{\text {eff }} & =\left(1-C_{1}\right) F_{y}+C_{l} F_{u} \\
C_{1} & =0.95-0.047 \mathrm{~L} \\
R_{n} & =\text { Nominal ultimate resistance of connection } \\
S_{\text {net }} & =\text { Net gage distance between outside bolts } \\
t & =\text { Plate thickness } \\
L & =\text { Distance from center of last row of bolts to plate } \\
\text { edge } & \left.=1_{1} \text { (see Figure } 4.8\right) \\
F_{y} & =\text { Yield stress } \\
F_{u} & =\text { Tensile strength }
\end{aligned}
$$

In a report by Williams and Richard [4], the following equation for determining the ultimate block shear load was presented:

$$
R_{u}=A_{v g} F_{V u}+A_{t g} F_{t u}
$$

where,

$$
\begin{aligned}
& \mathrm{R}_{\mathrm{u}}=\text { Nominal ultimate resistance of connection } \\
& \mathrm{A}_{\mathrm{vg}}=\text { gross shear area }=1_{2} \times \mathrm{s} \quad(\text { Figure } 4.8) \\
& \mathrm{F}_{\mathrm{Vu}}=\text { ultimate shear stress }=\mathrm{F}_{\mathrm{y}} / \sqrt{3} \\
& \mathrm{~A}_{\mathrm{tg}}=\text { gross tensile area } \\
& \mathrm{F}_{\mathrm{tu}}=\text { ultimate tensile stress }=\mathrm{F}_{\mathrm{u}}
\end{aligned}
$$

Williams and Richard recommend that, for connections with less than six bolts per row, the net shear area rather than the gross shear area be used in the above equation.

Block shear strength, by the AISC Load and Resistance Factor Design [15] approach, is the larger value determined by the following two equations:

or

$$
R_{\mathrm{n}}=\phi\left(0.6 \mathrm{~F}_{\mathrm{y}} \mathrm{A}_{\mathrm{vg}}+\mathrm{F}_{\mathrm{u}} \mathrm{A}_{\mathrm{nt}}\right)
$$

$$
R_{\mathrm{n}}=\phi\left(0.6 F_{\mathrm{u}} A_{\mathrm{ns}}+\mathrm{F}_{\mathrm{y}} A_{\mathrm{tg}}\right)
$$

where,

$$
\begin{aligned}
\phi & =0.75 \\
A_{v g} & =\text { Gross area subjected to shear } \\
A_{t g} & =\text { Gross area subjected to tension }
\end{aligned}
$$




$$
\begin{aligned}
& A_{n s}=\text { Net area subjected to shear } \\
& A_{n t}=\text { Net area subjected to tension } \\
& F_{y}=\text { Yield stress } \\
& F_{u}=\text { Tensile strength }
\end{aligned}
$$

In the following section, the capacities computed using the methods described above are compared with the experimental results. To permit comparison with allowable stress calculations, a load factor of 1.4 and a resistance factor of 0.75 are used for those equations written in terms of nominal ultimate resistance.

The four methods for computing tearout are seen to give maximum diagonal brace loads ranging from 34.8 kips to 57.8 kips as shown in Tables 4.7 a through 4.7d. The minimum margins of safety based on ultimate capacity range from 2.0 to 4.0 for all three specimens. For specimen No'. 3, which failed by tearout, the margins of safety for the various methods ranged between 2.2 and 3.6. The margins of safety based on the yield capacity for specimen No. 3 ranged between 1.1 and 1.8. The AISC-LRFD method [15] produced the most conservative estimate of design capacity while the method by Hardash and Bjorhovde [5] produced the least conservative. A better understanding of how well each of these methods is able to predict tearout capacity of the gusset is obtained by using the measured material properties in the calculations. A comparison of the various methods on this basis is given in the next section.

\subsection{Comparison Between Experimental and Calculated Capacities}

The design capacities reported above were based on assumed material strength of $F_{y}=36 \mathrm{ksi}$ and $F_{u}=58 \mathrm{ksi}$. To get an idea of how well buckling and tearout can be predicted, the calculations were repeated using measured material strength. The yield stress for the gusset was taken as the average of the six values of yield stress for the gusset plates reported in Table 3.2 and was equal to $46.7 \mathrm{ksi}$. Similarly, the ultimate strength was computed as the average of the six ultimate load values divided by the respective crosssectional area and was equal to $73.5 \mathrm{ksi}$. In addition, the factor of safety, load factor and resistance factor were not used in the calculations. Thus the 
values reported represent the computed nominal capacity of the gusset in terms of force in the diagonal bracing member. The computed capacities are compared with the experimental capacities for the applicable mode of failure.

\subsubsection{Buckling of the Gusset Plate}

A value of $K=0.5$ was used in the calculation of the buckling capacity rather than the value of $\mathrm{K}=0.65$ suggested by Thornton [6]. This theoretical K-value was used since ideal end conditions (no rotation) are closely approximated. The resulting nominal capacities are presented in Table 4.8. It is seen that for specimen No. 1, the nominal buckling capacity is 77.5 kips and the measured buckling capacity was 116 kips. The measured capacity divided by the computed capacity, or strength ratio, is 1.5. For Specimen No. 2, which also failed by buckling of the gusset, the nominal capacity is 83.4 kips, the measured buckling capacity was 138 kips, and the strength ratio is 1.7 . Thus it is seen that Thornton's method for computing buckling capacity is somewhat conservative predicting capacities roughly 60 to 70 percent of the measured capacities. Still, the calculations are simple to make and the results are not so conservative as to render the method impractical.

\subsubsection{Tearout of the Gusset Plate}

The computed nominal capacities for gusset tearout using the four methods described above are given in Table 4.9 along with the measured capacity for Specimen No. 3 which failed by tearout. The margin of safety is also presented. It is seen that the strength ratio ranges between 0.9 for the method by Williams and Bjorhovde [5] to 1.4 for the method by Williams and Richard [4]. The AISC-IRFD method gives a strength ratio of 1.1 and is relatively simple to apply. 
Table 4.1 - Experimental Results vs. Richard's Analytical Results ${ }^{1}$

Specimen No. 1 Specimen No. $2 \quad$ Specimen No. 3

Analytical Results from Fung and Richard [8]

$\begin{array}{llll}\text { Whitmore Yield } & 65 & 62 & 60 \\ \text { First Yield } & & & 61 \\ \text { Upper Gusset } & 78 & 62 & 61 \\ \text { Lower Gusset } & 76 & 66 & \\ & & & 76 \\ \text { General Yield } & 90 & 75 & 60 \\ \text { Upper Gusset } & 90 & 75 & \end{array}$

Experimental Results

Nonlinearity of

Load-defl. plot

First Yield ${ }^{2}$

Upper Gusset

Lower Gusset

General Yield ${ }^{3}$ Upper Gusset

Lower Gusset

1 The unit for the load is kips and all values are applied frame load.

2 The first yield load was taken as the load at which the Von Mises stress was greater than $36 \mathrm{ksi}$ at any rosette.

3 The general yield load was taken as the load at which the Von Mises stress was greater than $36 \mathrm{ksi}$ at a majority of the rosettes. 
Table 4.2 - Allowable Stress Design Brace Load for Specimen No. 1

\begin{tabular}{lllr}
\hline Connection & Element & $\begin{array}{l}\text { Limit } \\
\text { State }\end{array}$ & $\begin{array}{r}\text { Common Design P } \\
\text { (based on AI }\end{array}$ \\
& & & 77.4 kips \\
& Bolts & Shear & 50.8 \\
& Brace Web & Tearout & 73.1 \\
Brace & Gusset & Bearing & 45.4 \\
to & & Tearout & 65.3 \\
Gusset & & Whitmore & 41.4 \\
& WT & Buckling & 30.9 \\
& Conn. & Tearout & 125.0 \\
& & Gross- & 140.0 \\
& & Yield & 157.0 \\
& & Net- & 188.0
\end{tabular}

\begin{tabular}{|c|c|c|c|c|c|c|c|}
\hline & & & \multirow[b]{2}{*}{ Richard } & \multirow[b]{2}{*}{ Thornton } & \multirow[b]{2}{*}{$\begin{array}{l}\text { AISC } \\
\text { CASE I }\end{array}$} & \multicolumn{2}{|c|}{ AISC } \\
\hline & & & & & & $\begin{array}{l}\text { AISC } \\
\text { CASE II }\end{array}$ & $\begin{array}{l}\text { HEAVY } \\
\text { BRACING }\end{array}$ \\
\hline $\begin{array}{l}\text { Gusset } \\
\text { to Beam }\end{array}$ & $\begin{array}{l}\text { FW1 } \\
\text { Gusset }\end{array}$ & $\begin{array}{l}\text { Yield } \\
\text { Yield }\end{array}$ & $\begin{array}{l}90.0 \\
85.1\end{array}$ & $\begin{array}{l}146.5 \\
103.6\end{array}$ & $\begin{array}{l}* \\
*\end{array}$ & $\begin{array}{l}* \\
*\end{array}$ & $\begin{array}{l}59.0 \\
61.5\end{array}$ \\
\hline $\begin{array}{l}\text { Gusset } \\
\text { to } \\
\text { Column }\end{array}$ & $\begin{array}{l}\text { FW2 } \\
\text { Bolts } \\
\text { Clips }\end{array}$ & $\begin{array}{l}\text { Yield } \\
\text { Shear } \\
\text { Bearing } \\
\text { Net-shear } \\
\text { Axial }\end{array}$ & $\begin{array}{r}125.0 \\
211.0 \\
355.0 \\
257.4 \\
74.8\end{array}$ & $\begin{array}{r}223.1 \\
286.3 \\
483.3 \\
350.4 \\
20.6\end{array}$ & $\begin{array}{l}* \\
* \\
* \\
* \\
25.1\end{array}$ & $\begin{array}{l}* \\
* \\
* \\
* \\
17.5\end{array}$ & $\begin{array}{c}56.8 \\
* \\
* \\
* \\
20.8\end{array}$ \\
\hline $\begin{array}{l}\text { Beam } \\
\text { to } \\
\text { Column }\end{array}$ & $\begin{array}{l}\text { FW3 } \\
\text { Bolts } \\
\text { Clips } \\
\text { Beam web }\end{array}$ & $\begin{array}{l}\text { Yield } \\
\text { Shear } \\
\text { Bearing } \\
\text { Net-shear } \\
\text { Shear } \\
\text { Bending }\end{array}$ & $\begin{array}{r}106.0 \\
71.9 \\
122.0 \\
225.0 \\
136.0 \\
90.7\end{array}$ & $\begin{array}{r}66.8 \\
57.5 \\
96.0 \\
178.3 \\
107.8 \\
71.8\end{array}$ & $\begin{array}{l}* \\
* \\
* \\
* \\
* \\
*\end{array}$ & $\begin{array}{l}* \\
* \\
* \\
* \\
* \\
*\end{array}$ & $\begin{array}{l}* \\
* \\
* \\
* \\
* \\
*\end{array}$ \\
\hline
\end{tabular}

* This load will not control 
Table 4.3 - Allowable Stress Design Brace Load for Specimen No. 2

\begin{tabular}{lllr}
\hline Connection & Element & $\begin{array}{l}\text { Limit } \\
\text { State }\end{array}$ & $\begin{array}{c}\text { Common Design Prac } \\
\text { (based on AISC) }\end{array}$ \\
\hline & Bolts & Shear & 77.4 kips \\
& Brace Web Tearout & 50.8 \\
& & Bearing & 73.1 \\
Brace & Gusset & Tearout & 45.4 \\
to & & Bearing & 65.3 \\
Gusset & & Whitmore & 41.4 \\
& WT & Buckling & 34.8 \\
& Conn. & Gross- & 125.0 \\
& & Yield & 140.0 \\
& & Net- & 157.0 \\
& & Fracture & 188.0
\end{tabular}

\begin{tabular}{llll} 
& & & AISC \\
Richard Thornton & AISC & AISC & HEAVY \\
& CASE I & CASE II & BRACING \\
\hline
\end{tabular}

\begin{tabular}{|c|c|c|c|c|c|c|}
\hline Gus & FW1 & Yield & 61.8 & $\mathrm{NA}^{1}$ & $*$ & $*$ \\
\hline to Beam & Gusset & Yield & 58.5 & NA & $*$ & $*$ \\
\hline
\end{tabular}

\begin{tabular}{|c|c|c|c|c|c|c|c|}
\hline Gusset & FW2 & Yield & 93.1 & NA & $*$ & $*$ & 65.7 \\
\hline to & Bolts & Shear & 191.0 & $\mathrm{NA}$ & $*$ & $*$ & 108.0 \\
\hline \multirow[t]{4}{*}{ Column } & & Bearing & 325.0 & $\mathrm{NA}$ & $*$ & $*$ & 183.0 \\
\hline & Clips & Net- & 235.0 & $\mathrm{NA}$ & $*$ & $*$ & 133.0 \\
\hline & & Axial & 20.4 & NA & * & $*$ & $\mathrm{NL}^{2}$ \\
\hline & FW3 & Yield & 109.0 & $\mathrm{NA}$ & $*$ & $*$ & $\mathrm{NL}$ \\
\hline \multirow{2}{*}{$\begin{array}{c}\text { Beam } \\
\text { to }\end{array}$} & Bolts & Shear & 92.3 & $\mathrm{NA}$ & * & $*$ & NL \\
\hline & & Bearing & 157.0 & $\mathrm{NA}$ & $*$ & $*$ & NL \\
\hline \multirow[t]{3}{*}{ Column } & Clips & $\begin{array}{l}\text { Net- } \\
\text { Shear }\end{array}$ & 291.0 & $\mathrm{NA}$ & $*$ & $*$ & NL \\
\hline & Beam web & Shear & 176.0 & $\mathrm{NA}$ & * & $*$ & NL \\
\hline & & Bending & 117.0 & $\mathrm{NA}$ & $*$ & $*$ & NL \\
\hline
\end{tabular}

1 NA = Thornton's method is not applicable to this test specimen.

$2 \mathrm{NL}=$ No constraint on $\mathrm{P}$ due to this limit state. 
Table 4.4 - Allowable Stress Design Brace Load for Specimen No. 3

\begin{tabular}{lllr}
\hline Connection Element & $\begin{array}{l}\text { Limit } \\
\text { State }\end{array}$ & $\begin{array}{c}\text { Common Design Prac } \\
\text { (based on AIS }\end{array}$ \\
\hline & & & 77.4 kips \\
& Bolts & Shear & 50.8 \\
& Brace Web & Tearout & 73.1 \\
Brace & Gusset & Tearing & 45.4 \\
to & & Bearing & 65.3 \\
Gusset & & Whitmore & 41.4 \\
& & Buckling & 34.4 \\
& WT & Tearout & 125.0 \\
& Conn. & Gross- & 140.0 \\
& & Yield & 157.0 \\
& & Net- & 188.0
\end{tabular}

\begin{tabular}{lllll} 
& & & AISC \\
Richard Thornton & AISC & AISC & HEAVY \\
& CASE I & CASE II & BRACING \\
\hline
\end{tabular}

\begin{tabular}{|c|c|c|c|c|c|c|}
\hline Gusset & FW1 & Yield & 64.7 & $\mathrm{NA}^{1}$ & $\not{x}$ & $*$ \\
\hline to Beam & Gusset & Yield & 61.0 & NA & $\star$ & $*$ \\
\hline
\end{tabular}

$\begin{array}{cllrlrrr}\text { Gusset } & \text { FW2 } & \text { Yield } & 98.4 & \text { NA } & * & * & 68.8 \\ \text { to } & \text { Bolts } & \text { Shear } & 203.0 & \text { NA } & * & * & 113.0 \\ \text { Column } & & \text { Bearing } & 345.0 & \text { NA } & * & * & 191.0 \\ & \text { Clips } & \begin{array}{l}\text { Net- } \\ \text { Shear }\end{array} & 250.0 & \text { NA } & * & * & 139.0 \\ & & \text { Axial } & 21.2 & \text { NA } & * & * & \text { NL }^{2}\end{array}$

\begin{tabular}{cllrllll} 
& FW3 & Yield & 112.0 & NA & $*$ & $*$ & NL \\
Beam & Bolts & Shear & 94.6 & NA & $*$ & $*$ & NL \\
to & & Bearing 161.0 & NA & $*$ & $*$ & NL \\
Column & Clips & Net- & 299.0 & NA & $*$ & $*$ & NL \\
& Bhear & & & & & NL \\
& & Sheam web & Shear 180.0 & NA & $*$ & $*$ & NL \\
& & Bending 120.0 & NA & $*$ & $*$ & \\
\hline
\end{tabular}

$1 \quad \mathrm{NA}=$ Thornton's model not applicable to this test specimen.

$2 \mathrm{NL}=$ No constraint on $\mathrm{P}$ due to this limit state 
Table 4.5 - Comparison between Computed Design Capacities and Measured Capacities for Buckling of Gusset Plate (1)

\begin{tabular}{cccccc}
\hline $\begin{array}{c}\text { Specimen } \\
\text { No. }\end{array}$ & $\begin{array}{c}\text { Computed } \\
\text { Design } \\
\text { Capacity (2) }\end{array}$ & Yield (3) & Ultimate & Yield (3) & Ultimate \\
\cline { 3 - 6 } 1 & 30.9 & 50 & 116 & Strength Ratio (4) \\
2 & 34.8 & 65 & 138 & 1.6 & 3.8 \\
3 & 34.4 & 60 & 125 & 1.9 & 4.0 \\
\hline
\end{tabular}

Table 4.6 - Comparison between Computed Design Capacities and Measured Capacities for Yielding of Whitmore Section (1)

\begin{tabular}{|c|c|c|c|c|c|}
\hline \multirow{2}{*}{$\begin{array}{c}\text { Specimen } \\
\text { No. }\end{array}$} & \multirow{2}{*}{$\begin{array}{c}\text { Computed } \\
\text { Design } \\
\text { Capacity (2) }\end{array}$} & \multicolumn{2}{|c|}{ Measured Capacity } & \multicolumn{2}{|c|}{ Strength Ratio (4) } \\
\hline & & Yield (3) & Ultimate & Yield (3) & Ultimate \\
\hline 1 & 41.4 & 50 & 116 & $1.2^{*}$ & $2.8^{*}$ \\
\hline 2 & 41.4 & 65 & 138 & $1.6^{*}$ & $3.3^{x}$ \\
\hline 3 & 41.4 & 60 & 125 & 1.4 & 3.0 \\
\hline
\end{tabular}

* Minimum Strength Ratio

Notes:

(1) Reported values are loads in the diagonal brace.

(2) Based on $F_{y}=36 \mathrm{ksi}$.

(3) Yield is defined as departure from linearity of load vs. deflection curve (see Figures 3.4 through 3.6).

(4) Strength Ratio is the measured capacity divided by the computed design capacity. 
Table 4.7a - Comparison between Computed Design Capacities and Measured Capacities for Tearout of Gusset Plate (1)

AISC-ASD Design Method [13]

\begin{tabular}{|c|c|c|c|c|c|}
\hline \multirow{2}{*}{$\begin{array}{c}\text { Specimen } \\
\text { No. }\end{array}$} & \multirow{2}{*}{$\begin{array}{c}\text { Computed } \\
\text { Design } \\
\text { Capacity (2) }\end{array}$} & \multicolumn{2}{|c|}{ Measured Capacity } & \multicolumn{2}{|c|}{ Strength Ratio (4) } \\
\hline & & Yield (3) & Ultimate & Yield (3) & Ultimate \\
\hline 1 & 45.4 & 50 & 116 & $1.1^{*}$ & $2.6^{*}$ \\
\hline 2 & 45.4 & 65 & 138 & $1.4^{*}$ & $3.0^{*}$ \\
\hline 3 & 45.4 & 60 & 125 & 1.3 & 2.8 \\
\hline
\end{tabular}

Table 4.7b - Comparison between Computed Design Capacities and Measured Capacities for Tearout of Gusset Plate (1)

Williams and Richard Method [4]

\begin{tabular}{cccccc}
\hline $\begin{array}{c}\text { Specimen } \\
\text { No. }\end{array}$ & $\begin{array}{c}\text { Computed } \\
\text { Design } \\
\text { Capacity }(2)\end{array}$ & Yield (3) & Ultimate & Yield (3) & Ultimate \\
\cline { 3 - 6 } 1 & 37.9 & 50 & 116 & Strength Ratio (4) \\
2 & 37.9 & 65 & 138 & $1.3^{*}$ & $3.1^{*}$ \\
3 & 37.9 & 60 & 125 & $1.7^{*}$ & $3.6^{*}$ \\
\hline
\end{tabular}

* Minimum Strength Ratio

Notes:

(1) Reported values are loads in the diagonal brace.

(2) Based on $F_{\mathrm{y}}=36 \mathrm{ksi}$ and $F_{\mathrm{u}}=58 \mathrm{ksi}$.

(3) Yield is defined as departure from linearity of load vs. deflection curve (see Figures 3.4 through 3.6).

(4) Strength Ratio is the measured capacity divided by the computed design capacity. 
Table 4.7c - Comparison between Computed Design Capacities and Measured Capacities for Tearout of Gusset Plate (1)

Hardash and Bjorhovde Method [5]

\begin{tabular}{|c|c|c|c|c|c|}
\hline \multirow{2}{*}{$\begin{array}{c}\text { Specimen } \\
\text { No. }\end{array}$} & \multirow{2}{*}{$\begin{array}{c}\text { Computed } \\
\text { Design } \\
\text { Capacity (2) }\end{array}$} & \multicolumn{2}{|c|}{ Measured Capacity } & \multicolumn{2}{|c|}{ Strength Ratio (4) } \\
\hline & & Yield (3) & Ultimate & Yield (3) & Ultimate \\
\hline 1 & 57.8 & 50 & 116 & $0.9^{*}$ & $2.0^{*}$ \\
\hline 2 & 57.8 & 65 & 138 & $1.1^{*}$ & $2.4^{*}$ \\
\hline 3 & 57.8 & 60 & 125 & 1.0 & 2.2 \\
\hline
\end{tabular}

Table 4.7d - Comparison between Computed Design Capacities and Measured Capacities for Tearout of Gusset Plate (1)

$$
\text { AISC-LRFD Method [15] }
$$

\begin{tabular}{|c|c|c|c|c|c|}
\hline \multirow{2}{*}{$\begin{array}{c}\text { Specimen } \\
\text { No. }\end{array}$} & \multirow{2}{*}{$\begin{array}{c}\text { Computed } \\
\text { Design } \\
\text { Capacity (2) }\end{array}$} & \multicolumn{2}{|c|}{ Measured Capacity } & \multicolumn{2}{|c|}{ Strength Ratio (4) } \\
\hline & & Yield (3) & Ultimate & Yield (3) & Ultimate \\
\hline 1 & 34.8 & 50 & 116 & $1.4^{*}$ & $3.3^{*}$ \\
\hline 2 & 34.8 & 65 & 138 & $1.9^{*}$ & $4.0^{*}$ \\
\hline 3 & 34.8 & 60 & 125 & 1.7 & 3.6 \\
\hline
\end{tabular}

\section{* Minimum Strength Ratio}

Notes:

(1) Reported values are loads in the diagonal brace.

(2) Based on $F_{\mathrm{y}}=36 \mathrm{ksi}$ and $F_{\mathrm{u}}=58 \mathrm{ksi}$.

(3) Yield is defined as departure from linearity of load vs. deflection curve (see Figures 3.4 through 3.6).

(4) Strength Ratio is the measured capacity divided by the computed design capacity. 
Table 4.8 - Comparison between Computed Buckling Capacity and Measured Buckling Capacity for Specimens No. 1 and 2 (1)

\begin{tabular}{cccc}
\hline $\begin{array}{c}\text { Specimen } \\
\text { No. }\end{array}$ & $\begin{array}{c}\text { Computed Nominal } \\
\text { Capacity (2) }\end{array}$ & $\begin{array}{c}\text { Measured Ultimate } \\
\text { Capacity }\end{array}$ & $\begin{array}{c}\text { Strength } \\
\text { Ratic (3) }\end{array}$ \\
\hline 1 & 77.5 & 116 & 1.5 \\
2 & 83.4 & 138 & 1.7 \\
\hline
\end{tabular}

Table 4.9 - Comparison between Computed Tearout Capacity and Measured Tearout Capacity (Specimen No. 3) for Various Methods(1)

\begin{tabular}{lccc}
\hline Method & $\begin{array}{c}\text { Computed Nominal } \\
\text { Capacity (2) }\end{array}$ & $\begin{array}{c}\text { Measured Ultimate } \\
\text { Capacity }\end{array}$ & $\begin{array}{c}\text { Strength } \\
\text { Ratio (3) }\end{array}$ \\
\hline AISC-ASD [13] & 115 & 125 & 1.1 \\
Williams and Richard [4] & 91 & 125 & 1.4 \\
Hardash and Bjorhovde [5] & 137 & 125 & 0.9 \\
AISC-LRFD [15] & 111 & 125 & 1.1 \\
\hline
\end{tabular}

Notes:

(1) Reported values are loads in the diagonal brace.

(2) Based on $F_{y}=46.7 \mathrm{ksi}$ and $\mathrm{K}=0.50$.

(3) Strength Ratio is the measured capacity divided by the computed capacity. 


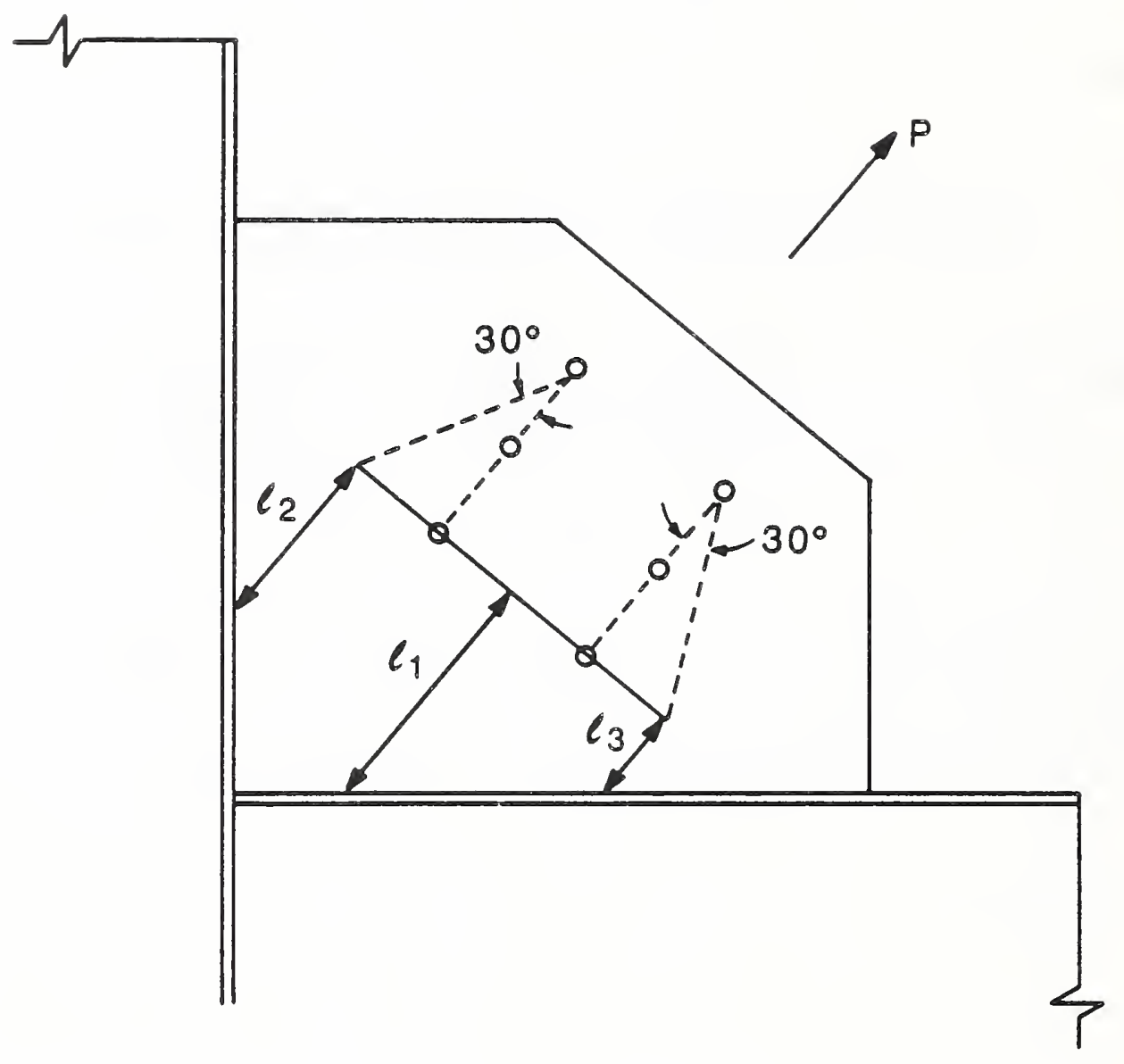

Figure 4.1 - Whitmore Section 


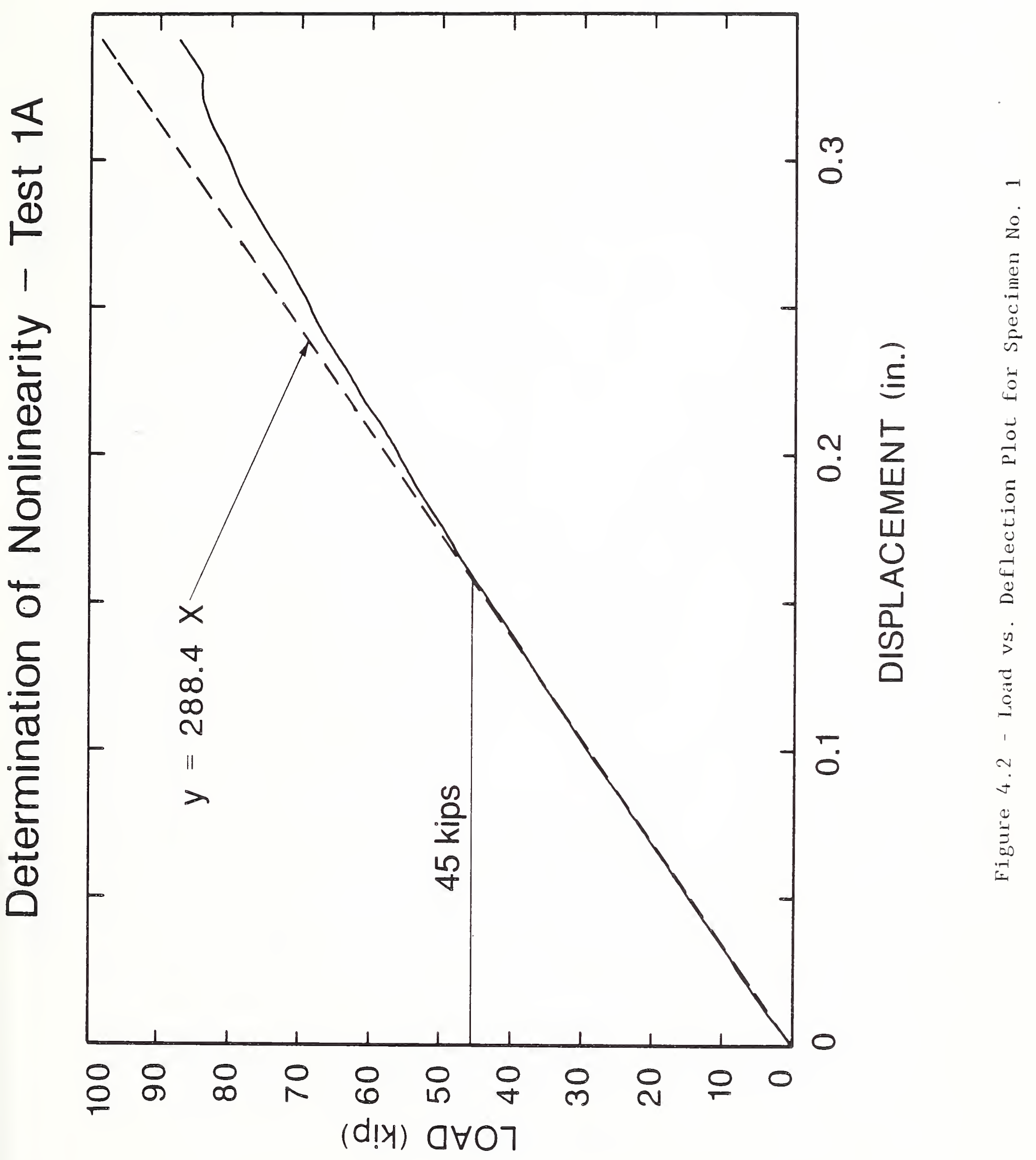




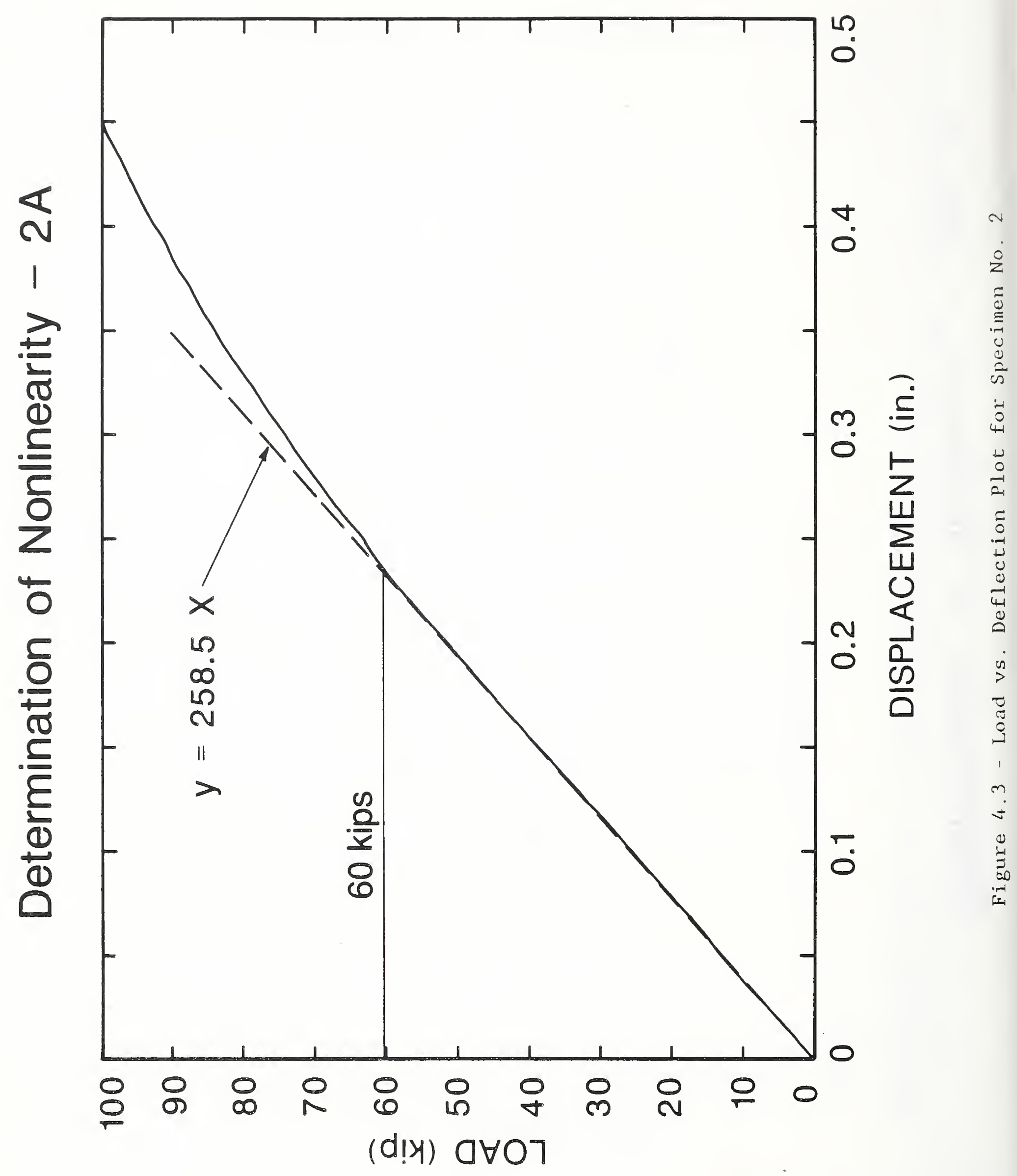




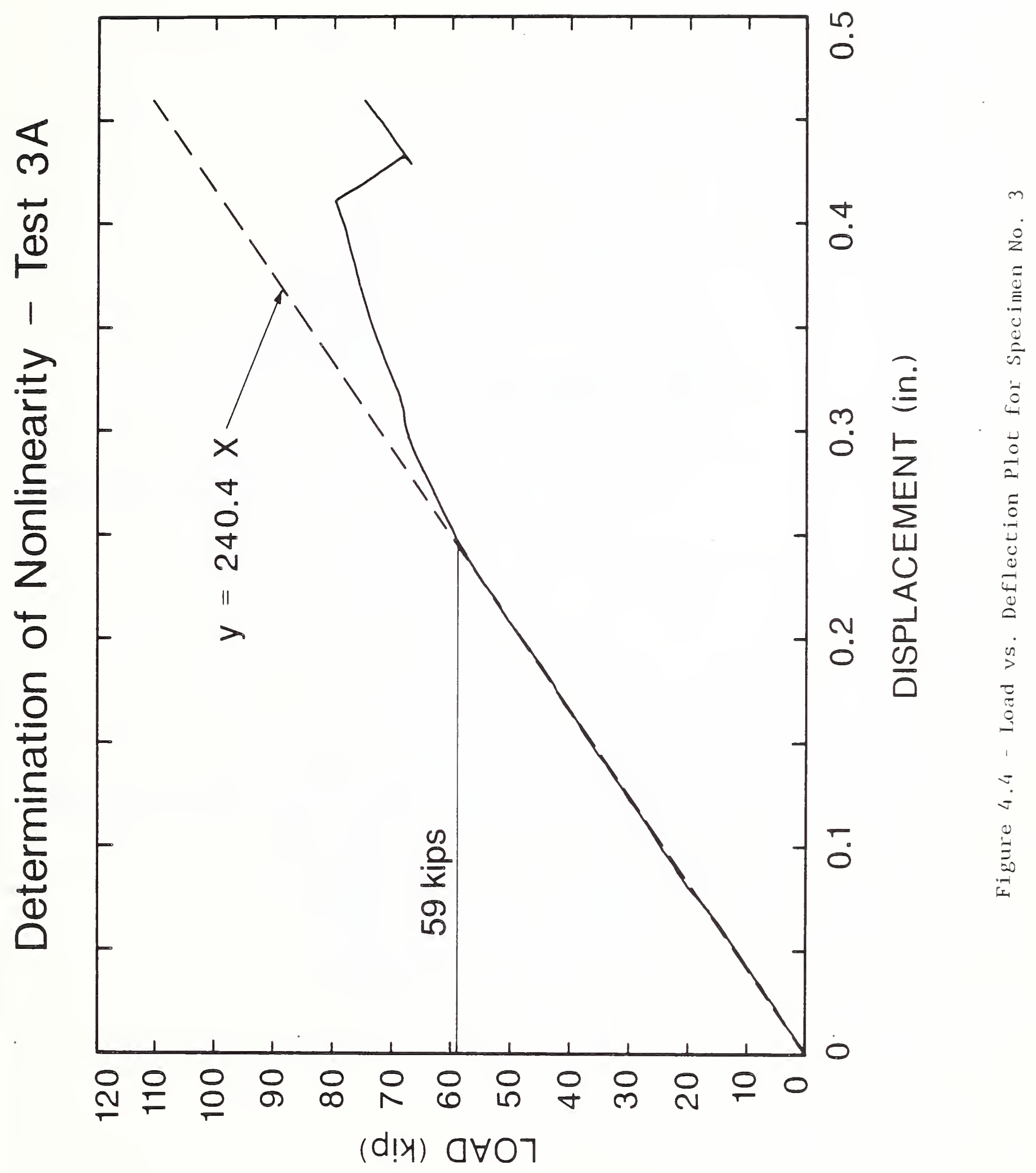




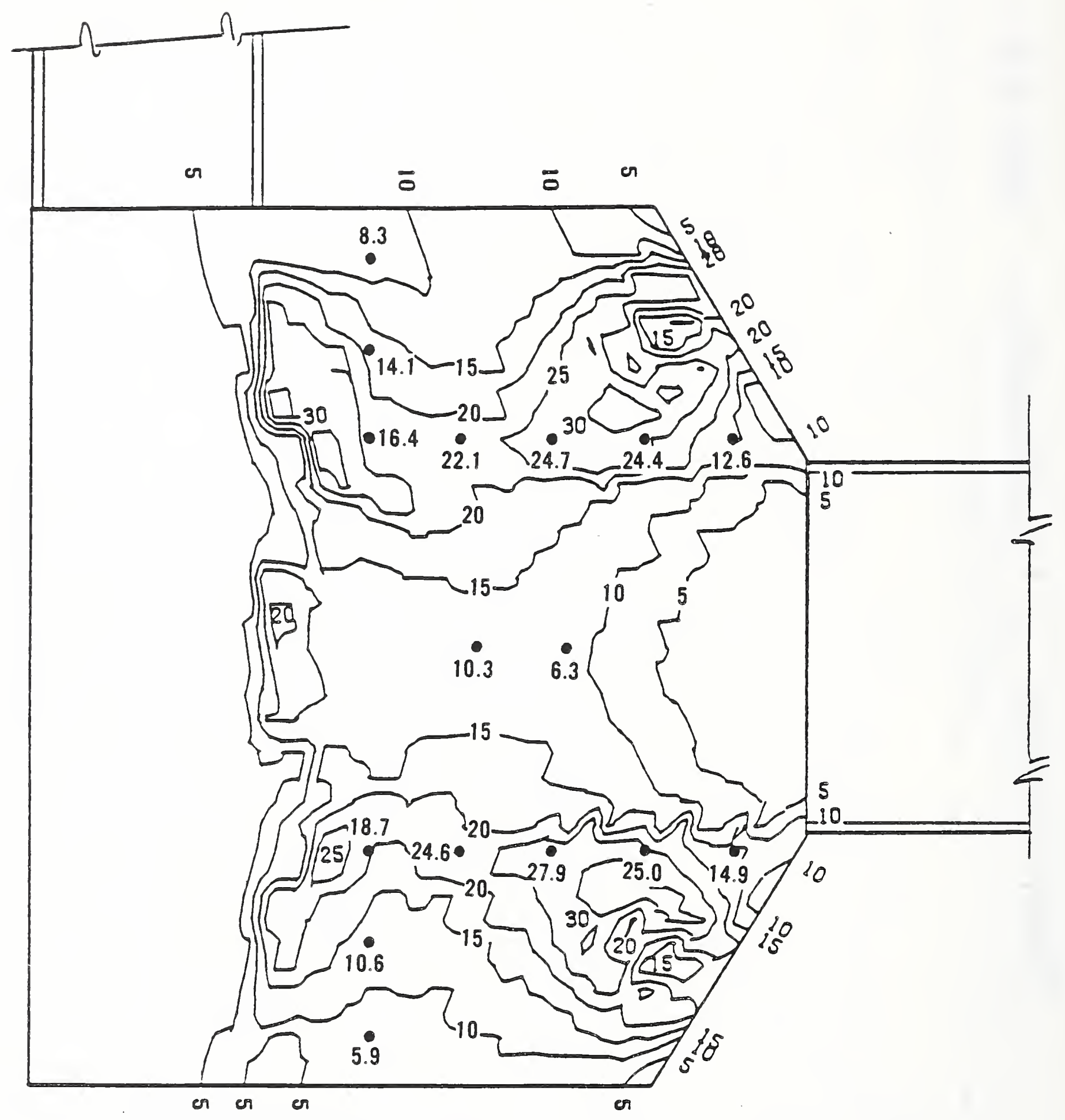

Figure 4.5 - Stress Contour Plot for Specimen No. 1 (Ref.[8]) with Experimental Values Superimposed 


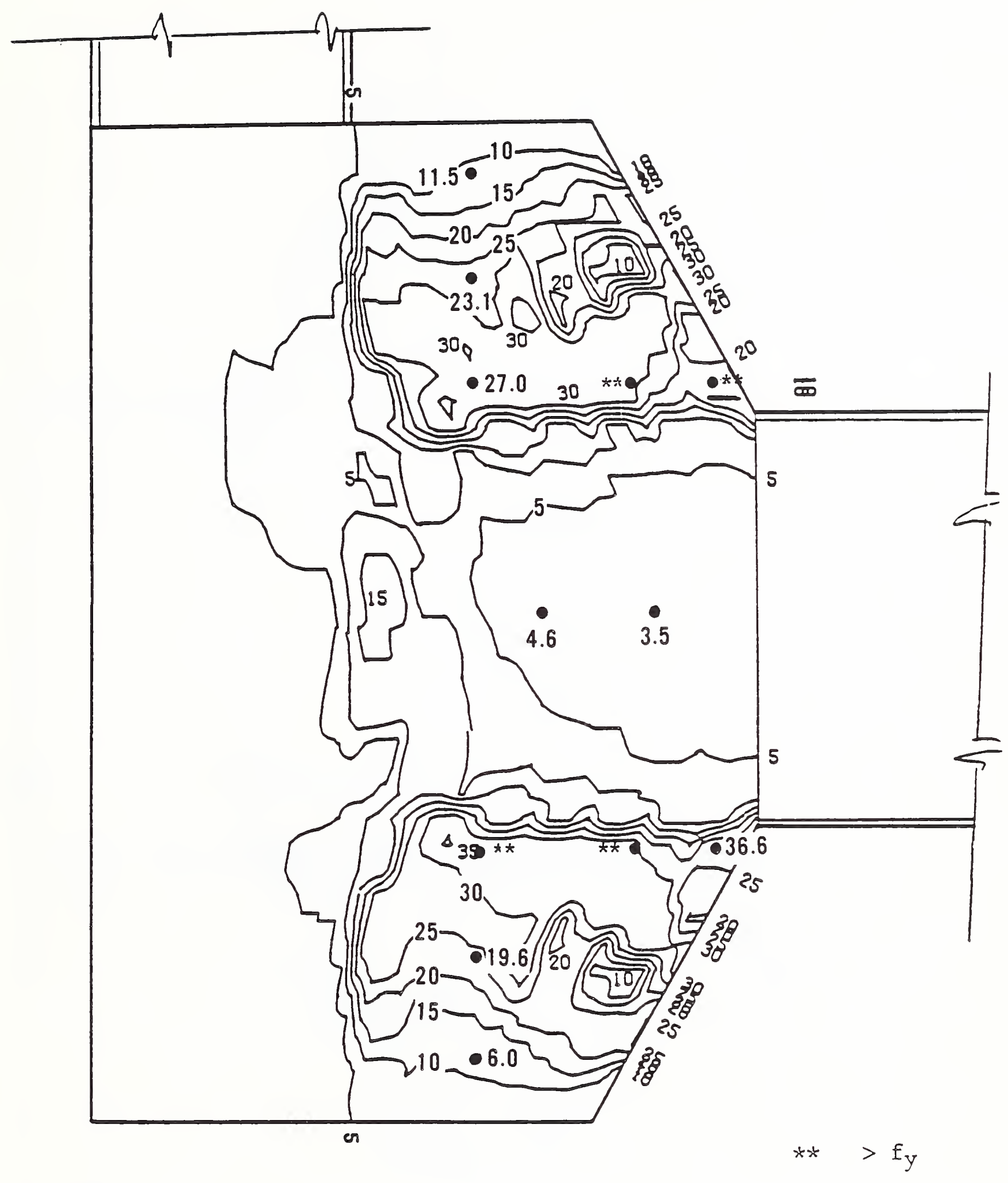

Figure 4.6 - Stress Contour Plot for Specimen No. 2 (Ref. [8]) with Experimental Values Superimposed 


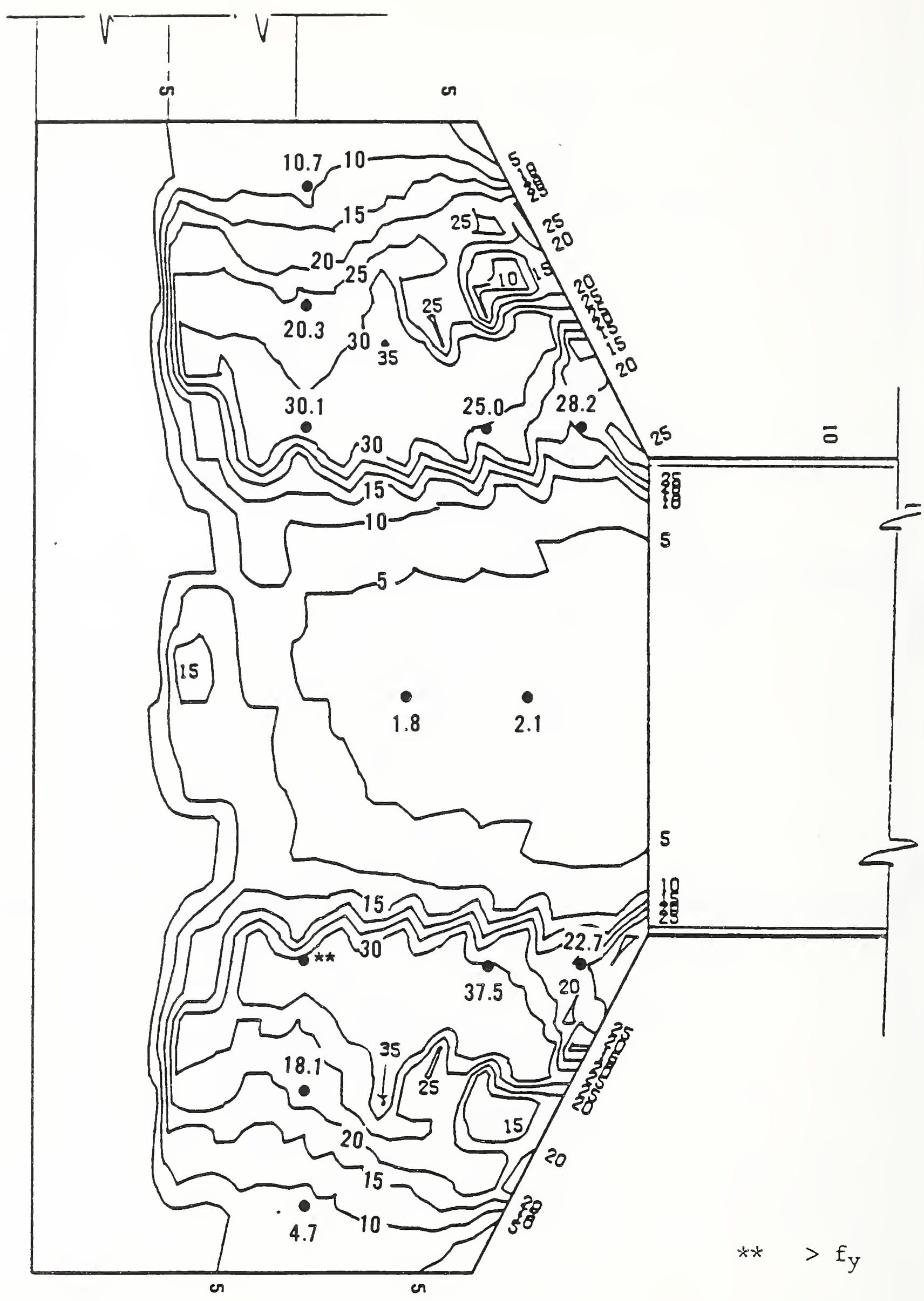

Figure 4.7 - Stress Contour Plot for Specimen No. 3 (Ref. [8]) with Experimental Values Superimposed 


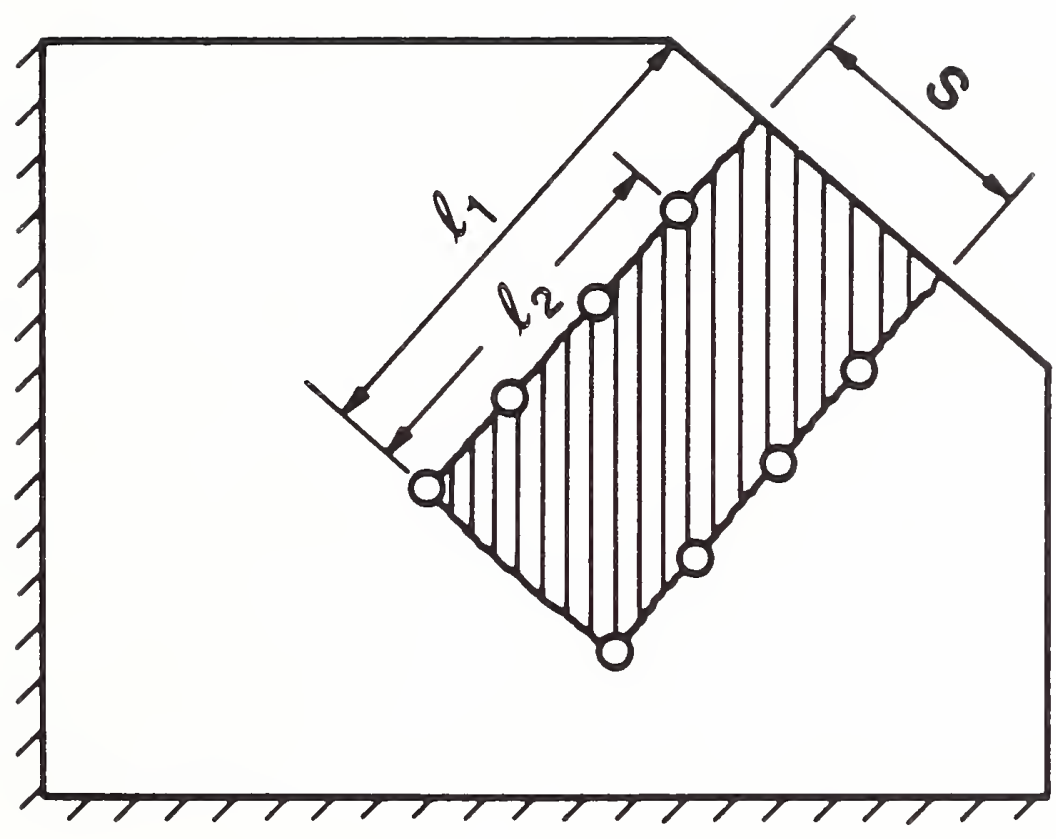

BLOCK SHEAR MODEL

Figure 4.8 - Block Shear Failure Mode 



\subsection{SUMMARY AND CONCLUSIONS}

\section{$5.1 \quad \underline{\text { Summary }}$}

The behavior of three diagonally braced steel subassemblages was studied experimentally. The parameters which were varied included the gusset geometry and column orientation. Specimen No. 1 was a strong-axis column connection in which the axes of the bracing members, beam and column all intersected at a single point. This connection was referred to as having no eccentricity. Specimen No. 2 was a strong-axis column connection in which the axes of the bracing members did not coincide with the intersection of the beam and column axes. Because forces in the diagonal bracing introduce a moment into a connection of this configuration, it was referred to as eccentric. Specimen No. 3 was similar to specimen No. 2 except that the column was oriented so that its weak axis acted in the plane of the bracing. The specimens were loaded to failure in their plane and load-deformation as well as strain data was recorded.

The failure mode for both strong-axis column connections was gusset buckling. The weak-axis column connection failed by tearing of the gusset plate. Specimen No. 2 with a compact gusset proved to be a stronger connection than Specimen No. 1. Although the mode of failure differed for Specimen No. 2 and Specimen No. 3, the failure load for the two specimens was essentially equal. The moment introduced by the eccentricity in the bracing was distributed to the beam and column in the strong-axis column connection. This moment was carried almost entirely by the beam in the weak-axis connection due to the flexibility in the web connection. The stress distribution in the gusset plates predicted by Richard's INELAS program, a nonlinear finite element program, compared very well with experimentally obtained stresses.

The connections were designed in accordance with AISC using Richard's guidelines for distributing the bracing loads to the main framing members. In general, all three subassemblages performed well. The failure loads for all three specimens were found to be well above the capacities predicted using a variety of methods. Generally, comparisons of design capacities with the experimental values resulted in a factor of safety in excess of 2 . The 
current method of computing gusset buckling capacity appears to be slightly consrevative predicting a capacity of 608 to 708 of that obtained experimentally. The capacity of the clip angles was computed to be very low using the AISC Specification, yet no distress in the clip angles was observed. One possible explanation for this is that frame action introduced a moment which loaded the gusset-to-column bolts in the opposite sense to the load produced by the bracing.

\subsection{Conclusions}

The following conclusions were drawn from the results of the NBS tests:

- Connections designed using the AISC Specification and Richard's equations for distributing the bracing loads to the framing members exceeded their design capacity by a factor of at least two.

- Failure of the clip angles, as predicted per the AISC Specification, was not observed and allowable bolt tension based on this criterion produces an unrealistically low connection capacity.

- Gusset buckling capacity, as predicted by Thornton's method, compares well with experimentally determined capacity.

- Gusset tearout capacity is predicted very closely using either Hardash and Bjorhovde's method or the AISC-LRFD approach.

- The weak-axis column connection had a capacity which was comparable to that of the strong-axis column connection despite the connection to a relatively flexible column web. However, the moment introduced by the eccentric bracing in Specimen No. 3 was resisted mainly by the beam.

- The moment introduced by the eccentricity of the bracing in specimen No. 2 was resisted mainly by the beam and column in proportion to I/L. 
The moments introduced into the beam and column by the eccentric brace loading were considerably less than the moments resulting from the rigid beam-to-column connection. 



\section{REFERENCES}

1. Richard, Ralph, "Analysis of Large Bracing Connection Designs for Heavy Construction", Proceedings of The 1986 National Engineering Conference, AISC, Nashville, June 12-14, 1986.

2. Whitmore, R. E., "Experimental Investigation of Stresses in Gusset Plates," Bulletin No. 16, Engineering Experiment Station, University of Tennessee, May, 1952.

3. Bjorhovde, Reidar, and Chakrabarti, S. K., "Tests of Full-Size Gusset Plate Connections," Journal of Structural Engineering, ASCE, Vol. 111, No. 3, March, 1985, pp. 667-684.

4. Williams, George C., and Richard, Ralph M., "Steel Connection Designs Based on Inelastic Finite Element Analysis," The University of Arizona, 1986.

5. Hardash, Steve G., and Bjorhovde, Reidar, "New Design Criteria for Gusset Plates in Tension", Engineering Journal, Vol. 22, No. 2, AISC, 1985, pp. 77-94.

6. Thornton, William A., "Bracing Connections for Heavy Construction," Engineering Journal, American Institute of Steel Construction, $3 r d$ Quarter, 1984, Vol. 21, No. 3, pp.139-148.

7. Hu, S. Z., and Cheng, J. J. Roger, "Compressive Behavior of Gusset Plate Connections," Structural Engibeering Report No. 153, University of Alberta, 1987.

8. Fung, John Y., Richard, Ralph M., "Inelastic Finite Element Analysis of Gusset Plates," The University of Arizona, 1987.

9. Vasarhelyi, Desi D., "Tests of Gusset Plate Models," Journal of the Structural Division, ASCE, Vol. 97, No. ST2, February, 1971, pp. 665-678.

10. Engineering for Steel Construction, American Institute of Steel Construction, Chicago, 1984.

11. Woodward, Kyle, and Rankin, Frank, "The NBS Tri-Directional Test Facility," NBSIR 84-2879, U.S. Department of Commerce, National Bureau of Standards, May, 1984.

12. 1984 Annual Book of ASTM Standards - Section 1, Iron and Steel Products, American Society for Testing and Materials, Philadelphia, 1984.

13. Manual of Steel Construction, 8 th. ed., American Institute of Steel Construction, Inc., 1980.

14. Personal communication with Dr. William Thornton.

15. Manual of Steel Construction - Load \& Resistance Factor Design, First Edition, American Institute of Steel Construction, Inc., 1986. 
16. Specification for Structural Joints Using ASTM A325 or A490 Bolts, American Institute of Steel Construction, Inc., 1985.

17. Thornton, William A., "Prying Action - A General Treatment," Engineering Journal, American Institure of Steel Construction, 2nd Quarter, 1985, Vol. 22, No. 2, pp. 67-75. 
Calculations of the design capacities were done by Dr. William Thornton and are presented here. The calculations for Specimens No. 2 and No. 3 are similar to calculations for Specimen No. 1 and are not presented.

Specimen No. 1

\section{A. Brace to gusset}

\section{AISC MANUAL}

1. Bolts: 6 A325N, 5/8 $\phi$

$R_{D S}=2 A_{b} F_{v}=2(0.3068) 21=12.9 \mathrm{k}$

Allowable Shear $=P_{\mathrm{V}}=6(12.9)=77.4 \mathrm{k}$

Bearing:

$$
\begin{aligned}
P_{b} & =6\left(1.2 \quad F_{u} D_{b} t\right) \\
& =6(1.2)(58)(0.625) \quad(0.25) \\
& =65.3 \mathrm{k}
\end{aligned}
$$

Table 1.5.2.1, p. 5-24

Ref. [16]

Table 2,

p. 6-269

2. Gusset: $1 / 4$ in. Plate, A36

Tearout:

Commentary

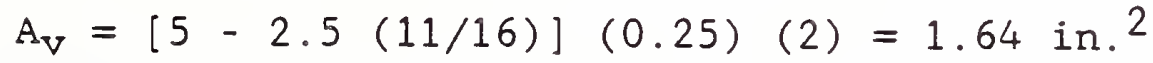

$$
\begin{aligned}
& A_{t}=[3-1(11 / 16)](0.25)=0.58 \text { in. }{ }^{2} \\
& P_{\text {to }}=0.30 \mathrm{~A}_{\mathrm{V}} \mathrm{F}_{\mathrm{u}}+0.5 \mathrm{~A}_{\mathrm{t}} \mathrm{F}_{\mathrm{u}} \\
& =0.3(1.64)(58)+0.5(0.58)(58) \\
& =45.4 \mathrm{k}
\end{aligned}
$$

Sect. 1.5.1.2

p. 5-108

Whitmore:

$$
\begin{aligned}
1_{W} & =4(\tan 30) 2+3=7.62 \mathrm{in} . \\
\mathrm{P}_{\mathrm{W}} & =1_{\mathrm{W}} \text { t } \mathrm{F}_{\mathrm{b}}=(7.62)(0.25)(0.6)(36) \\
& =41.4 \mathrm{k}
\end{aligned}
$$

Buckling [6]:

$l_{1}=8 \mathrm{in.}, l_{2}=14.75$ in., $l_{3}=1.5$ in. (Figure 4.1 )

$l_{\text {avg }}=8.08$ in. 
$\mathrm{kl} / \mathrm{r}=0.65(8.08) /(0.25 / \sqrt{12})=72$

$F_{a}=16.22 \mathrm{ksi}$

Table 3-36,

$\mathrm{P}_{\text {buckling }}=\mathrm{F}_{\mathrm{a}} 1_{\mathrm{w}} t=16.22(7.62)(0.25)$

$$
=30.9 \mathrm{k}
$$

3. Brace: W8 $\times 21$, A572, Gr. 50

Tearout:

$P_{\text {to }}=0.3(1.64)(65)+0.5(0.58)(65)=50.8 \mathrm{k}$

Bearing:

$P_{b}=1.2(65)(0.625)(0.25) 6=73.1 \mathrm{k}$

Gross Section:

Sect. 1.5.1.1

$A_{g}=6.16$ in. 2

p. $5-18$

$P_{\text {gross }}=0.6 \mathrm{Fy} \mathrm{A} A_{g}=0.6(50)(6.16)=185 \mathrm{k}$

Net Section:

$A_{n}=A_{g}-2 D t=6.16-2(0.75)(0.25)$

$=5.78$ in. ${ }^{2}$

Sect. 1.14.4 p. $5-44$

$A_{e}=C_{t} A_{n}=0.85(5.78)=4.91$ in. $^{2}$

Sect. 1.14.2.2

$P_{\text {net }}=4.91(0.5)(65)=160 \mathrm{k}$

p. 5-43

4. Connection: WT $5 \times 11$, A36

Tearout (Figure A.1):

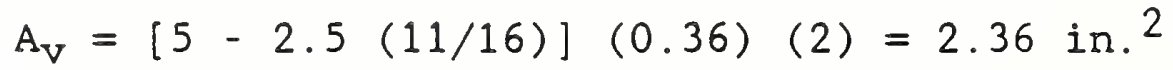

$$
\begin{aligned}
& A_{t}=[1.375-0.5(11 / 16)](0.36)(2)=0.74 \mathrm{in.}^{2} \\
& P_{\text {to }}=\left[\begin{array}{ll}
0.3(2.36)(58)+0.5(0.74)(58)] 2 \\
2
\end{array}\right. \\
& =125 \mathrm{k}
\end{aligned}
$$

Bearing:

$\mathrm{P}_{\mathrm{b}}=1.2(58)(0.625)(0.36)(6)(2)=188 \mathrm{k}$

Gross Section: $\mathrm{A}_{\mathrm{g}}=3.24 \mathrm{in}^{2}$

$P_{g}=3.24(0.6)(36)(2)=140 \mathrm{k}$ 
Net Section:

$$
\begin{aligned}
& A_{\text {net }}=3.24-2(0.75)(0.36)=2.70 \mathrm{in.}^{2} \\
& \text { Check }-0.85 \mathrm{Ag}_{\mathrm{g}}=2.75 \mathrm{in.}^{2}>2.70 \mathrm{in.}{ }^{2} \\
& \text { use } 2.70 \mathrm{in.}{ }^{2} \\
& \mathrm{P}_{\text {net }}=2.70(0.5)(58)(2)=157 \mathrm{k}
\end{aligned}
$$

B. Gusset to Column and Beam (Column: W $10 \times 49$, Beam: W 16 x 40)

1. Williams and Richard's Method (Figure A.2) Ref. [4]

$$
\begin{array}{ll}
\mathrm{R}_{\mathrm{B}}=\mathrm{P}[1.4 \mathrm{a} /(\mathrm{a}+\mathrm{b})-0.1] & \\
\theta_{\mathrm{B}}=0.6 \theta & \text { for } \theta \leq 45^{\circ} \\
\theta_{\mathrm{B}}=27+[8.5-20 \mathrm{a} /(\mathrm{a}+\mathrm{b})](45-\theta) & \text { for } \theta>45^{\circ} \\
\mathrm{H}_{\mathrm{B}}=\mathrm{R}_{\mathrm{B}} \cos \theta & \\
\mathrm{V}_{\mathrm{B}}=\mathrm{R}_{\mathrm{B}} \sin \theta & \\
\mathrm{H}_{C}=\mathrm{H}-\mathrm{H}_{\mathrm{B}} & \\
\mathrm{V}_{C}=\mathrm{V}-\mathrm{V}_{\mathrm{B}} &
\end{array}
$$$$
\text { for } \theta=30.92^{\circ}, a=23 \text { in., } b=11 \text { in. }
$$$$
R_{B}=0.847 \quad P
$$$$
\mathrm{H}_{\mathrm{B}}=0.803 \mathrm{P}
$$$$
\mathrm{V}_{\mathrm{B}}=0.269 \mathrm{P}
$$$$
\mathrm{H}_{\mathrm{C}}=0.055 \mathrm{P}
$$$$
v_{C}=0.245 \mathrm{P}
$$

2. FW1 (Figure A.3)

$$
\begin{aligned}
& f_{v}=H_{B} / 21=0.803 \mathrm{P} / 2(19)=0.021 \mathrm{k} / \mathrm{in} . \\
& \mathrm{f}_{t}=H_{C} / 2 \mathrm{l}=0.269 \mathrm{P} / 2(19)=0.007 \mathrm{k} / \mathrm{in} . \\
& \mathrm{f}_{\mathrm{r}}=\left(\mathrm{f}_{\mathrm{v}}^{2}+\mathrm{f}_{t^{2}}\right)^{1 / 2}=0.022 \mathrm{P} \\
& \mathrm{f}_{\mathrm{r}}=\text { capacity of } 3 / 16 \mathrm{in} \text {. weld } \\
& 0.022 \mathrm{P}=3(0.928) \\
& \mathrm{P}=126 \mathrm{k}
\end{aligned}
$$

Using the recommended variability ratio [4] to account for non-uniform force in weld:

$$
\mathrm{P}=126 / 1.4=90.0 \mathrm{k}
$$

\section{Gusset at FW1}

Shear: 


$$
\begin{aligned}
\sigma_{v} & =0.803 \mathrm{P} /[0.25(19)] \leq 0.4 \mathrm{~F}_{\mathrm{y}} \\
P & =0.4(36)(0.25)(19) / 0.803 \\
& =85.1 \mathrm{k}
\end{aligned}
$$

Tension:

$$
\begin{aligned}
\sigma_{t} & =0.269 \mathrm{P} /[0.25(19)] \leq 0.6 \mathrm{~F}_{\mathrm{y}} \\
\mathrm{P} & =0.6(36)(0.25)(19) / 0.269 \\
& =381 \mathrm{k}
\end{aligned}
$$

4. FW2 (Figure A.4)

$\tan \phi=0.055 / 0.245$

$$
\phi=12.65^{\circ}
$$

Since $\phi$ is small, treat resultant, $R=0.215 P$, as if it is a vertical shear.

$$
\begin{aligned}
& \text { For } k l=2.5, l=10 \text { in. }, a l=2.75 \text { in., } a=0.275 \\
& C=0.794 \\
& R=C C_{1} D l \\
& R=[0.794(1)(3)(10)(0.25 / 0.38)] 2 \\
& P=R / 0.251=125 \mathrm{k}
\end{aligned}
$$

5. Bolts at Clip Angles, 8 A325N, 5/8 $\phi$

Shear:

$R_{S S}=A_{b} F_{V}$

$8(0.3068)(21)=0.245 \mathrm{P}$

Sect. 1.5.2.2 p. $5-24$

$$
\mathrm{P}=210 \mathrm{k}
$$

Bearing:

Ref. [16]

Table 2,

$$
\mathrm{F}_{\mathrm{p}}=1.2 \mathrm{~F}_{\mathrm{u}} \mathrm{A}
$$

$0.245 P=F_{p}$

$$
\begin{aligned}
P & =1.2(58)[8(0.625)(0.25)] / 0.245 \\
& =355 \mathrm{k}
\end{aligned}
$$


6. Axial force on clip angles, $\mathrm{L} 31 / 2 \times 3 \times 1 / 4$, A36

$$
\begin{array}{ccc}
\text { Given: } b=2.375-0.25=2.125 \quad \text { (Figure A.2) } & \text { Ref. [17] } \\
a=3.5-2.375=1.125 & \\
\text { check } 1.25 b>1.125, \text { use } a=1.125 & \\
b^{\prime}=b-d / 2=2.125-5 / 16=1.8125 & \\
a^{\prime}=a+d / 2=1.125+5 / 16=1.4375 & \\
\rho & =b^{\prime} / a^{\prime}=1.2608 & \\
\delta & =1-d^{\prime} / p=1-(11 / 16) / 2=0.6563 & \text { Table } 1.6 .3 \\
B=55 A_{b}-1.8 V_{b} \leq 44 A b & \text { p. } 5-28 \\
=16.67-1.8 V_{b} \leq 13.5 &
\end{array}
$$

Try $P=30.9 \mathrm{k}$ (gusset buckling load controls so far)

Shear: $\quad V=0.245 P=0.245(30.9)=7.57 \mathrm{k}$

$$
\begin{gathered}
V_{b}=V / 8=7.57 / 8=0.946 \mathrm{k} / \mathrm{bolt} \\
\mathrm{B}=16.67-1.8(0.946)=14.97>13.5 \\
\text { use } \mathrm{B}=13.5 \mathrm{k} \\
\alpha=\frac{1}{\delta(1+\rho)} \frac{8 \mathrm{Bb}^{\prime}}{\mathrm{pt} \mathrm{F}_{\mathrm{y}}}-1 \\
=\frac{1}{0.6563(2.2608)} \frac{8(13.5)(1.8125)}{2(25)^{2}(36)}-1 \\
=28.64>1 \text { angle bending controls }
\end{gathered}
$$

Max. allowable tension per bolt, $\mathrm{T}_{\mathrm{b}}$

$\mathrm{T}_{\mathrm{b}}=\frac{\mathrm{p} r^{2} \mathrm{~F}_{\mathrm{y}}}{8 \mathrm{~b}^{\prime}}(1+\delta \alpha)$

Since $\alpha>1$, use $\alpha=1$

$$
\begin{aligned}
\mathrm{T}_{\mathrm{b}} & =\frac{2\left(0.25^{2}\right)(36)}{8(1.8125)} \quad(1.6563) \\
& =0.514 \mathrm{kip} / \mathrm{bolt}
\end{aligned}
$$

Max. allowable tension load is $\mathrm{T}=8(0.514)=4.11 \mathrm{k}$ 


$$
\begin{aligned}
0.055 \mathrm{P} & =4.11 \\
\mathrm{P} & =74.8 \mathrm{k}
\end{aligned}
$$

Re-check shear per bolt

$$
\begin{aligned}
\mathrm{V} & =0.245(74.8)=18.3 \mathrm{k} \\
\mathrm{V}_{\mathrm{b}} & =18.3 / 8=2.29 \mathrm{k} / \mathrm{bolt} \\
\mathrm{B} & =16.67-1.8(2.29)=12.54 \\
\alpha & =\frac{1}{0.6563(2.2608)} \quad \frac{8(12.54)(1.8125)}{2(0.25)^{2}(36)}-1 \\
& =26.56
\end{aligned}
$$

Since $\alpha$ still $>1, \mathrm{~T}_{\mathrm{b} \max }=0.514 \mathrm{k} / \mathrm{bolt} \quad$ OK

\section{Shear on Clip Angles}

$$
\begin{aligned}
0.245 \mathrm{P} & =0.3 \mathrm{~F}_{\mathrm{u}} \mathrm{A}_{\text {net }} \\
\mathrm{P} & =\frac{2(0.3)(58)[10-4(11 / 16)](0.25)}{0.245} \\
& =257.4 \mathrm{k}
\end{aligned}
$$

Sect. 1.5.1.2.2 p. $5-19$

Table XXIII

$$
\begin{aligned}
& \text { For } \mathrm{kl}=0, \mathrm{a}=0.25 \\
& c=0.630 \\
& R=C C_{1} D L=2[0.630(1)(3)(12)] \\
& =45.4 \mathrm{k} \\
& 0.538 P=45.4 \\
& P=84.3 \mathrm{k}
\end{aligned}
$$

\section{Beam Web}

Shear:

Sect. 1.5.1.2

$$
\begin{gathered}
\sigma_{V}=0.538 \mathrm{P} / \mathrm{A}_{\mathrm{W}} \leq 0.4 \mathrm{~F}_{\mathrm{Y}} \\
\mathrm{P}=0.4(50)(0.305)(12) / 0.538 \\
\mathrm{P}=136 \mathrm{k}
\end{gathered}
$$


Bending :

$$
\begin{aligned}
\mathrm{S} & =1 / 6(0.305) 12^{2}=7.32 \mathrm{in}^{2} \\
\mathrm{M} & =0.538 \mathrm{P}(4.5) \\
\sigma_{\mathrm{b}} & =\mathrm{M} / \mathrm{S} \leq 0.6 \mathrm{~F}_{\mathrm{y}} \\
\mathrm{P} & =0.6(50)(7.32) / 0.538(4.5) \\
\mathrm{P} & =90.7 \mathrm{k}
\end{aligned}
$$

\section{Bolts}

Shear:

Sect. 1.5.2.2

$$
\begin{aligned}
0.538 \mathrm{P} & =6 \mathrm{~A}_{\mathrm{b}} \mathrm{F}_{\mathrm{V}} \\
\mathrm{P} & =6(0.3068)(21) / 0.538 \\
& =71.9 \mathrm{k}
\end{aligned}
$$

Bearing:

$$
\begin{aligned}
0.538 \mathrm{P} & =1.2 \mathrm{~F}_{\mathrm{u}} \mathrm{D}_{\mathrm{b}} \mathrm{t} \\
\mathrm{P} & =1.2(58)(0.625)(0.25) / 0.538 \\
& =122 \mathrm{k}
\end{aligned}
$$

Ref. [16]

Table 2, p. 6-269

\section{Clip Angles}

Shear:

$$
\begin{aligned}
0.538 \mathrm{P} & =2\left(0.3 \mathrm{~F}_{\mathrm{U}}\right) \mathrm{A}_{\text {net }} \\
\mathrm{P} & =2(0.3)(58)[16-3(11 / 16)](0.25) / 0.538 \\
\mathrm{P} & =225 \mathrm{k}
\end{aligned}
$$

D. AISC Methods

Ref. [10]

1. Case II (Figure A.6)

Clip Angles:

$2 \mathrm{~T}\left(16^{2}+14^{2}+12^{2}+10^{2}+2^{2}\right) 2=2 \mathrm{~V}(5)$

$175 \mathrm{~T}=10 \mathrm{~V}$

From previous analysis, $\mathrm{T}_{\max }=0.514 \mathrm{kip} / \mathrm{bolt}$ for $1 / 4 \mathrm{in}$. clips

$$
v_{\max }=175(0.514) / 10=8.99 \mathrm{k}
$$


$0.514 P=8.99$

$$
\mathrm{P}=17.5 \mathrm{k}
$$

Since $P=17.5 \mathrm{k}$ is much smaller than any other capacity so far it will control. No need to check FW1, FW2, etc.

\section{Case I (Figure A.7)}

Clip Angles:

Neutral axis $=1 / 6$ of the connection length from bottom

$$
=36 / 6=6 \text { in. }
$$

$\Sigma$ Moment about neutral axis $=0$

Eq. $12 \mathrm{~T} / 28\left(28^{2}+26^{2}+24^{2}+22^{2}+14^{2}+12^{2}+10^{2}+2^{2}\right)+4 \mathrm{C}=2 \mathrm{~V}(5)$

$\Sigma$ Forces in $\mathrm{X}$-direction $=0$

Eq. $22 \mathrm{~T} / 28(28+26+24+22+14+12+10+2)=\mathrm{C}$

$$
C=9.857 \mathrm{~T}
$$

Substitute Eq. 2 in Eq. 1

$$
\begin{aligned}
211.7 \mathrm{~T} & +9.857 \mathrm{~T}(4)=10 \mathrm{~V} \\
\mathrm{~T}_{\max }= & 0.514 \mathrm{kip} / \mathrm{bolt} \\
\mathrm{V} & =12.91 \mathrm{k} \\
0.514 \mathrm{P} & =12.91 \mathrm{k} \\
\mathrm{P} & =25.1 \mathrm{k}
\end{aligned}
$$

This is the controlling load capacity for the connection using this method.

\section{Heavy Bracing Connections}

Generalizing the method given in these pages for

the connections to column flanges, one obtains (Figure A.8)

$$
H^{\prime \prime}=\frac{e_{1}}{e_{2}+e_{3}} V \quad, \quad H^{\prime}=H-H^{\prime \prime}, \quad M=H^{\prime} e_{2}
$$

The system of gusset forces $\mathrm{H}^{\prime}, \mathrm{M}$ and $\mathrm{H}^{\prime \prime}$ will provide translational and rotational equilibrium of the gusset with no secondary couples in the column or beam. 
Given: $e_{1}=5$ in., $e_{2}=8$ in., $e_{3}=5$ in.

$$
\begin{aligned}
& \mathrm{V}=(\sin \theta) \mathrm{P}=(\sin 30.92) \mathrm{P}=0.514 \mathrm{P} \\
& \mathrm{H}=(\cos \theta) \mathrm{P}=(\cos 30.92) \mathrm{P}=0.858 \mathrm{P} \\
& \mathrm{H}^{\prime \prime}=5 / 13 \mathrm{~V}=5 / 13(0.514 \mathrm{P})=0.198 \mathrm{P} \\
& \mathrm{H}^{\prime}=\mathrm{H}-\mathrm{H}^{\prime \prime}=0.858 \mathrm{P}-0.198 \mathrm{P}=0.660 \mathrm{P} \\
& \mathrm{M}=\mathrm{H}^{\prime} \mathrm{e}_{2}=0.660 \mathrm{P}(8)=5.28 \mathrm{P}
\end{aligned}
$$

FW1:

$$
\begin{aligned}
& f_{v}=0.660 P / 2(19)=0.0174 P \\
& \mathrm{f}_{\mathrm{b}}=5.28 \mathrm{P}(3) / 19^{2}=0.0439 \mathrm{P} \\
& f_{r}=0.0472 P=3(0.928) \text { capacity of } 3 / 16 \text { in. weld } \\
& P=59 k \\
& \phi=\tan ^{-1}(0.198 / 0.514)=21.06^{\circ} \\
& \text { where } \phi \text { is the angle of the resultant force } \\
& \text { at the column with the vertical axis. Since } \phi<45^{\circ} \text {, } \\
& \text { treat as } 0^{\circ} \text {. } \\
& R=C_{1} D I \quad \text { (see } B .4 \text { above) } \\
& =0.794 \text { (1) } 3 \text { (2) }(0.25 / 0.38)=31.3 \mathrm{k} \\
& 0.551 \mathrm{P}=31.3 \mathrm{k} \\
& P=56.8 \mathrm{k}
\end{aligned}
$$

Axial force of clip angles:

$$
\begin{aligned}
\mathrm{T}_{\max }= & 0.514 \mathrm{kip} / \text { bolt } \\
0.198 \mathrm{P} & =8(0.514)=4.11 \\
\mathrm{P} & =4.11 / 0.198 \\
& =20.8 \mathrm{k}
\end{aligned}
$$

Beam to column: Since no load is transferred to by the the beam to the column connection by this method, this connection does not limit the brace load, $P$.

E. Conclusions

1. Williams and Richard's method - brace capacity is $30.9 \mathrm{k}$, gusset buckling controls. 
2. AISC Method - brace capacity is $17.5 \leq \mathrm{P} \leq 25.1 \mathrm{k}$ Take $P \approx 21 \mathrm{k}$ (estimated capacity). Clip axial capacity controls. 


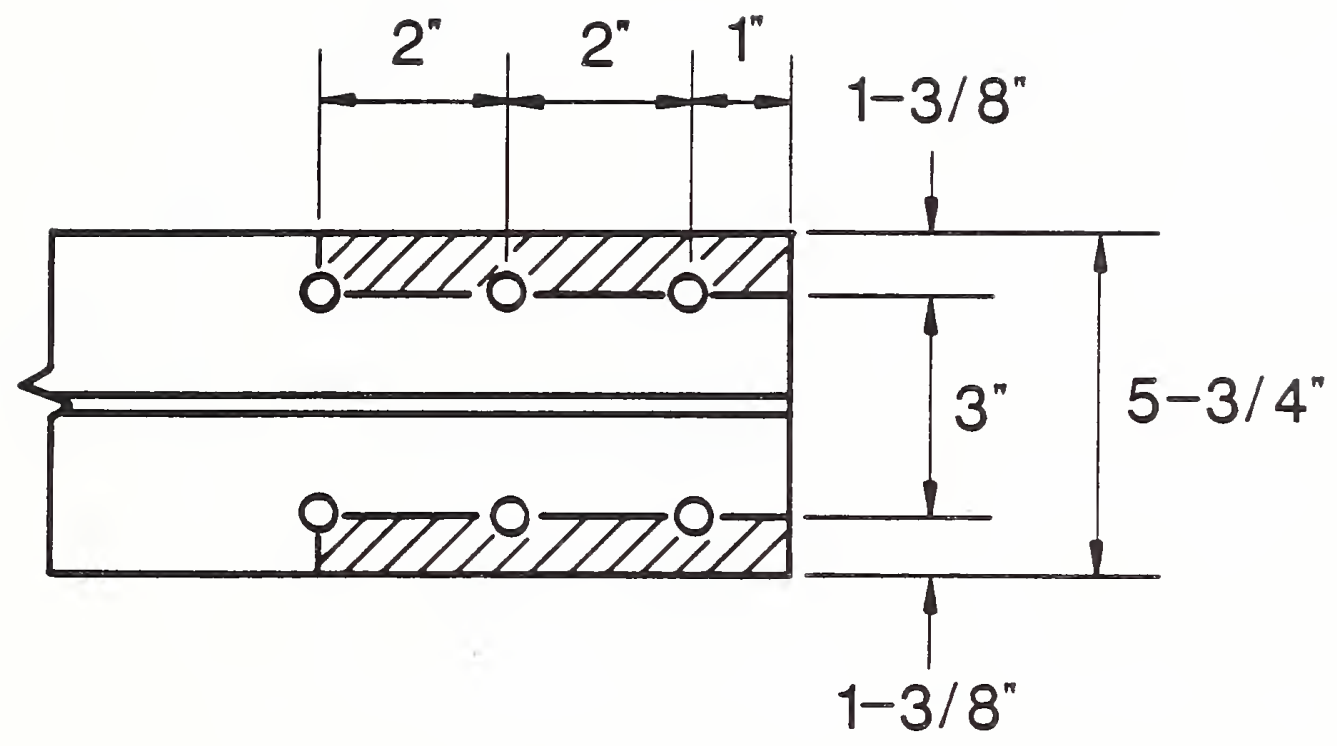

$T$ - Section Tearout

Figure A.1 - T-Section Tearout 

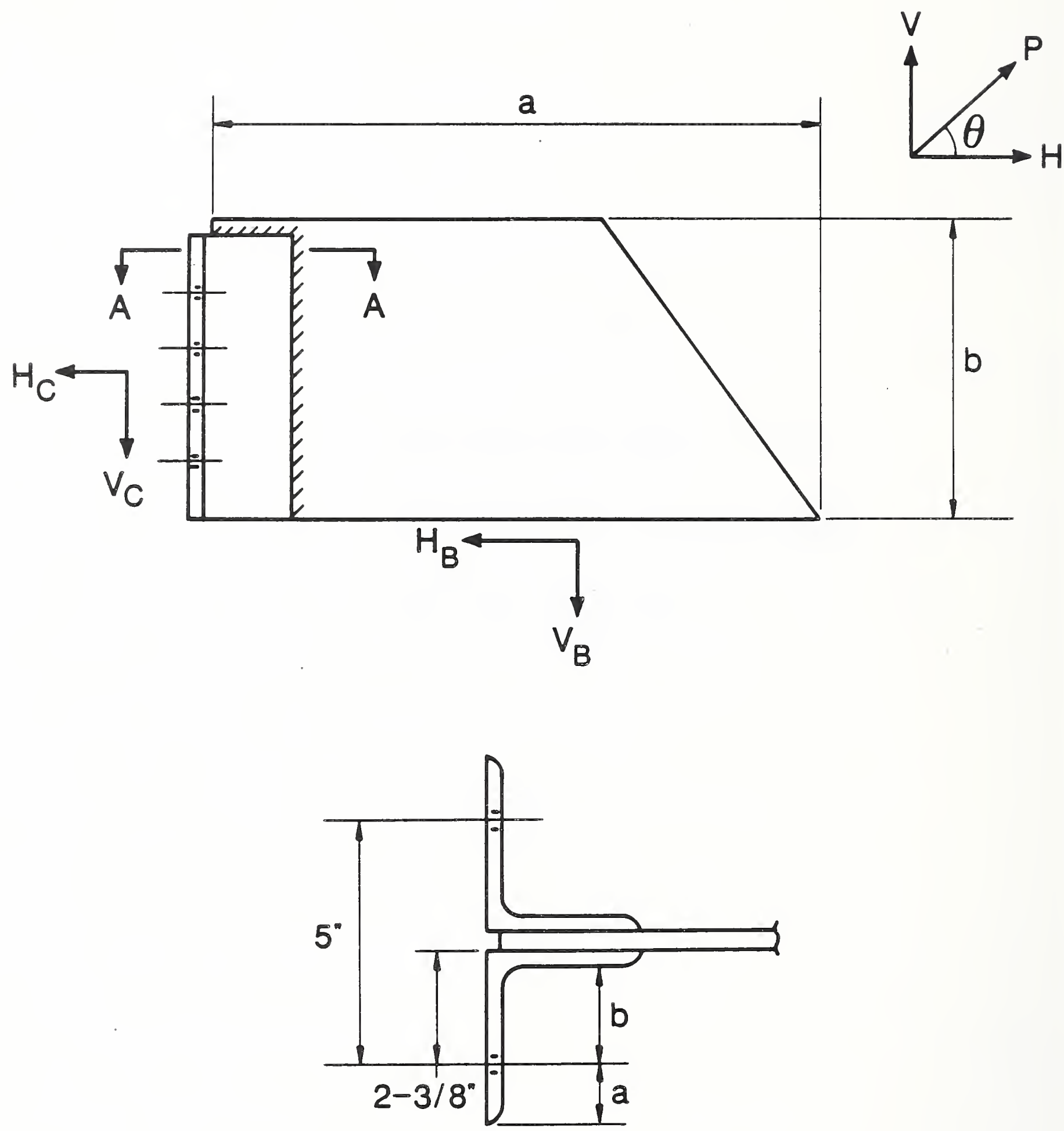

Section A-A

Figure A.2 - Williams and Richard's Brace Load Distribution 


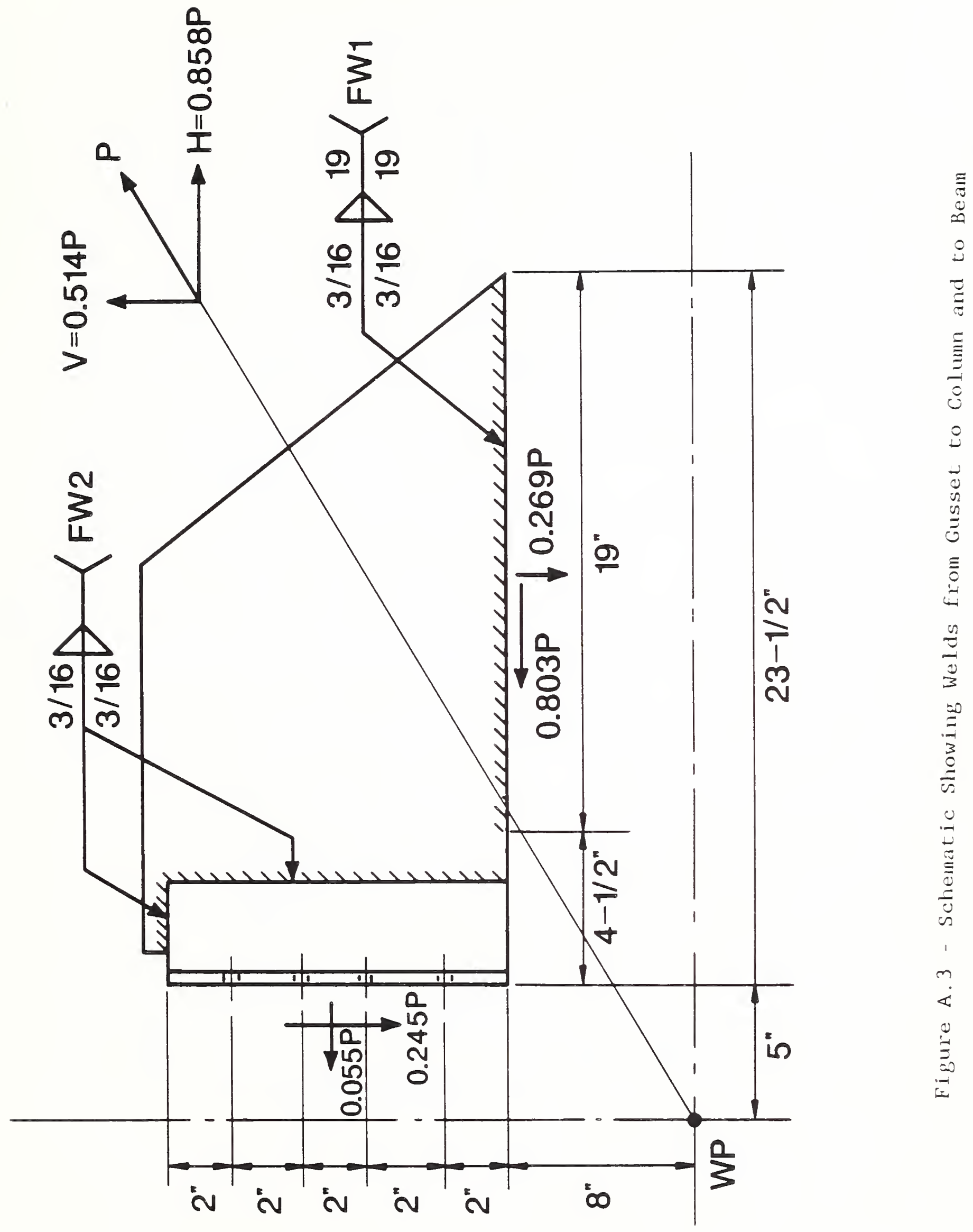




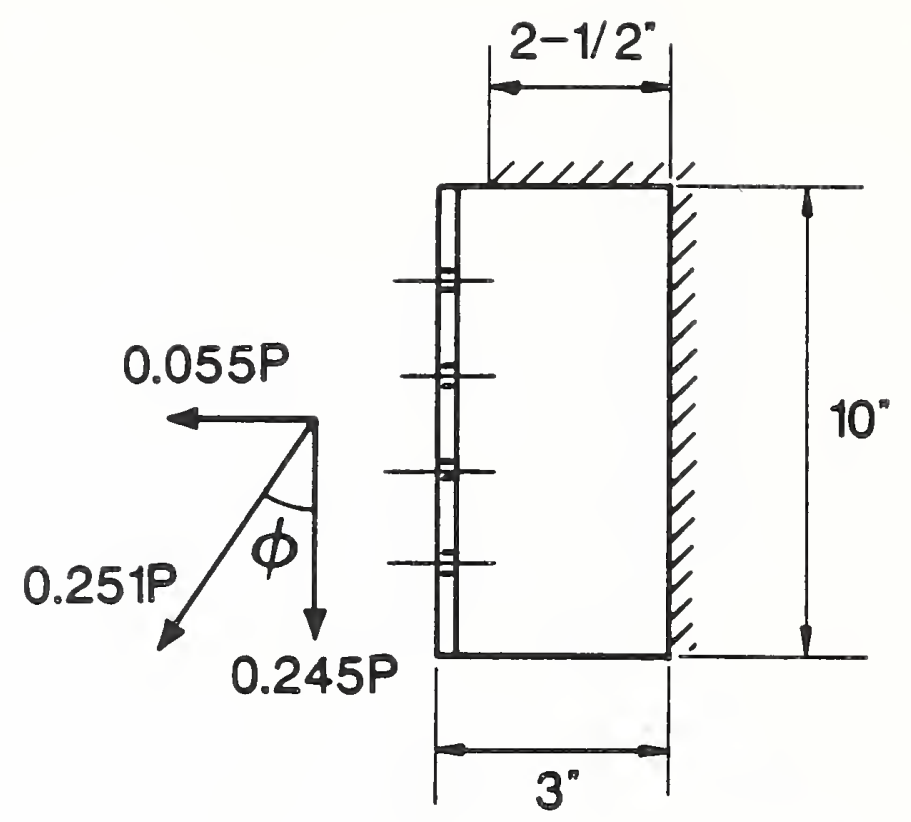

FW2

Figure A.4 Gusset to Column Connection Detail

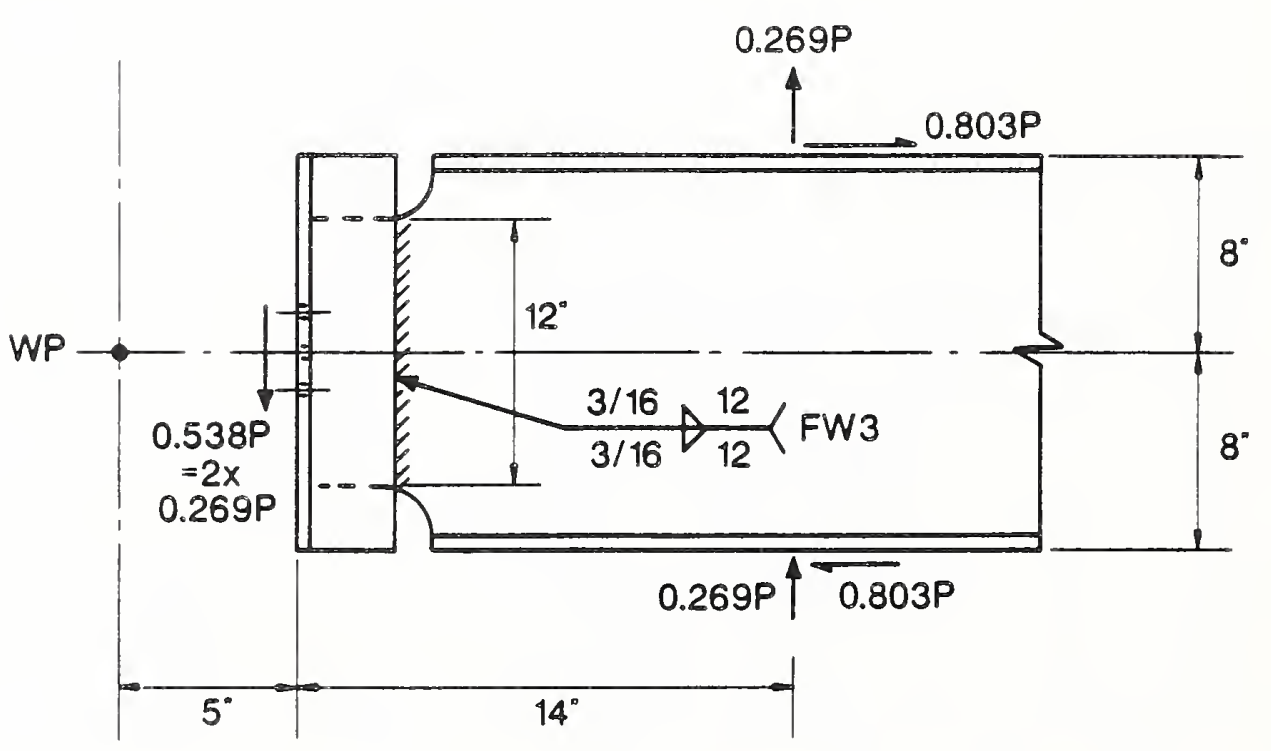

Figure A.5 - Beam to Column Connection Detail 


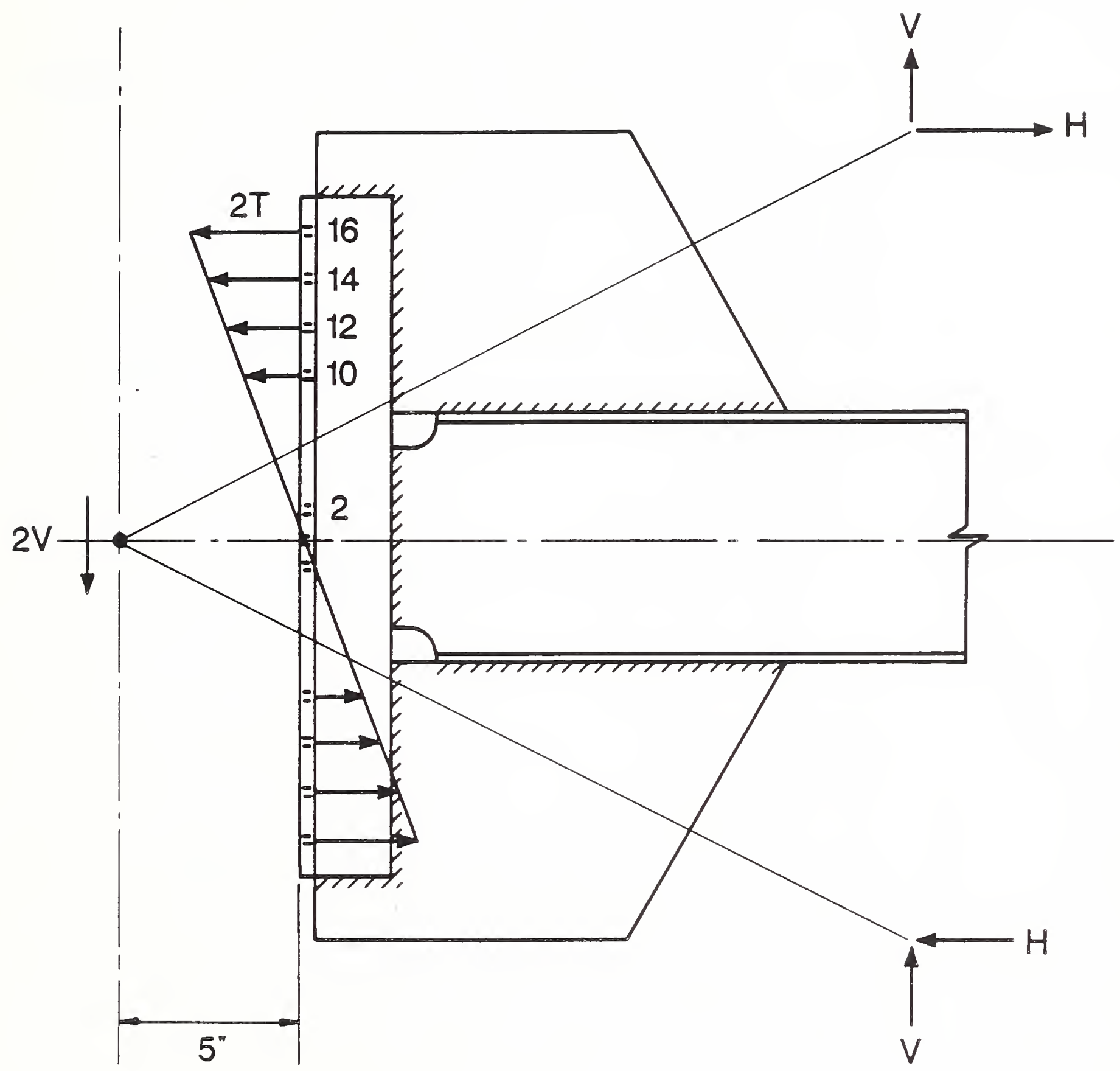

Figure A.6 - Schematic Showing AISC Case II 


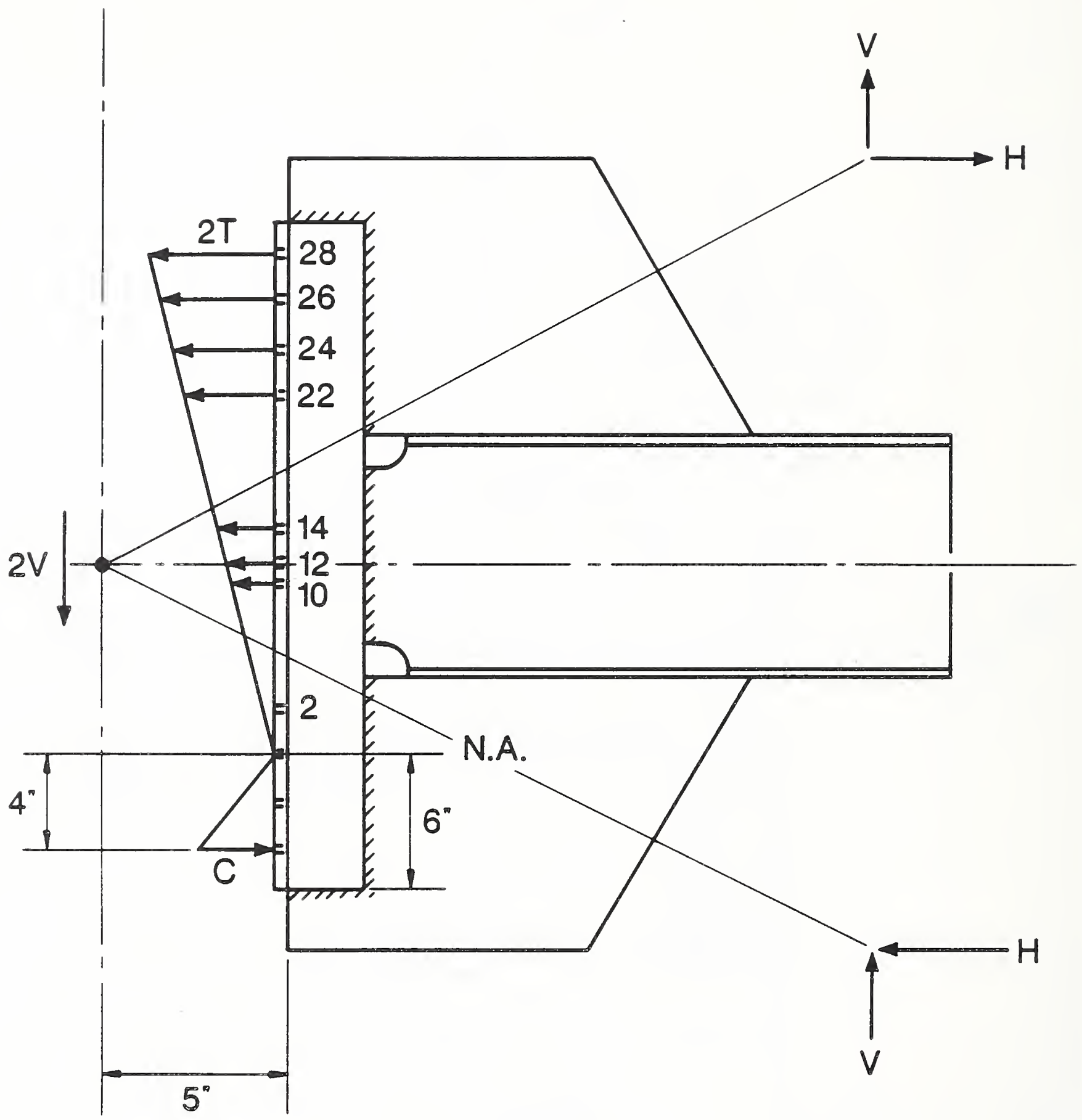

Figure A.7 - Schematic Showing AISC Case I 


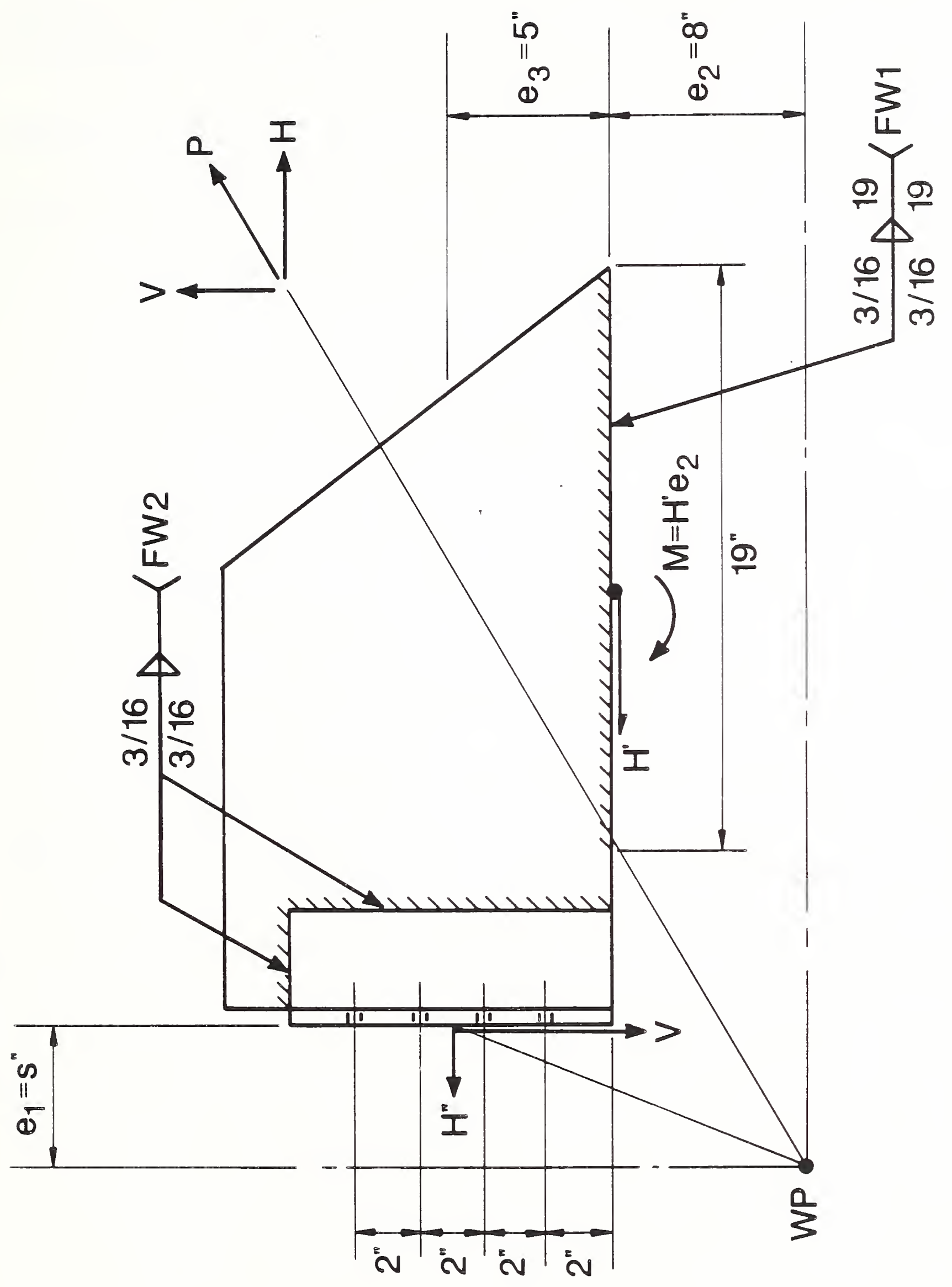

D 


\section{APPENDIX B - THORNTON'S MODEL}

Thornton proposed a model to distribute the force from the brace to the column and beam. His model is illustrated in Figure B.1. In the model, equilibrium of the gusset is satisfied.

Definitions of the various parameters are as follows:

$\mathrm{a}, \mathrm{b}$ Locate the centroids of the horizontal and vertical fastener groups.

$\alpha, \beta \quad$ Locate positions of forces acting on the horizontal and vertical fastener groups. Note that the ideal case is for $\alpha$ and $\beta$ to be equal to $a$ and $b$ respectively. If this were the case, moments $M_{B}$ (on beam edge) and $\mathrm{M}_{C}$ (on column edge) will be equal to zero.

P Brace load.

$\mathrm{H}, \mathrm{V} \quad$ Horizontal and vertical components of the brace load.

ec Half of the column depth

$e_{B} \quad$ Half of the beam depth

Geometric requirement: $\alpha$ and $\beta$ must satisfy the following equation:

$$
\alpha-\beta \tan \theta=\mathrm{K}
$$

$$
\begin{aligned}
& r=\sqrt{\left(\alpha+e_{C}\right)^{2}+\left(\beta+e_{B}\right)^{2}} \\
& K=e_{B}(\tan \theta)-e_{C}
\end{aligned}
$$

From geometry:

$$
\begin{array}{lr}
P \cos \theta=V & \text { Eq. } 2 \\
P \sin \theta=H & \text { Eq. } 3 \\
\cos \theta=\left(e_{B}+\beta\right) / r & \text { Eq. } 4 \\
\sin \theta=\left(e_{C}+\alpha\right) / r & \text { Eq. } 5 \\
V_{B} / H_{B}=e_{B} / \alpha & \text { Eq. } 6 \\
V_{C} / H_{C}=\beta / e_{C} & \text { Eq. } 7
\end{array}
$$

Eq. 1 
From equilibrium:

$\Sigma F_{X}: \quad V=V_{B}+V_{C}$

Eq. 8

$\Sigma F_{y}: \quad H=H_{B}+H_{C}$

Eq. 9

Solving:

$$
\begin{aligned}
& \mathrm{H}_{\mathrm{B}}=\mathrm{H}-\mathrm{H}_{\mathrm{C}} \\
& =H-V_{C} e_{C} / \beta \\
& \beta \mathrm{H}_{\mathrm{B}}=\beta \mathrm{H}-\mathrm{e}_{\mathrm{C}}\left(\mathrm{V}-\mathrm{V}_{\mathrm{B}}\right) \\
& =\beta H-e_{C} V+e_{C} V_{B} \\
& =\beta H-e_{C} V+e_{C}\left(e_{B} H_{B} / \alpha\right) \\
& \text { from Eq. } 9 \\
& \text { from Eq. } 7 \\
& \text { from Eq. } 8 \\
& \beta H_{B}-e_{C} e_{B} H_{B} / \alpha=\beta H-e_{C} V \\
& \mathrm{H}_{\mathrm{B}}\left(\alpha \beta-e_{\mathrm{B}} \mathrm{e}_{\mathrm{C}}\right) / \alpha=\beta \mathrm{H}-\mathrm{e}_{\mathrm{C}} \mathrm{V} \\
& \mathrm{H}_{\mathrm{B}}=\left[\alpha /\left(\alpha \beta-\mathrm{e}_{\mathrm{B}} \mathrm{e}_{\mathrm{C}}\right)\right]\left(\beta \mathrm{H}-\mathrm{e}_{\mathrm{C}} \mathrm{V}\right) \\
& =\left[\alpha /\left(\alpha \beta-e B e_{C}\right)\right]\left(\beta P \sin \theta-e_{C} P \cos \theta\right) \\
& =\left[\alpha /\left(\alpha \beta-e_{B} e_{C}\right)\right]\left(\beta \sin \theta-e_{C} \cos \theta\right) P \\
& =\left[\alpha /\left(\alpha \beta-e_{B} e_{C}\right)\right]\left[\beta\left(e_{C}+\alpha\right)-e_{C}\left(e_{B}+\beta\right)\right](1 / r) P \\
& \text { from Eqs. } 4 \& 5 \\
& =\left[\left(\alpha \beta e_{C}+\alpha^{2} \beta-\alpha e_{B} e_{C}-\alpha \beta e_{C}\right) P\right] /\left[r\left(\alpha \beta-e_{B} e_{C}\right)\right] \\
& =\alpha\left(\alpha \beta-e_{B} e_{C}\right) P /\left[r\left(\alpha \beta-e_{B} e_{C}\right)\right] \\
& H_{B}=(\alpha / r) P
\end{aligned}
$$

The equations for the remaining beam and column forces are obtained from statics. The beam and column forces are as follows:

$$
\begin{array}{ll}
\mathrm{H}_{\mathrm{B}}=(\alpha / \mathrm{r}) \mathrm{P} & \mathrm{V}_{\mathrm{B}}=\left(\mathrm{e}_{\mathrm{B}} / \mathrm{r}\right) \mathrm{P} \\
\mathrm{V}_{\mathrm{C}}=(\beta / \mathrm{r}) \mathrm{P} & \mathrm{H}_{\mathrm{C}}=\left(\mathrm{e}_{\mathrm{C}} / \mathrm{r}\right) \mathrm{P} \\
\mathrm{M}_{\mathrm{B}}=\mathrm{V}_{\mathrm{B}}(\alpha-\mathrm{a}) & \mathrm{M}_{\mathrm{C}}=\mathrm{H}_{C}(\beta-\mathrm{b})
\end{array}
$$


Solution:

1. In the above formulas, $\alpha$ and $\beta$ are unknown and are related by Eq. 1 . One solution is to designate one of them and use Eq. 1 to solve for the other. Since the horizontal edge is welded to the beam flange, it has a greater moment stiffness than the vertical edge which generally is connected to the column with clip angles. Therefore, let the horizontal edge carry $M_{B}$ and set the moment ${ }^{M_{C}}$ on the vertical edge be zero by setting $\beta=b$. Equation 1 is, then

$$
\alpha=k+b \tan \theta
$$

and the forces are computed using the above formulas.

2. Another method to determine $\alpha$ and $\beta$ is to minimize the eccentricities, $e_{h}$ $=(\alpha-a)$ and $e_{\mathrm{v}}=(\beta-b)$, using the following objective function, $\phi$ :

$$
\phi=[(\alpha-a) / a]^{2}+[(\beta-b) / b]^{2}-\lambda(\alpha-\beta \tan \theta-k)
$$

where $\lambda$ is the Lagrange multiplier. The results of the minimization are

$$
\begin{aligned}
& \alpha=\frac{K^{\prime} \tan \theta+K(a / b)^{2}}{D} \\
& \beta=\frac{K^{\prime}-K \tan \theta}{D}
\end{aligned}
$$

where,

$$
\begin{aligned}
& K=e_{b} \tan \theta-e_{c} \\
& K^{\prime}=a[\tan \theta+(a / b)] \\
& D=\tan ^{2} \theta+(a / b)^{2}
\end{aligned}
$$


The brace load, P, for Specimen No. 1 distributed to the column and beam using Thornton's method and the second solution is as follows:

Given:

$$
\begin{aligned}
& a=(23-4) / 2+4=13.5 \mathrm{in} . \\
& b=5 \mathrm{in.}(\mathrm{c} \cdot g . \text { of fasteners) } \\
& \theta=90-30.96=59.04^{\circ} \\
& e_{c}=5 \mathrm{in} . \\
& e_{b}=8 \mathrm{in} .
\end{aligned}
$$

Solution:

$$
\begin{aligned}
\mathrm{K} & =e_{\mathrm{b}} \tan \theta-e_{\mathrm{C}}=8.3 \mathrm{in} . \\
\mathrm{K}^{\prime} & =\mathrm{a}(\tan \theta+\mathrm{a} / \mathrm{b})=59.0 \mathrm{in} . \\
\mathrm{D} & =\tan ^{2} \theta+(\mathrm{a} / \mathrm{b})^{2}=10.1 \\
\alpha & =\left[\mathrm{K}^{\prime} \tan \theta+\mathrm{K}(\mathrm{a} / \mathrm{b})^{2}\right] / \mathrm{D}=15.7 \\
\beta & =\left(\mathrm{K}^{\prime}-\mathrm{K} \tan \theta\right) / \mathrm{D}=4.5 \\
\mathrm{r} & =\left[\left(\alpha+e_{C}\right)^{2}+\left(\beta+e_{\mathrm{b}}\right)^{2}\right]^{1 / 2}=24.2 \\
\mathrm{H}_{\mathrm{B}} & =(\alpha / \mathrm{r}) \mathrm{P}=0.65 \mathrm{P} \\
\mathrm{V}_{\mathrm{B}} & =\left(e_{\mathrm{B}} / \mathrm{r}\right) \mathrm{P}=0.33 \mathrm{P} \\
\mathrm{H}_{C} & =\left(e_{C} / \mathrm{r}\right) \mathrm{P}=0.21 \mathrm{P} \\
\mathrm{V}_{C} & =(\beta / \mathrm{r}) \mathrm{P}=0.19 \mathrm{P}
\end{aligned}
$$




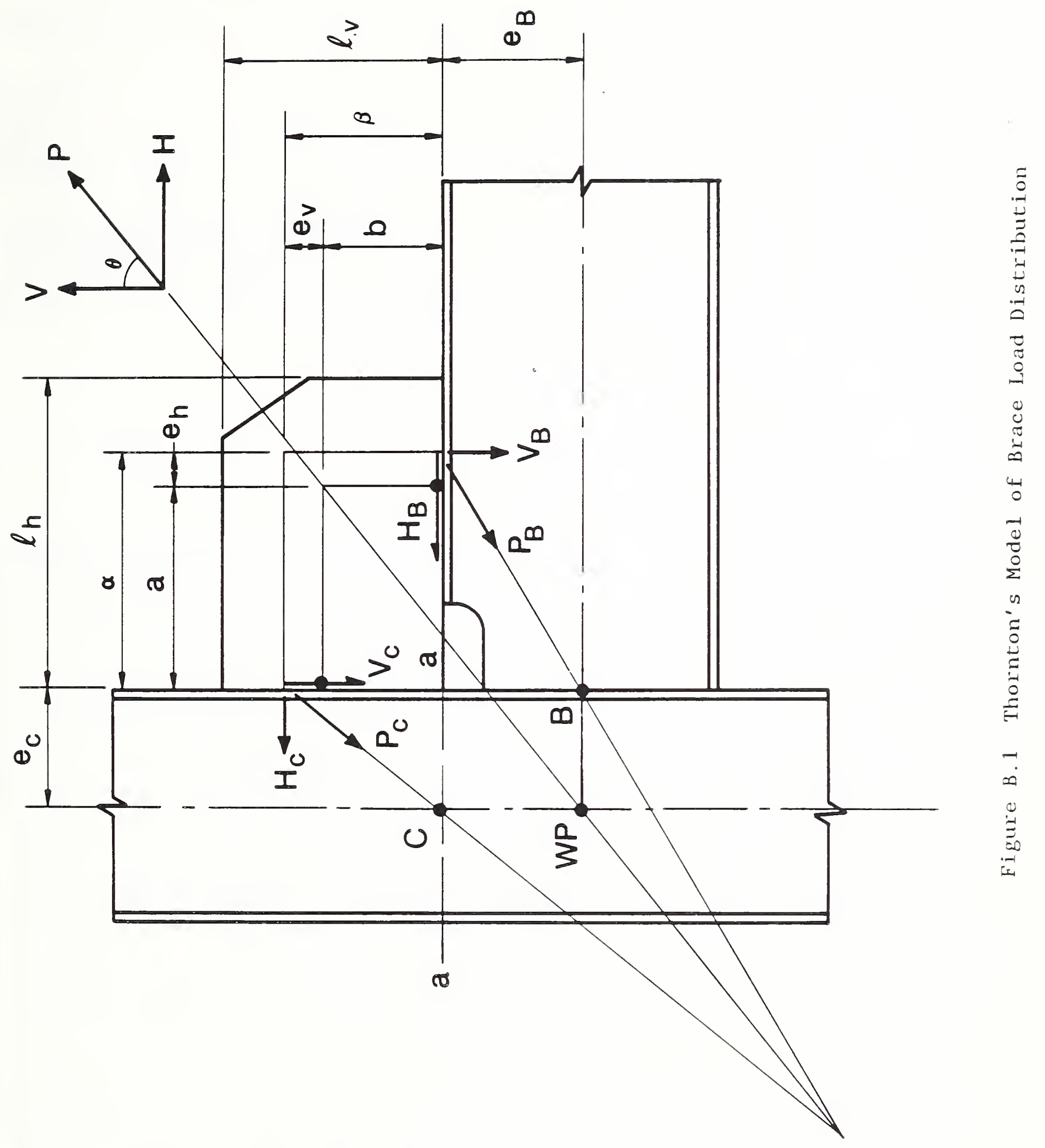



NBS.114A (REV. 2.8C)

U.S. DEPT. OF COMM.

BIBLIOGRAPHIC DATA

SHEET (See instruction s)

1. PUBLICATION OR

NISTITR NO: $8-3849$

2. Performing Organ. Report Nof 3. Publication Date

october 1988

4. TITLE AND SUBTITLE

Experimental Study of Gusseted Connections for Laterally Braced

Steel Buildings

5. AUTHOR(S)

John L. Gross and Geraldine Cheok

6. PERFORMING ORGANIZATION (If joint or other than NBS, see instructions)

7. ConeractGrant No.

NATIONAL BUREAU OF STANDARDS

U.S. DEPARTMENT OF COMMERCE

GAITHERSBURG, MD 20899

9. SPONSORING ORGANIZATION NAME AND COMPLETE ADDRESS (Street. City, State, ZIP)

8. Type of Repore \& Period Covered

10. SUPPLEMENTARY NOTES

Document describes a computer program: SF-185, FIPS Software Summary, is attached.

11. ABSTRACT (A 200-word or less factual summary of most significant information. If document includes a significant bibliography or literoture survey. mention it here)

The behavior of three diagonally braced steel subassemblages was studied experimentally. The parameters which were varied included the gusset geometry and column orientation. The specimens were loaded to failure in their plane and loaddeformation as well as strain data were recorded. The failure mode for the two strong-axis column connections was gusset buckling. The weak-axis column connection failed by tearing of the gusset plate. The moment introduced by the eccentricity in the bracing was distributed to the beam and column in the strongaxis column connection. This moment was carried almost entirely by the beam in the weak-axis connection due to the flexibility in the web connection. The failure loads for all three specimens were found to be well above those predicted using various methods. The current method of predicting gusset buckling appears to be very good giving a margin of safety of approximately three. Generally, comparisons of design capacities with the experimental values resulted in a factor of safety in excess of two. The capacity of the clip angles, in accordance with AISC, was computed to be very low yet no distress in the clip angles was observed. This was because frame action introduced loads in the gusset-to-column bolts which counteracted the load produced by the bracing.

12. KEY WORDS (Six to twelve entries; alphabetical order: capitalize only proper numes: and separate key words by semicolons)

Braced frames; connections; design; experimental study; gusset plates;

lateral bracing; steel buildings

13. AVAILABILITY

Unlimited

For Official Distribution. Do Not Release to NTIS

Order From Superintendent of Documents, U.S. Government Printing Office, Washington, D.C. 20402.

Z. Order From National Technical Information Service (NTIS), Springfield, VA. 22161
14. NO. OF

PRINTED PAGES

133

15. Price

$\$ 18.95$ 
